DEFORMATION SUBSTRUCTURES AND THEIR TRANSITIONS IN LASER SHOCK-COMPRESSED COPPER-ALUMINUM ALLOYS

M. A. Meyers, M. S. Schneider, H. Jarmakani, B. Kad, B. A. Remington, D. H. Kalantar, J. McNaney, B. Cao, J. Wark

October 22, 2007

Metallurgical and Materials Transactions 
This document was prepared as an account of work sponsored by an agency of the United States government. Neither the United States government nor Lawrence Livermore National Security, LLC, nor any of their employees makes any warranty, expressed or implied, or assumes any legal liability or responsibility for the accuracy, completeness, or usefulness of any information, apparatus, product, or process disclosed, or represents that its use would not infringe privately owned rights. Reference herein to any specific commercial product, process, or service by trade name, trademark, manufacturer, or otherwise does not necessarily constitute or imply its endorsement, recommendation, or favoring by the United States government or Lawrence Livermore National Security, LLC. The views and opinions of authors expressed herein do not necessarily state or reflect those of the United States government or Lawrence Livermore National Security, LLC, and shall not be used for advertising or product endorsement purposes. 


\title{
DEFORMATION SUBSTRUCTURES AND THEIR TRANSITIONS IN LASER SHOCK-COMPRESSED COPPER-ALUMINUM ALLOYS
}

\author{
M. A. Meyers ${ }^{1, \#}$, M. S. Schneider ${ }^{1}$, H. Jarmakani ${ }^{1}$, B. $\operatorname{Kad}^{1}$, B. A. Remington ${ }^{2}$, \\ D. H. Kalantar ${ }^{2}$, J. McNaney ${ }^{2}$, B. Cao ${ }^{1}$, and J. Wark ${ }^{3}$ \\ ${ }^{1}$ Materials Science and Engineering Program, Dept. of Mechanical and Aerospace Eng., \\ University of California, San Diego, La Jolla, CA 92093 USA \\ ${ }^{2}$ Lawrence Livermore National Laboratory, Livermore, CA 94450 USA \\ ${ }^{3}$ Dept. of Physics, Oxford U. Oxford, OX1 3PU UK
}

\begin{abstract}
It is shown that the short pulse durations $(0.1-10 \mathrm{~ns})$ in laser shock compression ensure a rapid decay of the pulse and quenching of the shocked sample in times that are orders of magnitude lower than in conventional explosively driven plate impact experiments. Thus, laser compression, by virtue of a much more rapid cooling, enables the retention of a deformation structure closer to the one existing during shock. The smaller pulse length also decreases the propensity for localization.

Copper and copper aluminum (2 and $6 \mathrm{wt} \% \mathrm{Al})$ with orientations [001] and [ $\overline{1} 34$ ] were subjected to high intensity laser pulses with energy levels of 70 to $300 \mathrm{~J}$ delivered in an initial pulse duration of approximately $3 \mathrm{~ns}$. The [001] and [ $\overline{1} 34]$ orientations were chosen since they respectively maximize and minimize the number of slip systems with highest resolved shear stresses. Systematic differences of the defect substructure were observed as a function of pressure, stacking-fault energy and crystalline orientation. The changes in the mechanical properties for each condition were compared using micro- and nano-hardness measurements and correlated well with observations of the defect substructure. Three regimes of plastic deformation were identified and their transitions modeled: dislocation cells, stacking-faults, and twins. An existing constitutive description of the slip to twinning transition, based on the critical shear stress, was expanded to incorporate the effect of stacking-fault energy. A new physically-based criterion accounting for stacking-fault energy was developed that describes the transition from perfect loop to partial loop homogeneous nucleation, and consequently from cells to stacking-faults. These calculations predict transitions that are in qualitative agreement with the effect of SFE.

Corresponding author: "mameyers@ucsd.edu
\end{abstract}




\section{INTRODUCTION}

Shock compressed copper has been extensively studied for almost fifty years [1]. Most of the studies were carried out with plate impact, where the plate was accelerated by gas-gun or explosives [2]. Today, laser shock and isentropic compression experiments are rapidly evolving as effective methods to explore the extreme pressure, strain-rate and temperature regimes inaccessible through other techniques [3-5]. Although laser shock compression does not yet have the temporal and spatial uniformity of pressure as plate impact experiments, it has a significant advantage, especially from the point-of-view of recovery. The post-shock cooling is orders of magnitude faster than in plate-impacted specimens because of two key factors: a) the short duration of the pulse and b) the rapid decay, creating a self-quenching medium.

The study of the response of metals to laser shocks was first carried out by Askaryon and Morez [6] in 1963 and further developed by others [7-10] to obtain Hugoniot data over a broad range of pressures. The shock pulse is created by focusing a laser beam on the surface of a material or a transparent ablator material that is placed on its surface. The rapid heating and thermal expansion of the material's surface results in a shock wave that propagates through the material. The duration of the shock pulse is in the nanosecond regime which allows heating to be limited to the first few atomic planes of the sample and to quickly diffuse away.

Johari and Thomas [11] studied the defect substructures of shocked copperaluminum alloys as early as 1964. It is well known that the addition of aluminum $(<7 \%$, the solubility limit) to copper lowers its stacking-fault energy and affects the deformation mechanisms activated [12]. Lowering the stacking-fault energy of a material increases its equilibrium partial dislocation spacing making it more difficult for partials to "pinch" and cross-slip. As a result, a change in deformation mechanisms arises where stacking-faults and twins become predominant. On the other hand, if the stacking-fault energy is relatively high, the tendency to cross-slip allows perfect dislocations to be the main contributor to plastic deformation. Rohatgi et al. [13-15] quantified the dislocation density as a function of stacking-fault energy in shock-deformed $\mathrm{Cu}-\mathrm{Al}$ alloys using a variety of techniques including Differential Scanning Calorimetry. The dislocation density in their shocked 
samples decreased with decrease in stacking-fault energy suggesting a change in deformation mechanism from slip to twinning.

In this paper, the results of laser shock compression of copper-aluminum alloys will be presented examining the effects of crystallographic orientation, pressure decay, and stacking-fault energy on the deformation microstructure and mechanical properties. The slip to twinning transition as a function of pressure, orientation and stacking-fault energy will be characterized, and a constitutive based criterion to predict this transition will be applied. This research is a continuation of previous work on monocrystalline copper $[3,4]$. A new criterion for the transition from perfect to partial dislocation nucleation is proposed. This criterion explains the transition from cells to stacking-faults, why for pure copper the cell structure gives rise to planar stacking-faults above a critical pressure, and how this transition pressure decreases with an decrease in stacking-fault energy.

\section{EXPERIMENTAL TECHNIQUES}

\subsection{LASER BASED EXPERIMENTS}

The shock experiments were carried out at the OMEGA Laser Facility at University

of Rochester's Laboratory for Laser Energetics and the Janus facility at Lawrence Livermore National Laboratory. An illustration of the OMEGA facility is shown in Figure 1(a). This major facility is 100 meters in length and 10 meters tall and can focus up to $40,000 \mathrm{~J}$ of energy on a target $\sim 3 \mathrm{~mm}$ in diameter for fusion research purposes. In the mode used for the current experiments, only one beam was used. The input laser energies used in the experiments were 70,200 , and $300 \mathrm{~J}$ with a $2.5 \mathrm{~ns}$ pulse duration. The laser spot size was $\sim 3 \mathrm{~mm}$ and provided energy densities on the order of $50 \mathrm{MJ} / \mathrm{m}^{2}$. Separate VISAR wave profile measurements were also performed on thin copper foils to obtain time-resolved data on the shock wave. These data were used as a calibrant for companion hydrodynamic simulations described below. Figure 1(b) shows the setup used for laser shock and recovery. The specimens were surrounded by a cylindrical holder and the back surface was supported by foam which acted as a deceleration medium.

For the recovery experiments, copper single crystals with 2 and 6 weight percent aluminum and orientations [001] and [ $\overline{1} 34]$ were selected. The [001] orientation is highly 
symmetrical (8 primary slip systems) whereas [ $\overline{1} 34]$ is highly asymmetrical (1 primary slip system and two secondary slip systems). The samples were cut into cylinders with a $5 \mathrm{~mm}$ length. They were mounted by press fit into foam-filled recovery tubes. The laser irradiation took place in a high vacuum chamber with a single laser beam for 70 and $200 \mathrm{~J}$ experiments. The experiments that occurred at $300 \mathrm{~J}$ required two overlapping lasers.

\subsection{RECOVERY SAMPLE PREPARATION}

Following the laser shock, the samples were recovered and then sectioned for transmission electron microscopy (TEM) by wire EDM at distances of approximately 0.25 , $0.75,1.25$, and $1.75 \mathrm{~mm}$ from the impact surface. The specimens (labeled A-D, Figure 2 (a)) were was then mechanically ground to a thickness of $100 \mu \mathrm{m}$ and electro-polished using a Struers Tenepol-3 with $30 \%$ nitric acid in methanol at $-35^{\circ} \mathrm{C}$. Figure $2(\mathrm{~b})$ illustrates the pressure decay as a function of distance in the specimen for the 200J experiment. Because the thin foils were prepared from samples cut at standard distances from the energy deposition surface, direct observation of changes in defect substructures could be correlated with the decay of the shock wave.

\subsection{RECOVERY SAMPLE HARDNESS}

To determine the extent of shock hardening within the specimens, a Leco DM-400 Hardness Tester was used to obtain Vickers numbers. The micro-indentation values were qualitatively compared among the different sample conditions and observations in the TEM. A load of $25 \mathrm{gf}$ or $50 \mathrm{gf}$ for $15 \mathrm{~s}$ was used to make the indentations. The average value for each specimen was determined by 10-15 hardness measurements. Both longitudinal and transverse sections were characterized. The data from the longitudinal orientation were compared with nano-identation measurements. Nano-indentation was carried out in a Nano Instruments Nano II for a limited number of samples.

\subsection{HYDRODYNAMIC SIMULATIONS}

One-dimensional hydrodynamic simulations were performed using the computer codes LASNEX [16] and Hyades [17]. Given the ratio of the laser spot size to the sample diameter and the depth of the removed TEM samples, the one-dimensional description is expected to be adequate for all but the samples removed form the deepest locations. The LASNEX code was used to simulate the appropriate laser material interaction and match the 
measured, time resolved velocimetry data to the input pressure profile. Hyades simulations were performed to consider the effect of material yield strength on the pressure decay of the shock wave as it travels through the sample. These simulations employed a standard pressure and strain dependent Steinberg-Guinan (S-G) constitutive description [18] to assess the uncertainty in the pressure that could be attributed to each location from which a TEM sample was removed. The yield strength in the S-G model is given as follows:

$$
\sigma_{y}=\sigma_{y_{o}}\left[1+\beta\left(\varepsilon+\varepsilon_{i}\right)\right]^{n} \times\left[1+\frac{1}{G_{o}} \frac{d G}{d P} \frac{P}{\eta^{1 / 3}}+\frac{1}{G_{o}} \frac{d G}{d T}(T-300)\right]
$$

where, $\sigma_{y_{o}}$ is the initial yield strength, $\beta$ is the strain hardening coefficient, $\mathrm{n}$ is the strainhardening exponent, $\varepsilon$ is the equivalent plastic strain and $\varepsilon_{\mathrm{i}}$ its initial value, $\mathrm{G}$ is the shear modulus, and $\mathrm{T}$ is temperature in Kelvin. Equation (1) holds provided that:

$$
\sigma_{y_{o}}\left[1+\beta\left(\varepsilon+\varepsilon_{i}\right)\right]^{n} \leq \sigma_{u}
$$

where, $\sigma_{u}$ is the saturation strength.

A range of yield strengths, $\sigma_{y o}$, from pure hydrodynamic $\left(\sigma_{y o}=0\right)$ to $870 \mathrm{MPa}$ were used. The upper bound was taken from dynamic yield strength measurements of Meyers [19]. The saturation strength, $\sigma_{u}$, and work hardening rate, $\beta$, were held constant at $680 \mathrm{MPa}$ and 0.45 respectively except for the highest yield strength simulation where the values 950 $\mathrm{MPa}$ and 0.45 were chosen. The results of these simulations are presented in Figure 2 (c) where, as expected, the cumulative effect of increasing levels of plastic dissipation result in increased uncertainty in the magnitude of the pressure wave at a given distance from the loading surface. These results were used to provide uncertainty bounds used in the discussion below.

\section{EXPERIMENTAL RESULTS AND DISCUSSION}

Observations were made for most of the specimens indexed as in Fig. 2 for the three shock conditions; 70, 200, and $300 \mathrm{~J}$. The complete TEM results (positions A-D) are shown in this section for the 200J experiments for the two orientations: [001] and [134]. For the other shock energies (300 J), TEM is only shown for position A. 


\subsection{POST-SHOCK COOLING IN LASER AND FLYER PLATE COMPRESSION}

Figure 3 shows the calculated temperature drop as a function of distance and time in both laser (a few ns initial pulse duration) and plate impact conditions (1.2 $\mu$ s initial pulse duration). The calculations were conducted for an initial pressure of $60 \mathrm{GPa}$ and temperature of $300 \mathrm{~K}$. The specimen lengths are $1 \mathrm{~mm}$ for laser shock and $250 \mathrm{~mm}$ for plate impact shock. The calculations were carried out according to the method described by Cao et al. [2]. The temperature distribution at time $\mathrm{t}=\mathrm{o}$ is set as the one provided directly from the shockwave profile. The calculation assumes that post-shock heat transfer dominates the process. The difference in cooling time is dramatic. This is due to the self quenching medium provided by the copper specimen in laser shock compression. Whereas the temperature drops to $400 \mathrm{~K}$ in $0.2 \mathrm{~s}$ for laser compression, it is still equal to to $600 \mathrm{~K}$ after $10,000 \mathrm{~s}$ in plate impact loading. This slow cooling rate in plate impact experiments is usually accelerated by having a water trap to capture the specimens. Nevertheless, this is an irregular and uncontrolled process, and thermal recovery easily sets in after high pressure (> $60 \mathrm{GPa}$ ) compression experiments. On the other hand, laser shock provides inherently a rapid post shock cooling; this is one of the most significant, yet unexplored, advantages of laser shock.

\subsection{LOOP GENERATION AT FRONT}

The TEM analysis of laser-shocked pure copper has been described in detail elsewhere [3-4]. The discussion is briefly presented here solely to demonstrate the effect of stacking-fault energy on $\mathrm{Cu}-\mathrm{Al}$ alloys. For the [001] orientation, shock experiments at 20 GPa pressures create a cellular dislocation organization with a medium density of $1 / 2$ [110]type dislocations. The average cell size is between 0.2 and $0.3 \mu \mathrm{m}$ cell size for $20 \mathrm{GPa}$. Qualitatively, these results confirm previous observations, albeit at a pulse duration that is lower by a factor of 10-100 than that applied by Murr [20]. The predicted cell size from Murr's data, at a pressure of $12 \mathrm{GPa}$, is $0.4 \mu \mathrm{m}$. One interesting feature is the observation of a large number of loops. Dislocation analysis revealed that they were shear loops and not prismatic loops. Figure 4(a) illustrates the shock front and formation of dislocation loops on the slip planes. In this homogeneous loop generation picture, the edge components of the 
dislocation move towards and away from the front, while the screw components move parallel to front. Figure 4(b) is an example of the numerous loops found in the $20 \mathrm{GPa}$ shocked copper specimens. Figure 4(c) shows similar loops (marked by arrows) that formed in a $\mathrm{Cu}-2 \% \mathrm{Al}$ alloy subjected to a higher $(\sim 35 \mathrm{GPa})$ pressure. Thus, the loop generation and expansion mechanism is being supported by a considerable amount of molecular dynamics computations ( Lomdahl and Holian [21]; Bringa [22]).

\subsection{TEM OF PURE COPPER}

At an energy level of $200 \mathrm{~J}$ (40 GPa initial pressure), dense dislocation tangles and stacking-faults were observed. Near the front surface, no dislocation cells are discernable, but four variants of stacking-faults are observed as shown in Figure 5(a). These traces are analogous to previous observations by Murr [23]. The features are significantly different from the dislocation cells observed at the lower energy and their traces have orientations along $<220>$.

Single crystal copper samples with [ $\overline{1} 34]$ orientation were shocked at energies of $70 \mathrm{~J}$ and $200 \mathrm{~J}$ corresponding to initial pressures of 20 and $40 \mathrm{GPa}$. The specimens shocked at $20 \mathrm{GPa}$ contained a well-defined cellular network comprised of $1 / 2<110>$ dislocations with a slightly larger $(0.3-0.4 \mu \mathrm{m})$ average cell size as compared to the [001] orientation, Figure 5(b). The dislocation density is on the order of $10^{13} \mathrm{~m}^{-2}$. The cells are comprised primarily of three dislocation systems: (111)[ $\overline{1} 01],(111)[1 \overline{1} 0],(\overline{1} 11)[101]$. At the higher energy of $200 \mathrm{~J}$ for the [ $\overline{1} 34$ ] orientation, the deformation substructure continued to be cellular, albeit with a finer $(0.15 \mu \mathrm{m})$ average cell size and a significantly higher dislocation density, $10^{14} \mathrm{~m}^{-2}$, Figure 5(c). This is in direct contrast to the mechanism change observed in [001] (Figure 5(a)). Again, the three slip systems previously described dominate the deformation sub-structure. A large number of loops are also visible. These were found to contribute to the cell walls and were often commonly found within the cells. The difference observed between the defect substructure of the [001] and [134] orientations is due to the orientation. Because of the symmetry of [001], interactions between dislocations are more frequent and enable the defects to relax into a stacking-fault-dominated substructure. The [ $\overline{1} 34$ ] orientation consisting of dislocations with limited mobility and interaction continues to form cells as the relaxed substructure. 


\subsection{TEM OF COPPER 2wt\% ALUMINUM}

Both pressure and crystal orientation significantly affect the deformation substructures of laser shocked $\mathrm{Cu}-2 \mathrm{wt} \% \mathrm{Al}$. For the [001] orientation shocked at $200 \mathrm{~J}$, stacking-faults were readily observed as the dominant defect substructure for position A as shown in Figure 6(a). Because of the $2 \mathrm{wt} \%$ addition of aluminum, the stacking-fault energy is nearly half that of pure copper and one would expect to observe twinning. However, this is not the case. Instead, four stacking-fault variants were observed. The faults are well defined with clean boundaries, have a regular spacing of $250 \mathrm{~nm}$, and were observed in equivalent proportions. When imaged at $B=[001]$, they appear at exactly $90^{\circ}$ to each other

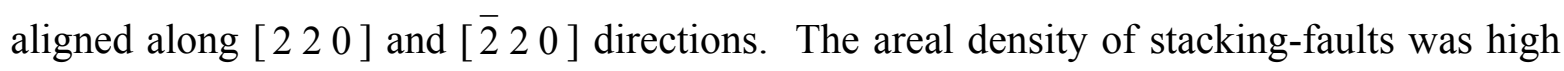
$\left(1.5 \times 10^{5} \mathrm{~m}^{-1}\right)$ as shown in the micrograph. The stacking-faults have a constant width of about $150 \mathrm{~nm}$, but vary considerably in length with an average on the order $1 \mu \mathrm{m}$. The spacing of the faults averages $280 \mathrm{~nm}+/-50 \mathrm{~nm}$. A moderate number of dislocations are also clearly observed between the stacking-faults. It is difficult to determine a dislocation density with the high density of faults, but a density on the order of $10^{12} \mathrm{~m}^{-2}$ is approximated by comparing several specimens.

Position $\mathrm{B}$ of the $\mathrm{Cu}-2 \mathrm{wt} \% \mathrm{Al}$ oriented along [001] also contains stacking-faults, though the density was about one-half of specimen A, $0.74 \times 10^{5} \mathrm{~m}^{-1}$ as shown in Figure 6(b). The width of the faults decreased by approximately half to $75 \mathrm{~nm}$, but the average spacing was found to be relatively similar: $300 \mathrm{~nm}+/-50 \mathrm{~nm}$. The stacking-faults were on average shorter $(800 \mathrm{~nm})$ and did not have clean boundaries as observed in A. Numerous dislocation loops were observed in the material, but the overall dislocation density was low.

Positions C and D contained loose dislocation cells (Figure 6(c) and (d)). The cell size for $\mathrm{C}$ was 200-300 $\mathrm{nm}$ and the thickness of the cell walls was $100 \mathrm{~nm}$. The average line length was about $100 \mathrm{~nm}$ and the dislocation density was on the order of $10^{14} \mathrm{~m}^{-2}$. Dislocations appeared to align themselves on specific planes yielding areas of dense tangles and regions where the substructure is less organized. For sample D, the cell size is approximately $700 \mathrm{~nm}$. The dislocation density is $10^{13} \mathrm{~m}^{-2}$ with a line length of $200 \mathrm{~nm}$. 
$\mathrm{Cu}-2 \%$ wt $\mathrm{Al}$ with [ $\overline{1} 34]$ orientation and shocked at $200 \mathrm{~J}$ exhibited twinning (position A, Figure 7(a)). Two variants are observed. The twins were found in a relatively low proportion, but are the systems predicted by Schmid factor calculations. The twins varied in size and proportion with the primary variant, (111)[ $\overline{2} 11]$, having an average length of $4 \mu \mathrm{m}$ and a width of 20-30 nm. The secondary variant, (1 $\overline{1} 1)[\overline{1} \overline{1} \overline{2}]$, had a greater number of twins, but they were shorter in length with an average of $2 \mu \mathrm{m}$. For [1 34 ], the primary twinning system has a Schmid factor of 0.4895 and the secondary system, 0.3857. It was expected that a co-secondary twinning variant would also be found, $(1 \overline{1} 1)[1 \overline{1} \overline{2}]$, but the occurrence of this system was relatively rare. This suggests that the sample may have been slightly misaligned from the [ $\overline{1} 34]$ loading axis, and thereby preferred the two observed twinning systems have higher Schmid factors than calculations indicate. A high density of dislocations was also observed (not shown here). These were found as tangles, loops, and a transitional structure between planar arrays and cells. The dislocation density was lower than in pure copper, $10^{14} \mathrm{~m}^{-2}$, possibly as a result of twinning competing with slip. The same decrease in dislocation density with decrease in stackingfault energy was observed by Rohatgi et al. [13-15].

In positions B-D (Figure 7(b)-(d)), the primary defect substructure was dislocations. Position B consisted of a high density of dislocations, $10^{14} \mathrm{~m}^{-2}$, with an average line length of $125 \mathrm{~nm}$ and cells averaging $125 \mathrm{~nm}$ in diameter. The dislocations were aligned to three dominant slip directions. Specimen $\mathrm{C}$ had a dislocation density of $10^{13} \mathrm{~m}^{-2}$ and a line length of $300 \mathrm{~nm}$. Cell sizes averaged $300 \mathrm{~nm}$, and were loosely defined as some dislocations were aligned in planar arrays. The spacing of these arrays was approximately $450 \mathrm{~nm}$. In specimen D, a large number of dislocation loops are observed in addition to the planar arrays/elongated cells. The cell size is $400 \mathrm{~nm}$, the line length is $300 \mathrm{~nm}$, and the dislocation density was on the order of $10^{12} \mathrm{~m}^{-2}$.

Consistent with Fig. 6(a), the [001] Cu-2wt\% Al shocked at $300 \mathrm{~J}$ ( 60 GPa) exhibited high densities of stacking-faults near the front surface (Position A) as shown in Figure $8(\mathrm{a})$. The areal density is calculated to be $1.6 \times 10^{5} \mathrm{~m}^{-1}$ and the spacing $(200 \mathrm{~nm})$ is much smaller than for position A of the $200 \mathrm{~J}$ experiment $(300 \mathrm{~nm})$. The lengths of the 
faults ranged from 1 to $5 \mu \mathrm{m}$ and their thickness averaged $100 \mathrm{~nm}$. They were aligned along $\{011\}$ directions when viewed from the (001) zone axis.

The $\mathrm{Cu}-2 \% \mathrm{wt} \mathrm{Al}$ oriented along [1 34$]$ and shocked at $300 \mathrm{~J}$ showed dramatic differences in the defect substructure. In position A, twinning was the dominating mechanism (Figure $8(b)$ ). The twins were the primary variant [ $\overline{2} 11]$ (111). They had an average width of $200 \mathrm{~nm}$, an average length of $3.5 \mu \mathrm{m}$, and thickness of $50 \mathrm{~nm}$. The twin spacing was about $500 \mathrm{~nm}$. Highly dense regions of dislocations were also observed between the twinned regions made of short lines with lengths of $50 \mathrm{~nm}$. No estimates of dislocation density were made due to the large number of twins

\subsection{TEM OF COPPER 6wt\% ALUMINUM}

The defect substructure for all energies in $\mathrm{Cu}-6 \mathrm{wt} \% \mathrm{Al}$ with [001] orientation consisted of either stacking-faults or dislocations since, for this system, the stacking-fault energy is less than $5 \mathrm{~mJ} / \mathrm{m}^{2}$. The dislocation structure consists of large planar arrays and regions of dislocation pileup since the low stacking-fault energy inhibits cross-slip. Many of the dislocations observed were Shockley partials: $\{11 \overline{1}\} \quad 1 / 6<112>$. They are glissile on $\{111\}$ planes. These dislocations form when $1 / 2<110>$ dislocations dissociate into $1 / 6<112>$ forming the boundaries of the stacking-faults.

For the [001] orientation and laser shocked at $200 \mathrm{~J}$, the defect substructure for the positions (A-C) was predominantly stacking-faults (Figure 9(a)-(c)). In specimen A, the stacking-faults had a width of $100 \mathrm{~nm}$, length of $1 \mu \mathrm{m}$, and spacing of $400 \mathrm{~nm}$. The areal density was $0.84 \times 10^{5} \mathrm{~m}^{-1}$. Dislocations were also observed throughout the specimen, typically near the fault boundaries. Specimen B contained stacking-faults with a width of $150 \mathrm{~nm}$, a length of $750 \mathrm{~nm}$, and a spacing of $600 \mu \mathrm{m}$. The areal density was $0.56 \times 10^{5} \mathrm{~m}^{-1}$. Dislocations were also observed with an average line length of $250 \mathrm{~nm}$. In specimen C, stacking-faults and dislocations were observed in equivalent proportions. The areal density of the faults was $2.4 \times 10^{5} \mathrm{~m}^{-1}$ from faults with an average width of $50 \mathrm{~nm}$, length of 500 $\mathrm{nm}$, and spacing of about $1 \mu \mathrm{m}$. The dislocation density was on the order of $10^{13} \mathrm{~m}^{-2}$ with an average line length of $250 \mathrm{~nm}$. 
For the $[\overline{1} 34]$ orientation of the $\mathrm{Cu}-6 \mathrm{wt} \% \mathrm{Al}$, three variants of stacking-faults were observed in each of the front surfaces (position A) for the three conditions: 70, 200 and 300 J. The Cu-6 wt\% Al [1 134$]$ specimens shocked at $200 \mathrm{~J}$ contained a residual defect substructure similar to the $70 \mathrm{~J}$ specimens. Position A had three variants of stacking-faults (Figure 10(a)). There was one primary stacking-fault orientation observed which had a larger width, $\sim 200 \mathrm{~nm}$, and an average length of $5 \mu \mathrm{m}$. The other two systems, as predicted by Schmid factors, are observed in equivalent amounts. They have widths on the order of $100 \mathrm{~nm}$ and lengths of an average $2 \mu \mathrm{m}$. The spacing for these three stacking-fault systems was equivalent, $250 \mathrm{~nm}$. The areal density for this specimen was found to be $1.44 \times 10^{5} \mathrm{~m}^{-1}$. The formation of the stacking-fault tetrahedra is likely a result of gliding screw dislocations. Twinning also was observed in small proportions, but only on the primary system, [ $\overline{2} 11$ ](111). In positions B and C (Figure 10(b) and (c)), dislocations dominate the defect substructure. Position B had a dislocation density of $10^{13} \mathrm{~m}^{-2}$ and an average line length of nearly $1 \mu \mathrm{m}$. The dislocations are preferentially aligned along specific planes with a spacing of $1 \mu \mathrm{m}$ and it is evident that there is one primary slip system, [ $\overline{1} 01$ ](111). Some stackingfaults were also observed with most being aligned to $[\overline{2} 11$ ](111). In specimen $C$, each of the three slip systems are observed and are spaced every $300 \mathrm{~nm}$ on specific planes. The average line length for the primary system is $400 \mathrm{~nm}$, whereas the secondary slip systems average about $150 \mathrm{~nm}$. The dislocation density is on the order of $10^{12-13} \mathrm{~m}^{-2}$.

The defect substructure of the $300 \mathrm{~J} \mathrm{Cu}-6 \mathrm{wt} \% \mathrm{Al}$ with [001] orientation specimens was similar to those shocked at $200 \mathrm{~J}$ (Figure 11(a)). The TEM revealed an areal density of $1.28 \times 10^{5} \mathrm{~m}^{-1}$ of faults with a $50 \mathrm{~nm}$ width, $150 \mathrm{~nm}$ spacing, and $1.5 \mu \mathrm{m}$ length. All four stacking-fault variants were observed creating rectangular patterns in the images similar to those observed in pure copper. The main difference between $\mathrm{Cu}-6 \mathrm{wt} \% \mathrm{Al}$ [ $\overline{1} 34$ ] samples shocked at $300 \mathrm{~J}$ and the other conditions was the appearance of stacking-faults throughout the specimen Figure 11(b). The areal density of stacking-faults for the specimen was $1.68 \times 10^{5} \mathrm{~m}^{-1}$. The three variants were present in unequal amounts as the primary system was $200 \mathrm{~nm}$ wide, $1 \mu \mathrm{m}$ long, and were spaced every $300 \mathrm{~nm}$, whereas the other two systems had widths of $75 \mathrm{~nm}$, were $1 \mu \mathrm{m}$ long, and a spacing of $100 \mathrm{~nm}$. Dislocations were 
visible in the cells formed by the crossing stacking-faults and they had a line length of 50$100 \mathrm{~nm}$.

To summarize this section, Table 1 gives the observed defect substructure for each specimen and the related defect density (stacking-fault areal density or dislocation density). It was found that stacking-faults typically formed at high pressures and then were found to decay into either cells or planar arrays of dislocations as the pressure decayed through the sample. The decreasing stacking-fault energy enhanced the propensity to form of stackingfaults for both orientations. It is also interesting to note that average line length tended to increase as dislocation densities decreased as the pressure wave decayed and the pulse duration broadened. Similarly, cells and planar arrays became more clearly defined as the time at pressure decreased and pulse duration increased. Both of these effects make sense in terms of dislocation theory (nucleation, growth, and movement). Twinning was not readily observed in most of these conditions suggesting there may be some unresolved time dependence to nucleate twins. However, it is possible that many of the stacking-faults observed are actually nano-twins. Because the thickness of the twin is small, the transmission electron microscope may not have been able to resolve the changes in the diffraction pattern. Additional work needs to be done on a high resolution transmission electron microscope to clarify this.

These results are plotted in Figure 12 ((a)-(c)). The positions A-D were converted into pressures through simulated pressure profiles. The transition from loose dislocations/cells to stacking-faults/twins is approximately indicated in Figure 12(a). As expected, this transition pressure decreases with decreasing stacking-fault energy. Figures 12(b) and (c) show the change of dislocation densities and stacking-fault densities versus pressure, respectively. For a specific pressure, the dislocation density decreases with decreasing stacking fault energy, consistent with plate-impact experiments by Rohatgi et al. [13-15]. Both deformation twinning and stacking-fault energy formation are the direct consequence of partial dislocation nucleation and expansion. This will be analyzed in section 4.2. In the case of twinning, one has separated loops of partial dislocations on adjacent planes. 


\subsection{EFFECT OF PRESSURE DECAY ON MECHANICAL PROPERTIES}

The shock amplitude at the surface of the $\mathrm{Cu}-\mathrm{Al}$ crystal can be extracted from the laser impact energies and hydrocode calculations which can be verified by VISAR measurements. A plot showing the decay of the pressure wave from a $70 \mathrm{~J}$ laser impact in pure copper is shown in Figure 2 (b). Due to the short duration of the laser pulse, the shock wave decays exponentially in amplitude and wavelength broadens near linearly with distance. The decrease in amplitude is a result of the release wave generated at the front free surface immediately following the end of the laser deposition.

As mentioned earlier, specimens were cut at regular distances from the impact surface, so that detailed characterization of the pressure decay could be performed. This section highlights results from micro- and nano-indentation measurements to obtain mechanical property data.

It has been well established that shock compression strengthens ductile materials more effectively than quasi-static deformation at the same effective strains. This hardening effect has been attributed to increased dislocation densities formed (and stored thereafter) in shock compression. The flow stress is related to the dislocation density by

$$
\tau=\tau_{0}+\mathrm{k} \rho^{1 / 2}
$$

where $\tau$ is the shear stress, $\tau_{0}$ is the stress obtained when $\rho^{1 / 2}$ is extrapolated to zero, $\mathrm{k}$ is a material constant, and $\rho$ is the dislocation density. Additionally, shock loading can increase the density of twinning, stacking-faults and point defects which are reflected in the hardness and strength of the recovered material. In this study, hardness measurements were made on the specimens characterized by transmission electron microscopy using micro- and nanoindentation measurements. This method provided an excellent way to examine the deformation substructures and relate the TEM observation images to actual mechanical properties.

Figure 13(a) shows the changes using microindentation hardness measurements for the pure copper oriented along [134]. Figures 13(b) and (c) show the hardness data for the $\mathrm{Cu}-2 \mathrm{wt} \% \mathrm{Al}$, and Figure 13(d) and (e) show it for the $\mathrm{Cu} 6 \mathrm{wt} \% \mathrm{Al}$ for orientations [001] and [1 34 ], respectively. Table 2 shows the initial and maximum Vickers hardness value achieved for each of the conditions. The hardness increases substantially with increasing 
laser shock energy; a rapid decrease in the hardness is observed in the first $1 \mathrm{~mm}$ of material. The hardness values are somewhat lower than those observed by Rohatgi et al. $[13-15,21]$. The measured values are shown in Table 2. This difference in the hardness measurements is attributed to grain size strengthening in the polycrystalline material used by Rohatgi et al. [13-15]

To achieve greater resolution, several samples were also examined by nanoindentation. Figure 14(a)-(c) shows how the hardness of a $\mathrm{Cu} 6 \% \mathrm{Al}$ sample shocked to energy levels of 70, 200 and $300 \mathrm{~J}(20,40$, and $60 \mathrm{GPa})$ changes with distance from the impact surface. This data was compared to the microhardness measurements shown in Figure 14(b). The data agrees showing that there is a substantial drop in hardness due to the rapid decay of the shock wave. Table 2 summarizes the results of the hardness measurements for both techniques by giving the maximum values obtained.

\section{ANALYSIS}

\subsection{THE SLIP-TWINNING TRANSITION}

In shock loading, the dislocation arrangements are more uniform than after quasi-static deformation of the material. High stacking-fault energy materials often are found to twin above a threshold pressure during shock compression whereas they may never twin at quasistatic conditions except at very low temperatures. Twinning propensity, however, increases in both modes of deformation (quasi-static and high-strain rate) when the stacking-fault energy is decreased. Stacking-fault energy can be manipulated in materials by alloying. For example, in copper, which has a relatively high stacking-fault energy (78 ergs $/ \mathrm{cm}^{2}$ [12]), the stacking-fault energy is nearly cut in half by adding 2 weight percent aluminum. This effect can be correlated to the change in the electron to atom ratio (e/a) in an alloy as given by (4) :

$$
\mathrm{e} / \mathrm{a}=(1-\mathrm{x}) \mathrm{Z}_{1}+\mathrm{Z}_{2}=1+\mathrm{xdZ}
$$

where $x$ is the atomic fraction of the solute in the alloy, $Z_{1}$ and $Z_{2}$ are the number of valence electrons for the solute and solvent atoms, respectively, and $d Z$ equals $\left(Z_{1}-Z_{2}\right)$. Gallagher [25] and Vöhringer [26] correlated the SFE to the electron/atom (e/a) ratio for copper alloys, Eqn. (2), and arrived at the following expression: 


$$
\ln \left(\frac{\gamma_{S F}}{\gamma_{C u}}\right)=K_{1}\left(\frac{C}{C+C_{\max }}\right)^{2}
$$

where $\gamma_{\mathrm{Cu}}$ is the stacking-fault energy for copper, and $C$ is the concentration of solute atoms. The maximum concentration of the solute is denoted by $C_{\max }$. The best fit was obtained with $K_{1}=12.5$ and $\gamma_{\mathrm{Cu}}=78 \pm 8 \mathrm{~mJ} / \mathrm{m} 2$. Equation 5 can be combined with the mathematical representation of data complied by Venables [27] and Vöhringer [28]. The twinning stress for a number of copper alloys has been shown to vary with the square root of the SFE:

$$
\sigma_{T}=K_{2}\left(\frac{\gamma_{S F}}{G b}\right)^{1 / 2}
$$

A good fit is obtained with $K_{2}=6 \mathrm{GPa}$ and a similar fit was satisfactorily obtained by Narita and Takamura [29] for Ni-Ge alloys. Substitution of Equation (5) into Equation (6) yields

$$
\sigma_{T}=\frac{K_{2}}{G b^{1 / 2}} \exp \left[\ln \gamma_{C u}+K_{1}\left(\frac{C}{C+C_{\max }}\right)^{2}\right]^{1 / 2}
$$

Table 3 shows the calculated stacking-fault energies and twinning stresses for materials of interest: copper and copper aluminum alloys. The calculated values for stacking-fault energy are compared to the experimentally obtained values. The twinning stresses are calculated based on the calculated stacking-fault energy values and neglect any grain size effects. Because a relationship between twinning stress and composition is possible, the effect of stacking-fault energy on the threshold pressure for twinning can by described analytically and compared to the experimental results observed by TEM in Section 3.

It was shown by Thomas $[11,30]$ that slip and twinning are competing deformation mechanisms and that they have a profound effect on the mechanical properties of materials such as martensitic steels and FCC metals. Slip has much higher temperature dependence than twinning; establishing slip and twinning domains. The goal of the current research effort has been to develop a constitutive description to quantitatively describe this transition as a function of orientation, stacking-fault energy, temperature, grain size, and strain rate. 
The methodology to be used in the prediction of the threshold shock amplitude for twinning was delineated by Murr et al. [31] and Meyers et al. [32]. The procedure presented herein can be used to predict the critical pressure for twinning in shock compression experiments. It is known that different metals have different threshold pressures for the initiation of twinning; it has been established by Murr [20] and Johari and Thomas [11] that this pressure is a function of stacking-fault energy, for FCC metals. Another important factor is orientation, which has never been quantified except in terms of resolved shear stress, which does not adequately describe the differences.

This is corroborated by experimental evidence presented earlier. One can obtain the critical twinning pressure as a function of $\varepsilon, \dot{\varepsilon}$, and T. The transition from slip to twinning occurs when the shear stress for twinning, $\tau_{\mathrm{T}}$, becomes equal to the shear stress for slip, $\tau_{\mathrm{s}}$, (i.e. $\tau_{\mathrm{T}} \geq \tau_{\mathrm{s}}$ or $\sigma_{T} \geq \sigma_{s}$ ) since both mechanisms are subjected to the same stress system at the shock front. It should be mentioned that the criterion described here is based on the critical shear stress for slip and twinning; the pressure only enters insofar as it determines the shear stress and strain rate. The application of this criterion to the shock front necessitates the knowledge of the strain rate. The strain rate at the shock front has been established by Swegle and Grady [33] to be:

$$
P=k_{S G} \dot{\varepsilon}^{1 / 4}
$$

Two separate aspects have to be considered in the analysis: (a) shock heating and (b) plastic strain at the shock front. Both shock heating and plastic strain by slip (and associated work hardening) alter the flow stress of material by slip processes and need to be incorporated into the computation. The total (elastic + plastic) uniaxial strain, $\varepsilon$, at the shock front is related to the change in specific volume by:

$$
\frac{V}{V_{0}}=e^{\varepsilon}
$$

The pressure dependence on strain, determined from Rankine-Hugoniot equations, equation of state, and Equation (9) is expressed as follows: 


$$
P=\frac{C_{0}^{2}\left(1-e^{\varepsilon}\right)}{V_{0}\left[1-S\left(1-e^{\varepsilon}\right)\right]^{2}}
$$

The constitutive response of the copper monocrystal is represented by the modified Zerilli-Armstrong expression below:

$$
\sigma_{S}=\sigma_{G}+C_{2} f(\varepsilon) \exp \left(-C_{3} T+C_{4} T \ln (\dot{\varepsilon})\right)
$$

where $\sigma_{G}, \mathrm{C}_{3}$, and $\mathrm{C}_{4}$ are adopted from [34] and $\mathrm{C} 2=115 \mathrm{MPa}$. The work hardening $f(\varepsilon)$ was incorporated by taking a polynomial representation of the stress-strain curve for single crystals with the [001] and [ $\overline{1} 34]$ orientations from [35]. This is the only manner by which the three stage response can be incorporated without excessive complexity. The [001] orientation is expected to have the lowest threshold pressure for twinning of all orientations, whereas [ $\overline{1} 34]$ should have a substantially higher threshold pressure due to its more gradual hardening. The polynomials used in these calculations are: For [001]:

$$
f(\varepsilon)=19466.2 \varepsilon^{6}-18522.2 \varepsilon^{5}+7332 \varepsilon^{4}-1582 \varepsilon^{3}+189.5 \varepsilon^{2}-2.4 \varepsilon+0.07
$$

For [1 134$]$ :

$$
f(\varepsilon)=-6293 \varepsilon^{6}+7441.4 \varepsilon^{5}-3163 \varepsilon^{4}+515.65 \varepsilon^{3}-4 \varepsilon^{2}+0.13 \varepsilon^{1}+0.059
$$

The normal twinning stress $\left(\sigma_{\mathrm{T}}\right)$ used in this calculation was $408 \mathrm{MPa}$, calculated from equation (6). We assume that this critical stress remains constant. The strain-rate and strain associated with a given shock pressure is calculated given by (8) and (9), respectively. The temperature rise is given by the following equation [36]:

$$
T_{\text {shock }}=10^{-19} P^{2}+2 \times 10^{-9} P+295.55
$$

The point at which the horizontal line drawn at the calculated twinning stress value intersects the Z-A stress-strain curve for a given shock pressure is defined as the critical twinning stress.

The addition of small amounts of aluminum in copper not only lowers the stackingfault energy, but drastically influences the strength and hardness. In pure metals, dislocations are relatively mobile, but when solute atoms are added the dislocation mobility 
is greatly reduced. In these alloys, the solute atoms become barriers to dislocation motion and can have the effect of locking them. Substantial work has been done developing solid solution theory for concentrated solid solutions [37-40]. It has been determined that the flow stress of concentrated solid solutions is related to the atomic concentration of the solute by

$$
\sigma_{0} \propto\left[C_{S}\right]^{2 / 3}
$$

where $\sigma_{0}$ is the flow stress and $C_{S}$ is the concentration of the solute. Copper-aluminum has been shown to follow this description [41]. It was therefore assumed reasonable to incorporate this compositional term into the modified Z-A equation as shown below

$$
\sigma_{s}=\sigma_{G}+C_{S}{ }^{2 / 3} C_{2} f(\varepsilon) \exp \left(-C_{3} T+C_{4} T \ln (\dot{\varepsilon})\right)
$$

After incorporating the effect of stacking-fault energy on the twinning stress using Equation 6 (with experimental SFEs of $2 \mathrm{wt} \% \mathrm{Al}=37 \mathrm{~mJ} / \mathrm{m}^{2}$, 4-wt $\% \mathrm{Al}=7 \mathrm{~mJ} / \mathrm{m}^{2}$, and 6-wt $\% \mathrm{Al}=4 \mathrm{~mJ} / \mathrm{m}^{2}$ ) and the solid solution hardening into the modified Z-A equation, it was possible to calculate the critical pressure for twinning in copper-aluminum alloys. Figure 15 shows the results from this analysis. For copper-aluminum oriented to [001], the critical pressure necessary to nucleate twinning drops from $55 \mathrm{GPa}$ for pure copper to $5 \mathrm{GPa}$ for $\mathrm{Cu}$ $6 \mathrm{wt} \% \mathrm{Al}$. For copper-aluminum oriented to [1 34 ], the change is from $80 \mathrm{GPa}$ in pure copper to $12 \mathrm{GPa}$ for $\mathrm{Cu}-6 \mathrm{wt} \% \mathrm{Al}$.

\subsection{THE CELL TO STACKING-FAULT TRANSITION}

The nucleation of loops has been modeled by Cottrell [42], Xu and Argon [43], Rice [41] and others. An intriguing mechanism was proposed by Khantia and Vitek [42] for the generation of dislocations under extreme conditions. At pressures above 3-3.2 GPa, the activation energy for loop nucleation falls below the thermal energy and the nucleation should become thermally activated, whereas under conventional deformation at ambient temperature it is not.

Meyers [46] proposed in 1977 that dislocations in shock compression were homogeneously generated by loop expansion. Figure 16 (a) shows a shear loop generated on 
a plane making an angle of $45^{\circ}$ with the shock compression plane. Whereas the nucleation and growth of perfect dislocation loops can lead to the formation of a cellular structure after multiple cross-slip and relaxation of the dislocation configurations, the stacking-fault packets observed in shock compression above $20 \mathrm{GPa}$ cannot be accounted for by this mechanism.

Thus, one has to analyze the energetics for the nucleation of partial dislocation loops. This treatment parallels the one for perfect dislocations. Fig. 16 (b) shows a partial dislocation loop. There are two significant differences between Fig. 16 (a) and (b): (a) the formation of a stacking-fault; (b) the dislocation composing the loop is Burgers vector $b_{p}$. The critical radius can be found from the maximum of the energy vs. radius curve:

$$
\frac{\mathrm{dE}}{\mathrm{dr}}=0
$$

For a perfect dislocation, the critical nucleus size and energetic barrier for the nucleation of loops can be calculated in a simplified approach, by an energetic analysis in which the total energy is the sum of the increase of the energy $E_{1}$, due to circular dislocation loop (assumed to be one half edge and one half screw), and the work W carried out by the applied stress $\tau$ on the loop of radius $r$ :

$$
\mathrm{E}=\mathrm{E}_{1}-\mathrm{W}=\frac{1}{2} \mathrm{~Gb} \mathrm{~b}^{2} \mathrm{r}\left(\frac{2-v}{1-v}\right) \ln \left(\frac{2 \mathrm{r}}{\mathrm{r}_{0}}\right)-\pi \mathrm{r}^{2} \tau \mathrm{b}
$$

This is described in detail by Hull and Bacon and Cottrell [47].

The critical radius is then calculated as a function of shear stress $\tau$ :

$$
\mathrm{r}_{\mathrm{c}}=\frac{\mathrm{Gb}}{8 \pi \tau}\left(\frac{2-v}{1-v}\right)\left(\ln \frac{2 \mathrm{r}_{\mathrm{c}}}{\mathrm{r}_{0}}+1\right)
$$

The total energy of the partial dislocation includes three components, the energy of dislocation line, $\mathrm{E}_{1}$, the energy of stacking-faults, $\mathrm{E}_{2}$, and the work done by shear stress, $\mathrm{W}$ :

$$
\mathrm{E}=\mathrm{E}_{1}+\mathrm{E}_{2}-\mathrm{W}
$$

In this case, the energy of the stacking-fault has to be accomplished by the generation and expansion of dislocation loops. The shear stresses generated by shock compression are on the order of the stresses required for the nucleation of shear loops.

$$
\mathrm{E}=\frac{1}{4} \mathrm{~Gb} \mathrm{~b}_{\mathrm{p}}^{2} \mathrm{r}\left(\frac{2-v}{1-v}\right) \ln \left(\frac{2 \mathrm{r}}{\mathrm{r}_{0}}\right)+\pi \mathrm{r}^{2} \gamma_{\mathrm{SF}}-\pi \mathrm{r}^{2} \tau \mathrm{b}_{\mathrm{p}}
$$


The critical radius is obtained from:

$$
r_{c}=\frac{G\left(\frac{b}{\sqrt{3}}\right)^{2}}{8 \pi\left(\frac{\tau b}{\sqrt{3}}-\gamma_{S F}\right)}\left(\frac{2-v}{1-v}\right)\left(\ln \frac{2 r_{c}}{r_{0}}+1\right)
$$

where $v$ is Poisson's ratio, 0.34 for copper. $\gamma$ is stacking-fault energy of copper, $78 \mathrm{~mJ} / \mathrm{m}^{2} . \mathrm{G}$ is the shear modulus of copper, equal to $45 \mathrm{GPa}$ at zero pressure and changes with pressure as [48]:

$$
\mathrm{G}=45+1.36 \mathrm{P} \quad(\mathrm{GPa})
$$

$\mathrm{b}$ is Burgers vector. $\mathrm{b}_{0}$ is equal to $2.55 \AA$ at zero pressure and changes with shock pressure as:

$$
\mathrm{b}=\left[\frac{\mathrm{C}_{0}^{2}}{2 \mathrm{PS}^{2} \mathrm{~V}_{0}}\left(\sqrt{1+\frac{4 \mathrm{PSV}_{0}}{\mathrm{C}_{0}^{2}}}+\frac{2 \mathrm{~S}(\mathrm{~S}-1) \mathrm{V}_{0} \mathrm{P}}{\mathrm{C}_{0}^{2}}-1\right]^{1 / 3} \mathrm{~b}_{0}\right.
$$

where $\mathrm{C}_{0}$ is $3.94 \mathrm{Km} / \mathrm{s}, \mathrm{S}$ is 1.489 , and $\mathrm{V}_{0}$ is the unit volume of copper $\left(\mathrm{m}^{3} / \mathrm{kg}\right)$ at zero pressure. The shear stress, $\tau$, can be calculated from shock pressure:

$$
\tau=-\frac{1-2 v}{2(1-v)} P
$$

The calculated results are shown in Figure 17(a). It can be seen that it is much easier to generate the perfect dislocations at lower pressure than that of partial dislocations. While with the increasing of pressure, partial dislocation is of more favorite. Figure 17(b) shows the effect of aluminum content on the transition pressure. As expected, it decreases with decreasing SFE. For 5\% Al, the stacking-fault loops have a smaller radius than perfect dislocation loops. This is in good agreement with experiments. The rationale presented in this section explains, albeit not exactly, how the structure of dislocations can change from cells to stacking-fault packets. The predicted transition of $6 \mathrm{GPa}$ for pure copper is actually lower than the experimentally observed results. Experimental evidence for such an abrupt transition has been gradually amassing and the TEM micrograph of Figure 19 is clear: there are regions of cell and stacking-fault formation, with well delineated boundaries. The TEM micrograph from Fig. 18 comes from a quasi-isentropic laser compression experiment at a nominal pressure of 24 GP for a [001] monocrystal. One sees adjacent regions of stacking- 
faults and dislocatiuon cells, with a well defined discrete boundary. This was a fortuitous observation and the transition can be caused by pressure or strain rate. Nevertheless, it clearly illustrates the dual nature of the microstructure induced. It should be noted that these results are not in agreement with MD computations by Germann and coworkers [49-52] which predict perfect dislocations for shock along [111] and partial dislocations and stacking-faults for [001], even at pressures slightly above the HEL. The reason for this disagreement is not understood at the present moment.

\section{CONCLUSIONS}

1. It is demonstrated that laser-driven shock compression experiments can provide unique information on the processes of defect generation at high strain rates. The results are fully consistent with gas-gun experiments which yield pulse durations higher by two orders of magnitude. The pulse duration in the current experiments was on the order of nanoseconds, two orders of magnitude lower than plate impact experiments.

2. It is shown, through heat transfer calculations, that post shock cooling is orders of magnitude faster in laser than in plate impact experiments. This is a significant advantage of laser shock compression that enables this technique to be extended to much higher pressures.

3. The experimental results for pure copper obtained in a previous investigation were successfully extended to $\mathrm{Cu}-\mathrm{Al}$ alloys. Two crystallographic orientations were investigated: [001] and [134]. For [001], the activation of eight slip systems simultaneously provides a higher work-hardening rate at the outset of plastic deformation. This results in higher dislocation densities and "tighter" cells. It also has a direct bearing on twinning. The orientation [ $\overline{1} 34]$ has less symmetry and a much more gradual work hardening curve correlating to lower dislocation densities and larger cell sizes.

4. For pure copper, there are two clear regimes of plastic deformation with different microstructural features: slip, dominated by dislocations organizing themselves into cells, and twinning/stacking-faults, characterized by planar features. The orientation dependence of the threshold pressure for twinning cannot be explained by differences in Schmid factors alone. The experimentally determined slip-twinning transition occurs for pressures that are 
orientation dependent: $30 \mathrm{GPa}$ initial pressure for [001] and $40 \mathrm{GPa}$ initial pressures for [1 34 ]. These values are higher than earlier results by DeAngelis and Cohen [53]: $14 \mathrm{GPa}$ for [001] and $16 \mathrm{GPa}$ for [111].

5. Copper-aluminum alloys ( 2 and 6 weight $\%$ ) were studied in order to determine quantitatively the effect of stacking- fault energy on the slip-twinning transition. Somewhat surprisingly, twinning was not a dominant mechanism in the deformation behavior. However, large numbers of stacking-faults were observed at higher pressures. The experimental results are compared with analytical calculations similar to pure copper. Experimentally, the transition between dislocation substructures and stacking-faults/twins occurs at pressures of $9 \mathrm{GPa}$ and $16 \mathrm{GPa}$ for $\mathrm{Cu}-2 \mathrm{wt} \% \mathrm{Al}$ with [001] and [ $\overline{1} 34$ ] orientations, respectively. For $\mathrm{Cu}-6 \mathrm{wt} \% \mathrm{Al}$, the transition occurred at $2.0 \mathrm{GPa}$ along [001] and $5 \mathrm{GPa}$ along [ $\overline{1} 34$ ].

6.The experimental results are compared with analytical predictions that enable the calculation of the threshold pressure for mechanical twinning. The predicted results compare qualitatively with experimental observations. The deformation transition between slip and twinning was analytically studied. A constitutive procedure developed earlier was applied to all compositions (pure $\mathrm{Cu}, \mathrm{Cu}-2 \mathrm{wt} \% \mathrm{Al}$, and $\mathrm{Cu}-6 \mathrm{wt} \% \mathrm{Al}$ ) and for [001] and [ $\overline{1} 34$ ] orientations. Slip and twinning are assumed to be competing mechanisms and the analytical predictions are compared to experimental results. The calculated transition pressures for pure $\mathrm{Cu}$ are $55 \mathrm{GPa}$ for [001] and $80 \mathrm{GPa}$ for [ 134 ]. The calculated pressures for $\mathrm{Cu}-2 \mathrm{wt} \%$ $\mathrm{Al}$ are $35 \mathrm{GPa}$ for [001] and $60 \mathrm{GPa}$ for [1 34$]$. The calculated pressures for $\mathrm{Cu}-6 \mathrm{wt} \% \mathrm{Al}$ are $5 \mathrm{GPa}$ for [001] and $12 \mathrm{GPa}$ for [ 134$]$. The calculated results are the first attempt to predict the orientation dependence of the twinning threshold. Although they do not directly match experimental observations on twinning, they qualitatively explain the difference encountered.

7. The homogeneous loop nucleation model [19, 49] for shock compression was applied to the transition between cells and stacking-fault packets: this mechanism proposes that shear loops are nucleated at the shock front and that this may be a thermally activated process. Experimental results and analysis of loops support this mechanism. This model enables the calculation of the energetics of partial and perfect dislocation generation. 
Although under ambient (zero pressure, room temperature) conditions perfect dislocation loops have a lower critical radius than partial loops, at a critical shock pressure, the situation is reversed. This was used to calculate a transition pressure from perfect to partial dislocation loops that predicts a change from dislocation cells to stacking faults.

8. The lower dislocation density encountered for $\mathrm{Cu}-6 \% \mathrm{Al}$ can be due to the fact that a grater fraction of the shock generated dislocations is annihilated. Partial dislocations can more easily be constricted on unloading and therefore disappear. Recent MD simulations predict exactly this phenomenon; the dislocation density decreases abruptly upon unloading. On the other hand, perfect dislocations cross slip with much more ease and are therefore locked into the substructure.

Acknowledgements: This research was supported by the Department of Energy through Grants DEFG0398DP00212 and DEFG0300SF2202. Portions of this work were performed under the auspices of the U.S. Department of Energy by Lawrence Livermore National Laboratory under Contract DE-AC52-07NA27344. 


\section{REFERENCES}

1. Smith, S. C., Trans. AIME, 1958, vol. 212, pp. 574-78.

2. Cao, B. Y., Lassila, D. H., Schneider, M. S., Kad, B. K., Huang, C. X., Xu, Y. B., Kalantar, D. H., Remington, B. A., Meyers, M. A., Mat. Sci. Eng. A, 2005, Vol. 409, pp. 270-281.

3. Schneider, M. S., Kad, B. K., Kalantar, D. H., Remington, B. A., Meyers, M. A., Met Trans A, 2004, Vol. 35 A, 263.

4. Schneider, M. S., Kad, B. K., Kalantar, D. H., Remington, B. A., Kenik, E., Jarmakani, H., Meyers, IJIE, 2005, Vol. 32, pp. 473-507.

5. McNaney, J. M., Edwards, M. J., Becker R., Lorenz K. T., Remington B. A., Met. Trans A, 2004, Vol. 35A, pp 265.

6. Askaryon, G.A. and Morez, E.M., JETP Lett., 1963, Vol. 16, pp. 1638.

7. White, R.M., J. Appl. Phys., 1963, Vol. 34, pp. 2123.

8. Bell, C.E. and Landt, J.A., Appl. Phys. Lett., 1967, Vol. 10, pp. 46.

9. Panarella, E. and Savic, P., Can. J Phys., 1968, Vol. 46, pp. 143.

10. Skeen, C.H. and York, C.M., J. Appl. Letts, 1968, Vol. 12, pp. 369.

11. Johari, O. and Thomas, G., Acta Met., 1964, Vol 12, pp. 1153-59.

12. Murr, L.E., Interfacial Phenomena in Metals and Alloys, Addison-Wesley, Reading, MA, 1975, p.142.

13. Rohatgi, A. and Vecchio, K.S., Mat. Sci. Eng. A, 2002, Vol. A328, pp. 256.

14. Rohatgi, A, Vecchio,, K. S., GrayIII, G. T., Acta Mat., 2001, vol.49, pp.427-438.

15. Rohatgi, A., Vecchio, K. S., Gray III, G. T., Met Trans. 2001, Vol. 135, pp.135-145.

16. Zimmerman, G. B. and Kruer, W. L., Comments Plasma Phys. Controlled Fusion 2, 1975, pp. 51.

17. Rubenchik, A. M., Feit, M. D., Perry, M. D., and Larsen, J. T, Appl. Surf. Sci. 1998, Vol. 129, pp. 193.

18. Steinberg, D. J., Cochran, S. G., and Guinan, M. W., J. Appl. Phys., 1980, Vol. 51, pp. 1496. 
19. Meyers, M. A., Gregori, F., Kad, B. K., Schneider, M. S., Kalantar, D. H., Remington, B, A, Ravichandran, G., Boehly, T., and Wark, J. S., Acta. Metall., 2003, Vol. 51, pp. 1211-1228.

20. Murr, L. E., in Shock Waves and High-Strain-Rate Phenomena in Metals, Eds. M.A. Meyers and L.E. Murr, Plenum, NY, 1981, pp. 607.

21. Holian B. L. and Lomdahl P. S., Science, 1998; Vol. 280, pp. 2085.

22. Bringa, E. M., Caro, A., Wang, Y, Victoria, M., McNaney, J. M., Remington, B. A., Smith, R. F., Torralva, B. R., Swygenhoven H. V, Science, 2005, Vol. 309, pp. $1838-1841$.

23. Murr, L.E., Scripta Met., 1978, Vol. 12, pp. 201.

24. Rohatgi, A., Thesis: A Microstructural Investigation of Shock Loading Effects in FCC Materials, UCSD, 1999.

25. Gallagher, P. C. J., Met Trans., 1970, Vol. 1, pp. 2429.

26. Vöhringer, O., Z. Metallk., 1974, Vol. 56, pp. 585.

27. Venables, J.A., in Deformation Twinning, Eds. R.E. Reed-Hill, J.P. Hirth and H.C. Rogers, Gordon and Breach, New York, 1964, pp.77.

28. Vöhringer, O., Z. Metallk., 1972, Vol. 11, 1119.

29. Narita, N. and Takamura, J.-I., in Dislocations in Solids, Ed. F.R.N. Nabarro. Elsevier, Amsterdam, 1992, Vol. 9, pp.135.

30. Thomas, G., Acta Met., 1965, Vol. 13, pp. 1211.

31. Murr, L.E., Meyers, M.A., Niou, C.-S., Chen, Y.-J., Pappu, S. and Kennedy, C., Acta Mater., 1997, Vol. 45, pp. 157.

32. Meyers, M.A., Voehringer, O. and Lubarda, V.A., Acta Mater., 2001, Vol. 49, pp. 4025.

33. Swegle, J.W. and Grady, D.E., J. Appl. Phys., 1983, Vol. 58, pp. 941.

34. Zerilli, F.J. and Armstrong, R.W., J. Appl. Phys., 1987, Vol. 61, pp. 1816.

35. Diehl, J. Z., Metallk., 1956, Vol. 47, pp. 331-341. 
36. Meyers, M. A., Dynamic Behavior of Materials, J. Wiley, NY, 1994.

37. Vöhringer, O., Z. Metallk., 1976, Vol. 67, pp. 51.

38. Kan, T. and Haasen, P., Mat Sci Eng., (1969-70), Vol. 5, pp. 237.

39. Labusch, R., Phys. Stat. Solidi, 1970, Vol. 41, pp. 659.

40. Jax, P., Kratochvil, P., and Haasen, P., Acta Met., 1970, Vol. 18, pp. 237.

41. Rohatgi, A., Thesis: A Microstructural Investigation of Shock Loading Effects in FCC Materials, UCSD, 1999.

42. Cottrell, A., Dislocations and Plastic Flow in Crystals, Oxford at the Clarendon press, 1953, p. 54.

43. Xu, G. and Argon, A. S., Phil. Mag., 2000, vol. 80. pp.605-611.

44. Rice, J. R. , J. mech. Phys. Sol., 1992, vol. 40, pp. 256.

45. Khantia, M. and Vitek, V., Acta mat., 1997, vol. 45, pp. 4675.

46. Meyers, M. A., Scripta Mat., 1978, Vol. 12, pp. 21.

47. Hull, D. and Bacon, D. J., Introduction to Dislocations, Butterworth-Heinemann, Oxford, 2001, p. 147.

48. Preston, D. L. and Wallace, D. C., Solid State Communications, 1992, Vol. 81(3), pp.277.

49. Germann TC, Holian BL, Lomdahl PS. Phys Rev Lett., 2000, Vol. 84, pp. 5351.

50. Germann TC, Tanguy D, Holian BH, Lomdahl PS, Mareschal M, Ravelo R., Met Trans., 2004, Vol. 35A, pp. 2609.

51. Tanguy D, Mareschal M, Lomdahl PS, Germann TC, Holian BL, Ravelo R., Phys Rev B., 2003, Vol. 68, pp. 144111.

52. Kadau, K., Germann, T. C., Lomdahl, P. S., Holian, B. L., Kadau, D., Ental, P., Kreth, M., Westerhof, F., Wolf, D. E., Met. and Mat. Trans., 2004, Vol. 35A, pp. 2719.

53. De Angelis, R.J. and Cohen, J.B., J. of Metals, 1963, Vol. 15, pp. 681. 


\section{TABLES}

Table 1: Summary of results for residual defect substructure in $\mathrm{Cu}-\mathrm{Al}$ alloys.

\begin{tabular}{|c|c|c|c|c|c|}
\hline \multirow[t]{2}{*}{ SAMPLE } & & \multicolumn{4}{|c|}{ POSITION } \\
\hline & & $\mathbf{A}$ & B & $\mathbf{C}$ & D \\
\hline $\mathrm{Cu}-2 \% \mathrm{Al} 001$ & $70 \mathrm{~J}$ & $\begin{array}{c}\text { dislocations } \\
10^{15} \mathrm{~m}^{-2}\end{array}$ & $\begin{array}{c}\text { Cells } 0.4 \text { um } \\
10^{14} \mathrm{~m}^{-2}\end{array}$ & $\begin{array}{c}\text { Cells } 0.7 \text { um } \\
10^{13} \mathrm{~m}^{-2}\end{array}$ & $\begin{array}{l}\text { Cells } 1.2 \text { um } \\
10^{12-13} \mathrm{~m}^{-2}\end{array}$ \\
\hline $\mathrm{Cu}-2 \% \mathrm{Al} 001$ & $200 \mathrm{~J}$ & $\begin{array}{l}\text { Stacking-faults } \\
1.44 \times 10^{5} \mathrm{~m}^{-1}\end{array}$ & $\begin{array}{l}\text { Stacking-faults } \\
0.74 \times 10^{5} \mathrm{~m}^{-1}\end{array}$ & $\begin{array}{c}\text { Cell } 0.25 \mathrm{um} \\
10^{14} \mathrm{~m}^{-2}\end{array}$ & $\begin{array}{c}\text { Cells } 0.7 \text { um } \\
10^{13} \mathrm{~m}^{-2}\end{array}$ \\
\hline $\begin{array}{c}\mathrm{Cu}-2 \% \mathrm{Al} 001 \\
300 \mathrm{~J}\end{array}$ & $300 \mathrm{~J}$ & $\begin{array}{c}\text { Stacking-faults } \\
1.6 \times 10^{5} \mathrm{~m}^{-1}\end{array}$ & $\begin{array}{l}\text { Stacking-faults } \\
0.86 \times 10^{5} \mathrm{~m}^{-1}\end{array}$ & $\begin{array}{c}\text { Cells } 0.1 \text { um } \\
10^{14} \mathrm{~m}^{-2}\end{array}$ & $\begin{array}{c}\text { Cell size } 0.15 \\
10^{13-14} \mathrm{~m}^{-2}\end{array}$ \\
\hline $\begin{array}{c}\mathrm{Cu}-2 \% \mathrm{Al} 134 \\
70 \mathrm{~J}\end{array}$ & $70 \mathrm{~J}$ & $\begin{array}{c}\text { Planar/Cells } \\
10^{15} \mathrm{~m}^{-2}\end{array}$ & $\begin{array}{l}\text { Planar arrays - } \\
\qquad 10^{13} \mathrm{~m}^{-2}\end{array}$ & $\begin{array}{c}\text { Planar array } \\
10^{13} \mathrm{~m}^{-2}\end{array}$ & $\begin{array}{c}\text { Planar Array } \\
10^{12} \mathrm{~m}^{-2}\end{array}$ \\
\hline $\begin{array}{c}\mathrm{Cu}-2 \% \mathrm{Al} 134 \\
200 \mathrm{~J}\end{array}$ & $200 \mathrm{~J}$ & Twinning & $\begin{array}{l}\text { Cells } 0.12 \text { um } \\
10^{14} \mathrm{~m}^{-2}\end{array}$ & $\begin{array}{l}\text { Cells } 0.3 \text { um } \\
10^{13} \mathrm{~m}^{-2}\end{array}$ & $\begin{array}{c}\text { Planar arrays } \\
10^{12} \mathrm{~m}^{-2}\end{array}$ \\
\hline $\begin{array}{c}\mathrm{Cu}-2 \% \mathrm{Al} 134 \\
300 \mathrm{~J}\end{array}$ & $300 \mathrm{~J}$ & Twinning & $\begin{array}{l}\text { Cells } 0.10 \text { um } \\
10^{14} \mathrm{~m}^{-2}\end{array}$ & $\begin{array}{l}\text { Cells } 0.50 \text { um } \\
10^{13} \mathrm{~m}^{-2}\end{array}$ & $\begin{array}{l}\text { Cells } 0.5 \text { um } \\
10^{12-13} \mathrm{~m}^{-2}\end{array}$ \\
\hline $\mathrm{Cu}-6 \% \mathrm{Al} 001$ & $70 \mathrm{~J}$ & $\begin{array}{l}\text { Stacking-faults } \\
0.88 \times 10^{5} \mathrm{~m}^{-1}\end{array}$ & $\begin{array}{l}\text { Stacking-faults } \\
0.22 \times 10^{5} \mathrm{~m}^{-1}\end{array}$ & $\begin{array}{c}\text { Planar arrays } \\
10^{12-13} \mathrm{~m}^{-2}\end{array}$ & $\begin{array}{c}\text { Planar arrays } \\
10^{11-12} \mathrm{~m}^{-2}\end{array}$ \\
\hline $\mathrm{Cu}-6 \%$ Al 001 & $200 \mathrm{~J}$ & $\begin{array}{l}\text { Stacking-faults } \\
0.84 \times 10^{5} \mathrm{~m}^{-1}\end{array}$ & $\begin{array}{l}\text { Stacking-faults } \\
0.56 \times 10^{5} \mathrm{~m}^{-1}\end{array}$ & $\begin{array}{l}\text { Stacking-faults } \\
0.24 \times 10^{5} \mathrm{~m}^{-1}\end{array}$ & \\
\hline $\mathrm{Cu}-6 \%$ Al 001 & $300 \mathrm{~J}$ & $\begin{array}{c}\text { Stacking-faults } \\
1.3 \times 10^{5} \mathrm{~m}^{-1}\end{array}$ & $\begin{array}{c}\text { Stacking-faults } \\
0.74 \times 10^{5} \mathrm{~m}^{-1} \\
\end{array}$ & $\begin{array}{l}\text { Stacking-faults } \\
0.26 \times 10^{5} \mathrm{~m}^{-1}\end{array}$ & \\
\hline $\mathrm{Cu}-6 \% \mathrm{Al} 134$ & $70 \mathrm{~J}$ & $\begin{array}{l}\text { Stacking-faults } \\
0.58 \times 10^{5} \mathrm{~m}^{-1}\end{array}$ & $\begin{array}{c}\text { Planar arrays } \\
10^{13} \mathrm{~m}^{-2}\end{array}$ & $\begin{array}{c}\text { Planar arrays } \\
10^{13} \mathrm{~m}^{-2} \\
\end{array}$ & $\begin{array}{c}\text { Planar arrays } \\
10^{12} \mathrm{~m}^{-2}\end{array}$ \\
\hline $\mathrm{Cu}-6 \% \mathrm{Al} 134$ & $200 \mathrm{~J}$ & $\begin{array}{l}\text { Stacking-faults } \\
1.44 \times 10^{5} \mathrm{~m}^{-1}\end{array}$ & $\begin{array}{c}\text { Planar Arrays } \\
10^{13} \mathrm{~m}^{-2}\end{array}$ & $\begin{array}{c}\text { Planar arrays } \\
10^{12} \mathrm{~m}^{-2}\end{array}$ & \\
\hline $\mathrm{Cu}-6 \% \mathrm{Al} 134$ & $300 \mathrm{~J}$ & $\begin{array}{l}\text { Stacking-faults } \\
1.69 \times 10^{5} \mathrm{~m}^{-1}\end{array}$ & $\begin{array}{l}\text { Stacking-faults } \\
0.82 \times 10^{5} \mathrm{~m}^{-1}\end{array}$ & $\begin{array}{c}\text { Planar arrays } \\
10^{13} \mathrm{~m}^{-2}\end{array}$ & $\begin{array}{c}\text { Planar arrays } \\
10^{12}\end{array}$ \\
\hline
\end{tabular}


Table 2: Maximum hardness measurements for pure $\mathrm{Cu}$ and $\mathrm{Cu}-\mathrm{Al}$ alloys for micro and nanoindentation. Measurements are also compared with values obtained for shocked polycrystalline samples [X].

\begin{tabular}{|c|c|c|c|c|}
\hline \multicolumn{5}{|c|}{ Microhardness Measurements - Maximum Hardness (HVN) } \\
\hline Sample & Unshocked & $20 \mathrm{GPa}$ & $40 \mathrm{GPa}$ & $60 \mathrm{GPa}$ \\
\hline Pure Copper [001] & 44 & 91.3 & 102 & 123 \\
\hline Pure Copper [ $[\overline{1} 34]$ & 37 & 82.4 & 101 & 113 \\
\hline $\mathrm{Cu}-2 \mathrm{wt} \% \mathrm{Al}[001]$ & 111.6 & 186 & 211 & 218.2 \\
\hline $\mathrm{Cu}-2 \mathrm{wt} \% \mathrm{Al}[\overline{1} 34]$ & 91.2 & 130 & 158.2 & 198 \\
\hline $\mathrm{Cu}-6 \mathrm{wt} \% \mathrm{Al}[001]$ & 123 & 175 & 203 & 241 \\
\hline $\mathrm{Cu}-6 w t \% \mathrm{Al}[\overline{1} 34]$ & 105.2 & 148 & 169 & 213.5 \\
\hline \multicolumn{5}{|c|}{ Nanoidentation Measurements - Maximum Hardness (GPa) } \\
\hline Sample & Unshocked & $20 \mathrm{GPa}$ & 40 GPa & $60 \mathrm{GPa}$ \\
\hline Pure $\mathrm{Cu}[001]$ & --- & --- & --- & 1.1 \\
\hline $\mathrm{Cu}-6 \mathrm{wt} \% \mathrm{Al}[001]$ & 1.2 & 1.6 & 1.8 & 2.8 \\
\hline \multicolumn{5}{|c|}{$\begin{array}{c}\text { Microindentation Measurements of Shocked Polycrystalline } \mathrm{Cu} \text { and } \\
\mathrm{Cu}-\mathrm{Al} \text { Alloys by Flyer Plate Experiments } \mathrm{P}=35 \mathrm{GPa}\end{array}$} \\
\hline Pure Cu (Hv) & \multirow{2}{*}{\multicolumn{2}{|c|}{\begin{tabular}{c|}
$\mathrm{Cu}-2 \mathbf{w t} \%$ Al $(\mathbf{H v})$ \\
160
\end{tabular}}} & Cu-2wto & Al (Hv) \\
\hline 140 & & & \multicolumn{2}{|c|}{230} \\
\hline
\end{tabular}


Table 3: Calculated and experimentally determined SFE for $\mathrm{Cu}-\mathrm{Al}$ alloys.

\begin{tabular}{|c|c|c|c|}
\hline Material Composition & $\begin{array}{c}\text { SFE mJ/m } \\
\text { (Experimental) }\end{array}$ & $\begin{array}{c}\text { SFE } \mathbf{~ m J} / \mathbf{m}^{2} \\
\text { (Calculated) }\end{array}$ & $\begin{array}{c}\text { Twinning } \\
\text { Stress (MPa) }\end{array}$ \\
\hline $\mathrm{Pure} \mathrm{Cu}$ & 57 & $78+/-8$ & 408 \\
\hline $\mathrm{Cu}$ 0.2-wt\% Al & ---- & 70 & - \\
\hline $\mathrm{Cu} 2-\mathrm{wt} \% \mathrm{Al}$ & 37 & 39 & 330 \\
\hline $\mathrm{Cu} 4-\mathrm{wt} \% \mathrm{Al}$ & 7 & 19 & 145 \\
\hline $\mathrm{Cu} 6-\mathrm{wt} \% \mathrm{Al}$ & 4 & 5 & 108 \\
\hline
\end{tabular}




\section{FIGURE CAPTIONS}

Figure 1: (a) Schematic of Omega Laser Facility at the University of Rochester; (b) Laser shock compression setup.

Figure 2: (a) TEM foil slices labeled A-E were cut for analysis; (b) Simulated Pressure profile as a function of distance from the shocked surface, E=200J, (c) Peak pressure vs. depth for different material strengths simulated by LASNEX and HYADES.

Figure 3: (a) Temperature change as a function time and distance for copper plate-impacted at $60 \mathrm{GPa}, \mathrm{T}_{\mathrm{o}}=300 \mathrm{~K}$; (b) Temperature change as a function time and distance in laser-shocked copper at $60 \mathrm{GPa}, \mathrm{T}_{\mathrm{o}}=298 \mathrm{~K}$.

Figure 4: (a) Nucleation of dislocation loops at the shock front; (b, c) Observation of loops in shocked $\mathrm{Cu}(40 \mathrm{~J} ; \mathrm{b})(1=$ large; $\mathrm{s}=$ small; e=elongated $)$ and $\mathrm{Cu}-2 \% \mathrm{Al}(70 \mathrm{~J} ; \mathrm{c})$ specimens.

Figure 5: Defect substructure for pure copper (a) Four sets of stacking-faults (marked as A, B, C, D) observed in [001] shocked with energy of $200 \mathrm{~J}$ (40GPa), g=200, $\mathrm{B}=[001]$; (b) Defect substructure of [ $\overline{1} 34]$ copper, shocked with a laser energy of $70 \mathrm{~J}$ in beam direction [011], $\mathrm{g}=[\overline{2} \overline{2} 2]$; (c) [ $1 \overline{3} 4]$, shocked with a laser energy of $200 \mathrm{~J}$ in beam direction [011], $\mathrm{g}=[\overline{2} \overline{2} 2]$.

Figure 6:Defect substructures of $\mathrm{Cu}-2 \mathrm{wt} \% \mathrm{Al}$ with [001] orientation shocked at $200 \mathrm{~J}$ (40 GPa) imaged with $\mathrm{B}=(001)$ and $g=[020]$ for all conditions: (a) Specimen $\mathrm{A} \sim 0.25$ $\mathrm{mm}$ from impacted surface; (b) Specimen B $\sim 0.75 \mathrm{~mm}$ from impacted surface, (c) 
Specimen $\mathrm{C} \sim 1.25 \mathrm{~mm}$ from impacted surface; (d) Specimen D $1.75 \mathrm{~mm}$ from impacted surface.

Figure 7:Bright field images of $\mathrm{Cu}-2 \mathrm{wt} \% \mathrm{Al}$ with [ $\overline{1} 34$ ] orientation shocked at $200 \mathrm{~J}$ (40 GPa) imaged with $\mathrm{B}=(011)$ and $g=[02 \overline{2}]$ for all conditions: (a) Specimen $\mathrm{A} \sim$ $0.25 \mathrm{~mm}$ from impacted surface; (b) Specimen $\mathrm{B} \sim 0.75 \mathrm{~mm}$ from impacted surface, (c) Specimen $C \sim 1.25 \mathrm{~mm}$ from impacted surface; (d) Specimen D $~ 1.75$ $\mathrm{mm}$ from impacted surface.

Figure 8: Defect substructures of $\mathrm{Cu}-2 \mathrm{wt} \% \mathrm{Al}$ shocked at $300 \mathrm{~J}(60 \mathrm{GPa})$, specimens $\mathrm{A} \sim$ $0.25 \mathrm{~mm}$ from impacted surface; ; (a) [001] imaged with $\mathrm{B}=(001)$ and $g=[020]$ (b) $[\overline{1} 34]$ imaged with $B=(011)$ and $g=[02 \overline{2}]$.

Figure 9: Bright field images of $\mathrm{Cu}-6 \mathrm{wt} \% \mathrm{Al}$ with [001] orientation shocked at $200 \mathrm{~J}$ (40 GPa) imaged with $\mathrm{B}=(001)$ and $g=[020]$ for all conditions: (a) Specimen $\mathrm{A} \sim 0.25$ mm from shocked surface; (b) Specimen B $0.75 \mathrm{~mm}$ from shocked surface, (c) Specimen $\mathrm{C} \sim 1.25 \mathrm{~mm}$ from shocked surface.

Figure 10: Bright field images of Cu- $6 \mathrm{wt} \% \mathrm{Al}$ with [ $\overline{1} 34$ ] orientation shocked at $200 \mathrm{~J}$ (40 GPa) imaged with $\mathrm{B}=(011)$ and $g=[02 \overline{2}]$ for all conditions: (a) Specimen $\mathrm{A} \sim$ $0.25 \mathrm{~mm}$ from impact surface; (b) Specimen $\mathrm{B} \sim 0.75 \mathrm{~mm}$ from impacted surface, (c) Specimen $\mathrm{C} \sim 1.25 \mathrm{~mm}$ from impacted surface.

Figure 11: Defect substructures of $\mathrm{Cu}-6 \mathrm{wt} \% \mathrm{Al}$ shocked at $300 \mathrm{~J}(60 \mathrm{GPa})$; specimen A $0.25 \mathrm{~mm}$ from shocked surface (a) [001]; (b) [ $\overline{1} 34$ ] orientation imaged with $\mathrm{B}=$ (011) and $g=[02 \overline{2}]$. 
Figure 12: Experimental results for laser-shocked $\mathrm{Cu}-\mathrm{Al}$ alloys; (a) Experimentally observed transition from dislocation cells and planar arrays to stacking-faults and twins as a function of composition; (b) experimentally observed dislocation densities as a function of pressure; (c) experimentally determined areal densities of stackingfaults as a function of pressure.

Figure 13: Microhardness measurements taken on transverse sections (A, B, C, D) as a function of distance from impact surface $(.25, .75,1.25$, and $1.75 \mathrm{~mm})$ : (a) pure copper with [ $\overline{1} 34]$ orientation; (b) $\mathrm{Cu}-2 \mathrm{wt} \% \mathrm{Al}$ with [001] orientation; (c) $\mathrm{Cu}-$ $2 \mathrm{wt} \% \mathrm{Al}$ with [1 34$]$ orientation; (d) Cu-6wt\% Al with [001] orientation; and (e) Cu-6wt\% Al with [ $\overline{1} 34]$ orientation.

Figure 14: Nanoindentation measurements taken in the longitudinal direction for $\mathrm{Cu}-6 \mathrm{wt} \%$ Al with [1]34] orientation: (a) shocked at $70 \mathrm{~J}$ (20GPa); (b) shocked at $200 \mathrm{~J}$ (40 GPa). The microhardness values are shown for comparison; (c) shocked at $300 \mathrm{~J}$ $(60 \mathrm{GPa})$.

Figure 15: Calculated Twinning Pressures at different Al compositions.

Figure 16: Generation of (a) perfect and (b) partial dislocations in shocked samples.

Figure 17: (a) Critical radius of perfect and partial dislocations decrease with the shock pressure; (b) transition pressure as a function of weight percent Al.

Figure 18: Stacking-faults and cells in same TEM micrograph of laser compressed [001] copper demonstrating that there is a critical value for transition. 


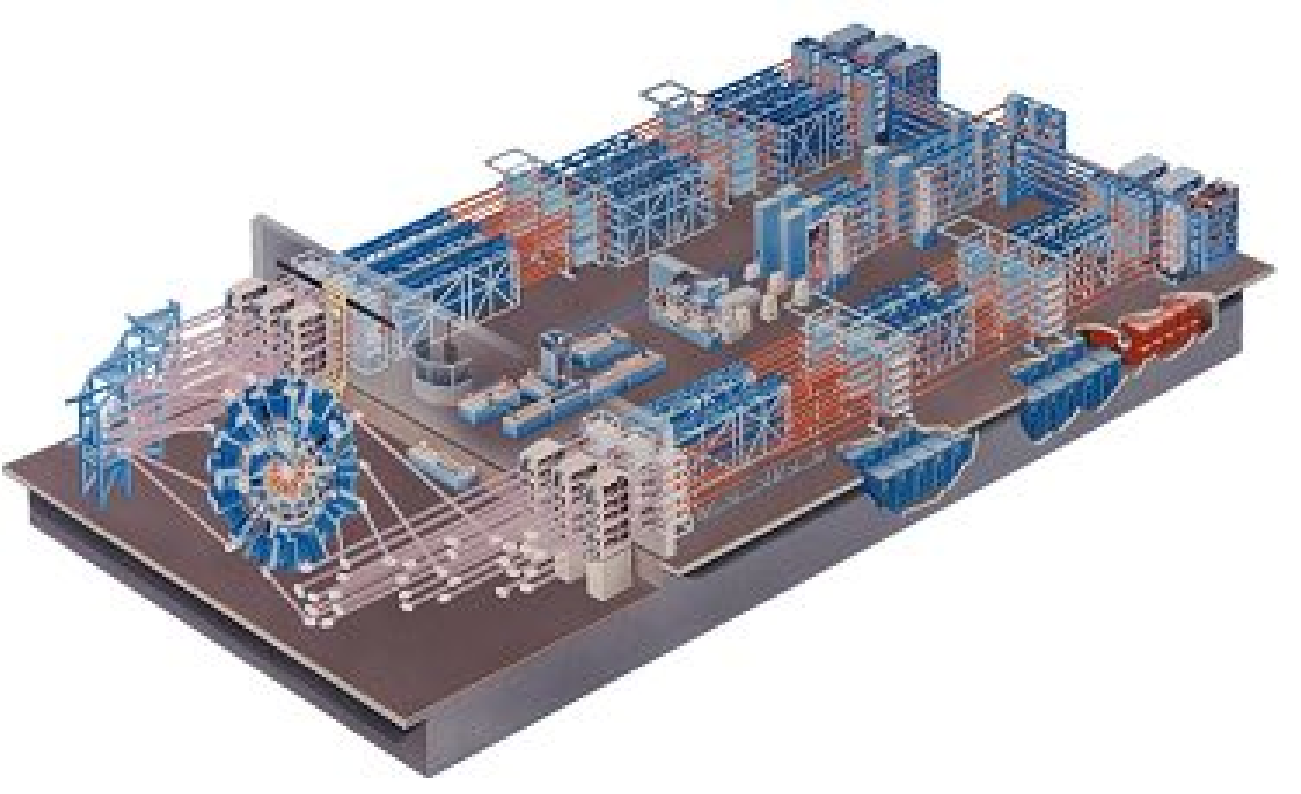




\section{Laser Beam}

Recovery

Tube

$0.05 \mathrm{~g} / \mathrm{m}^{3}$ foam 


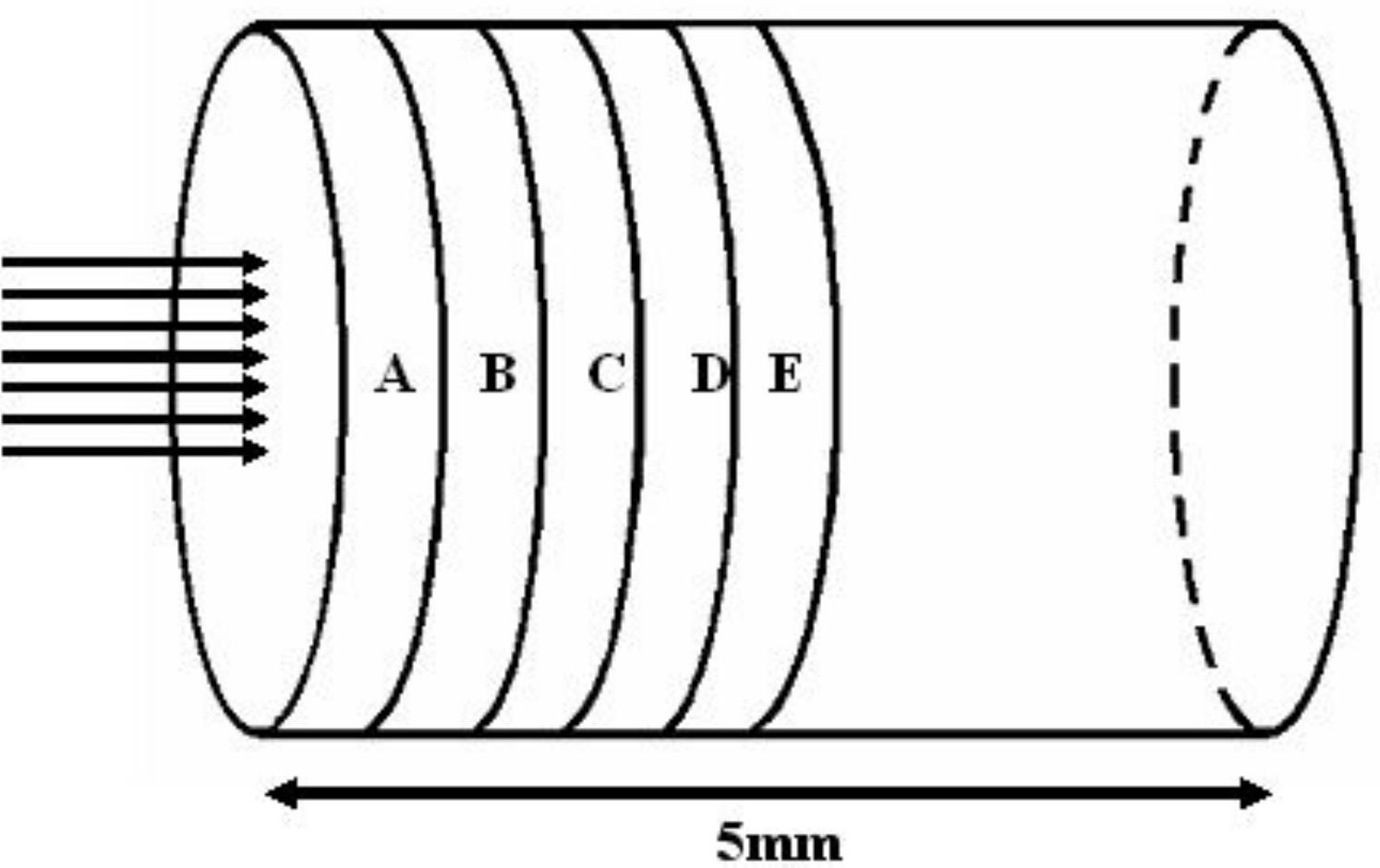




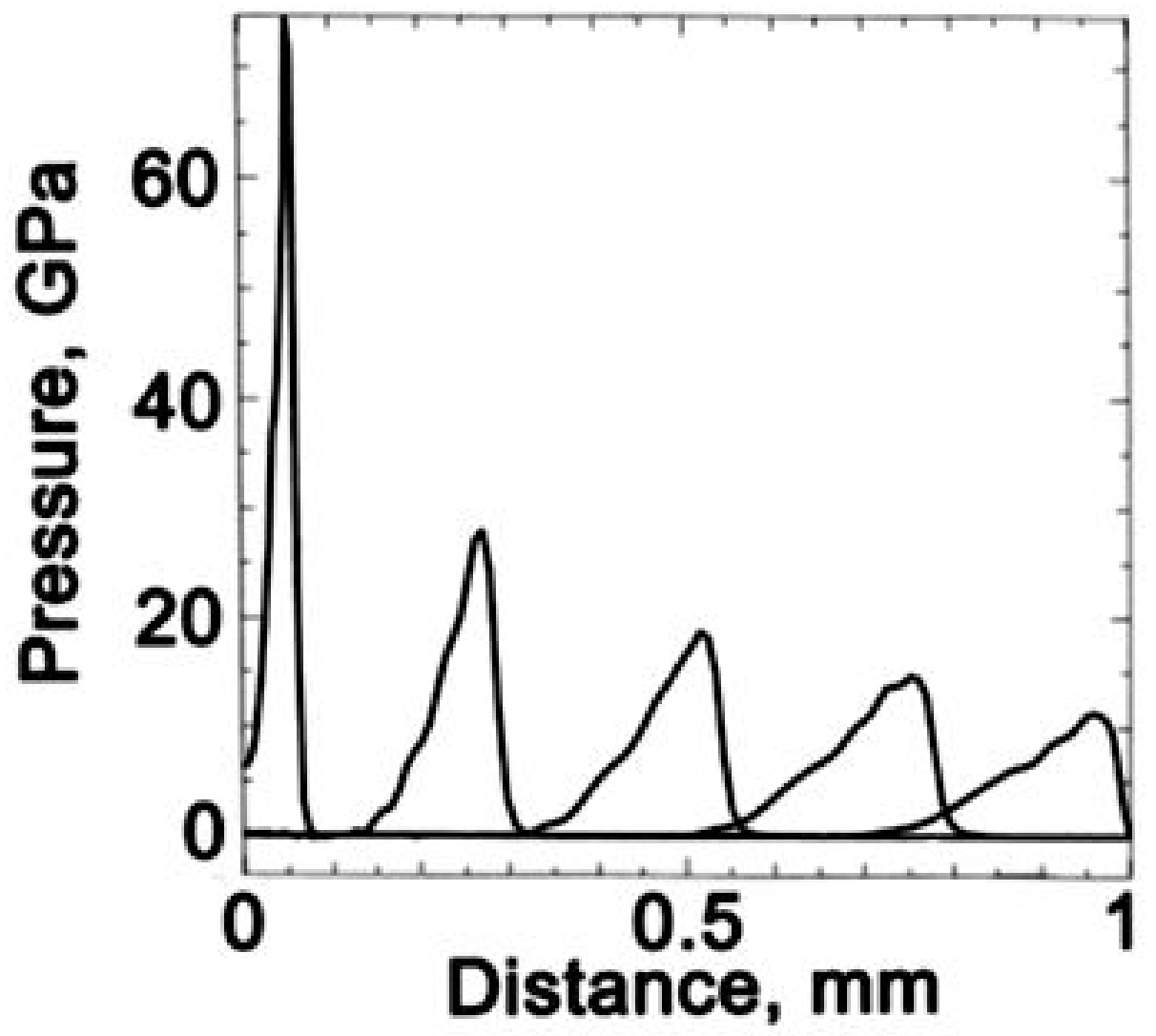




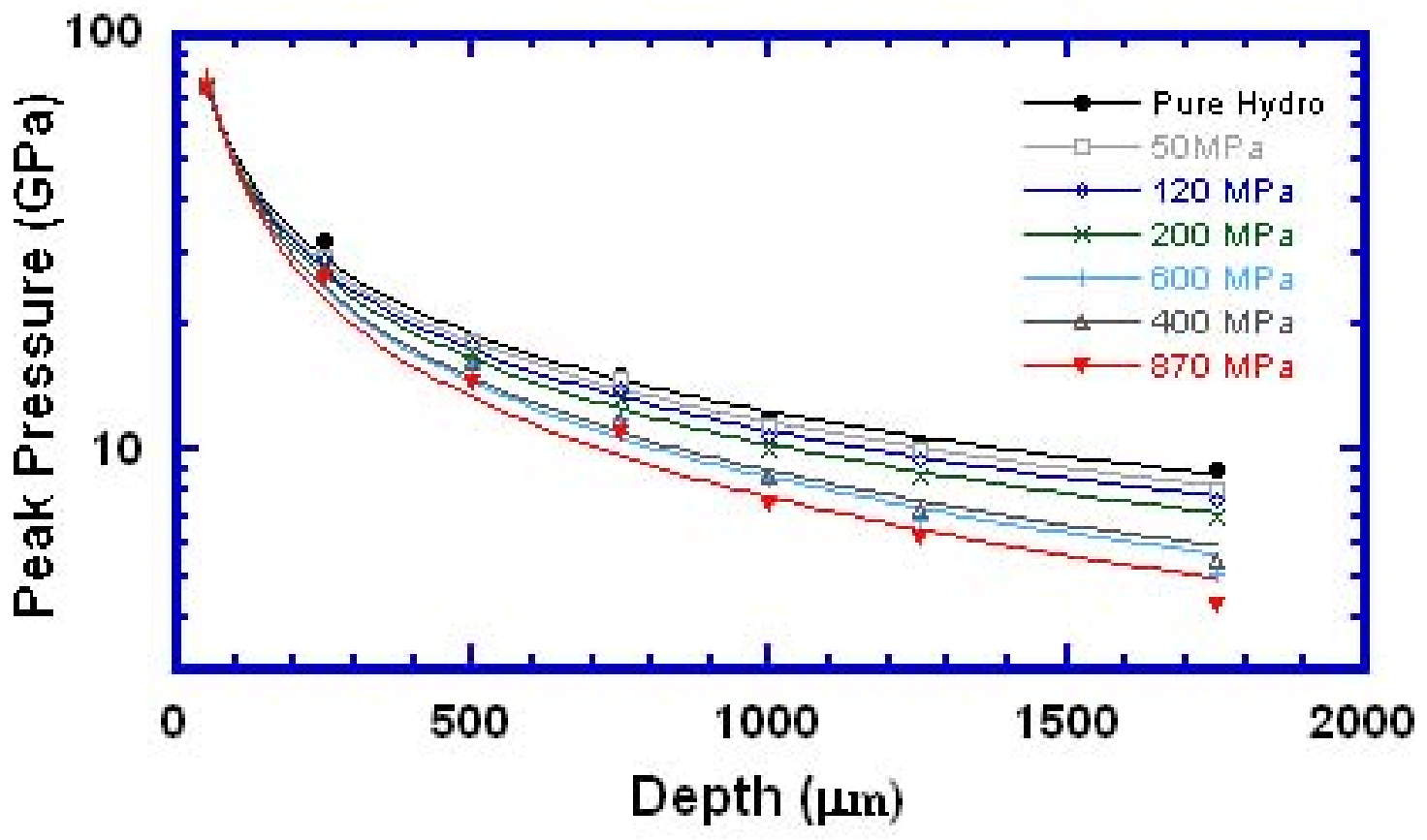




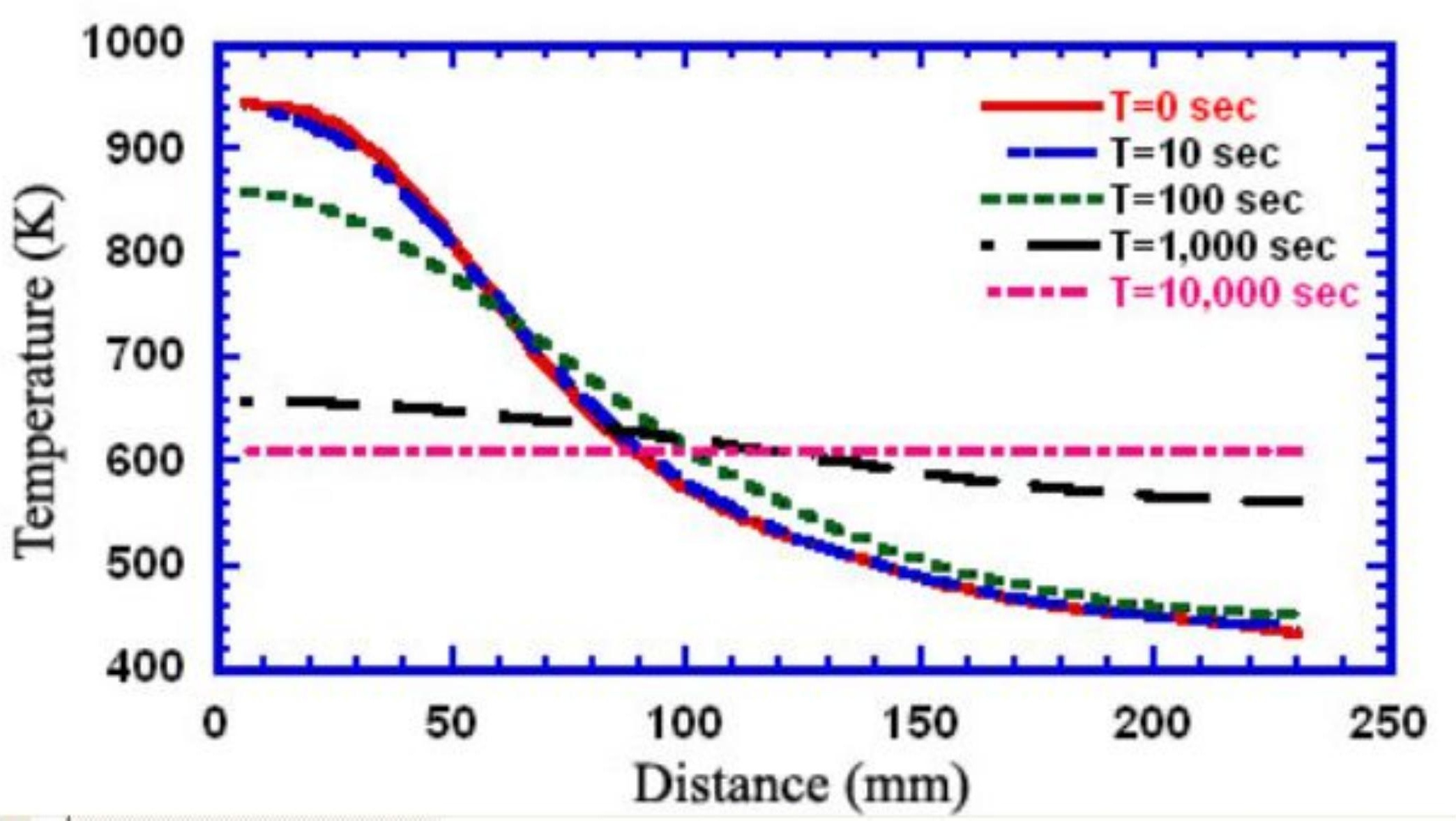


\{111\} Slip Planes

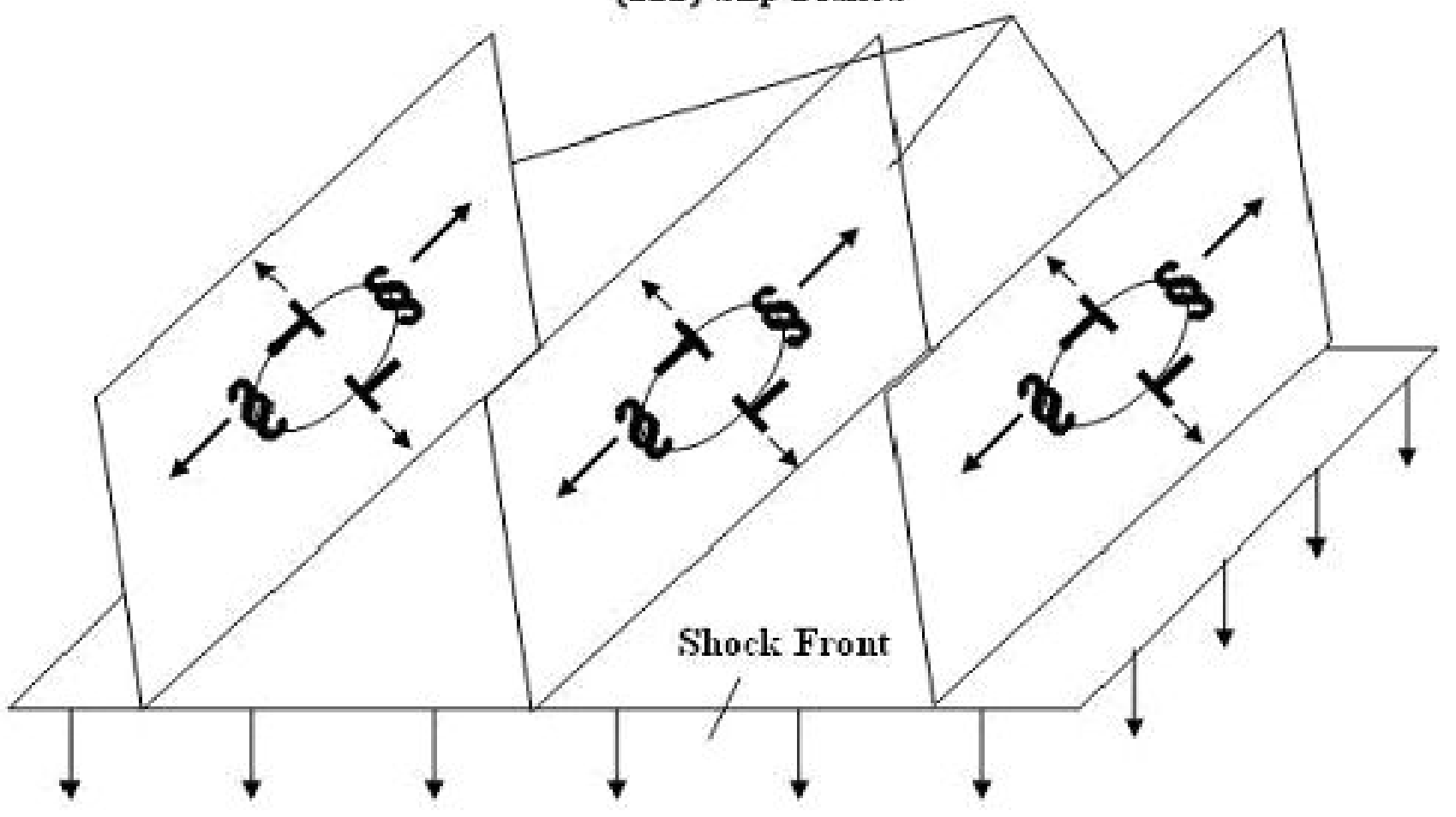




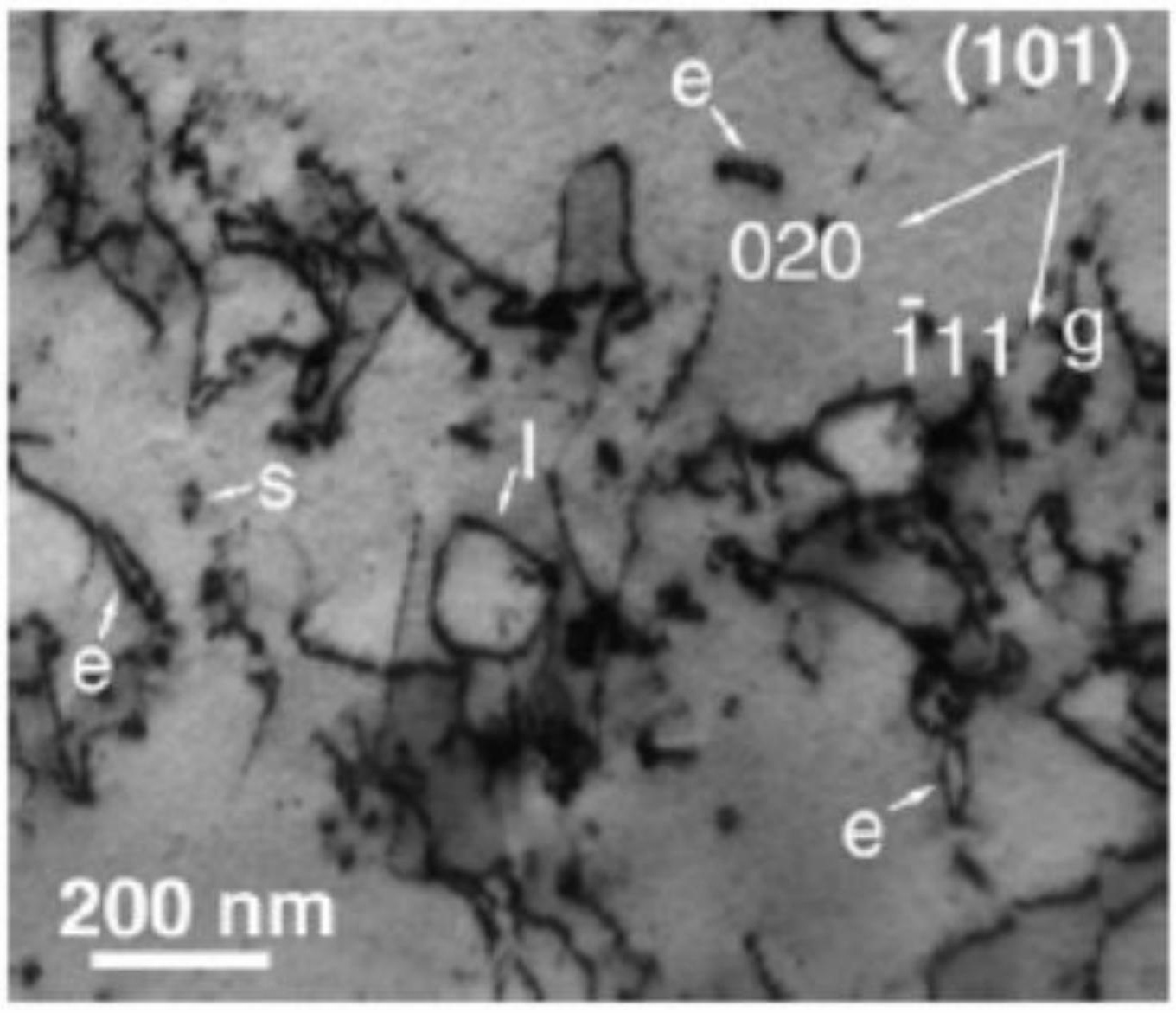




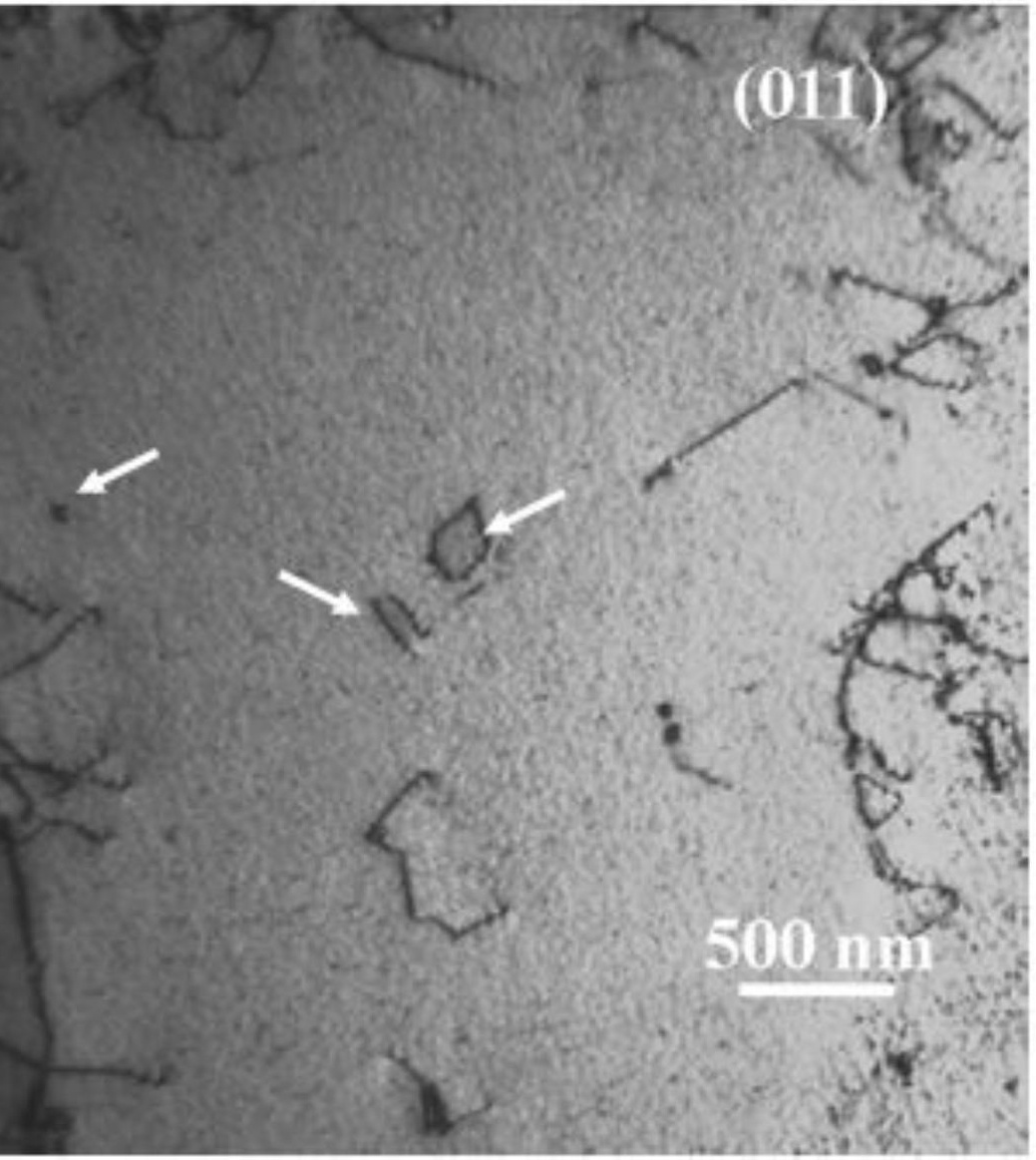




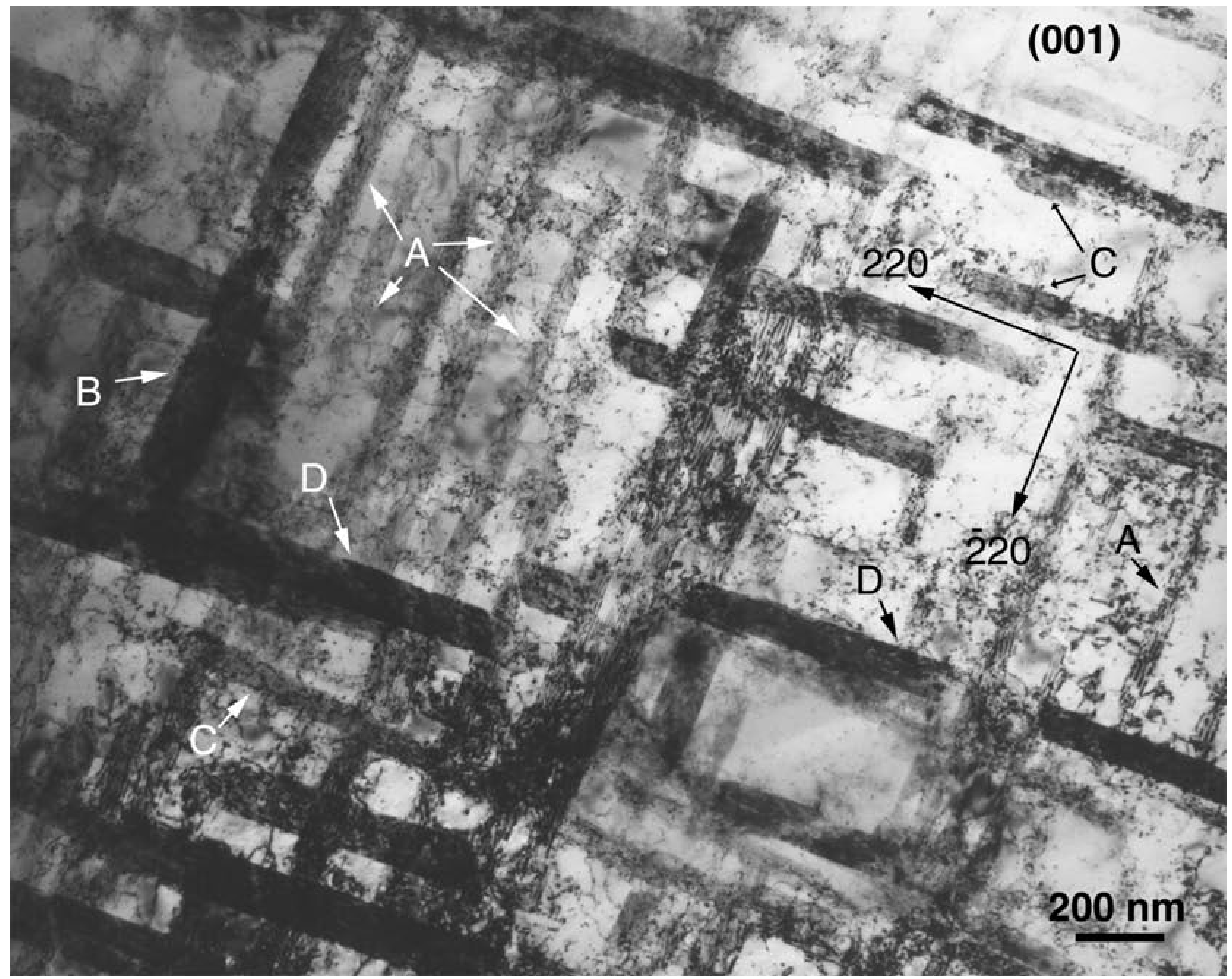




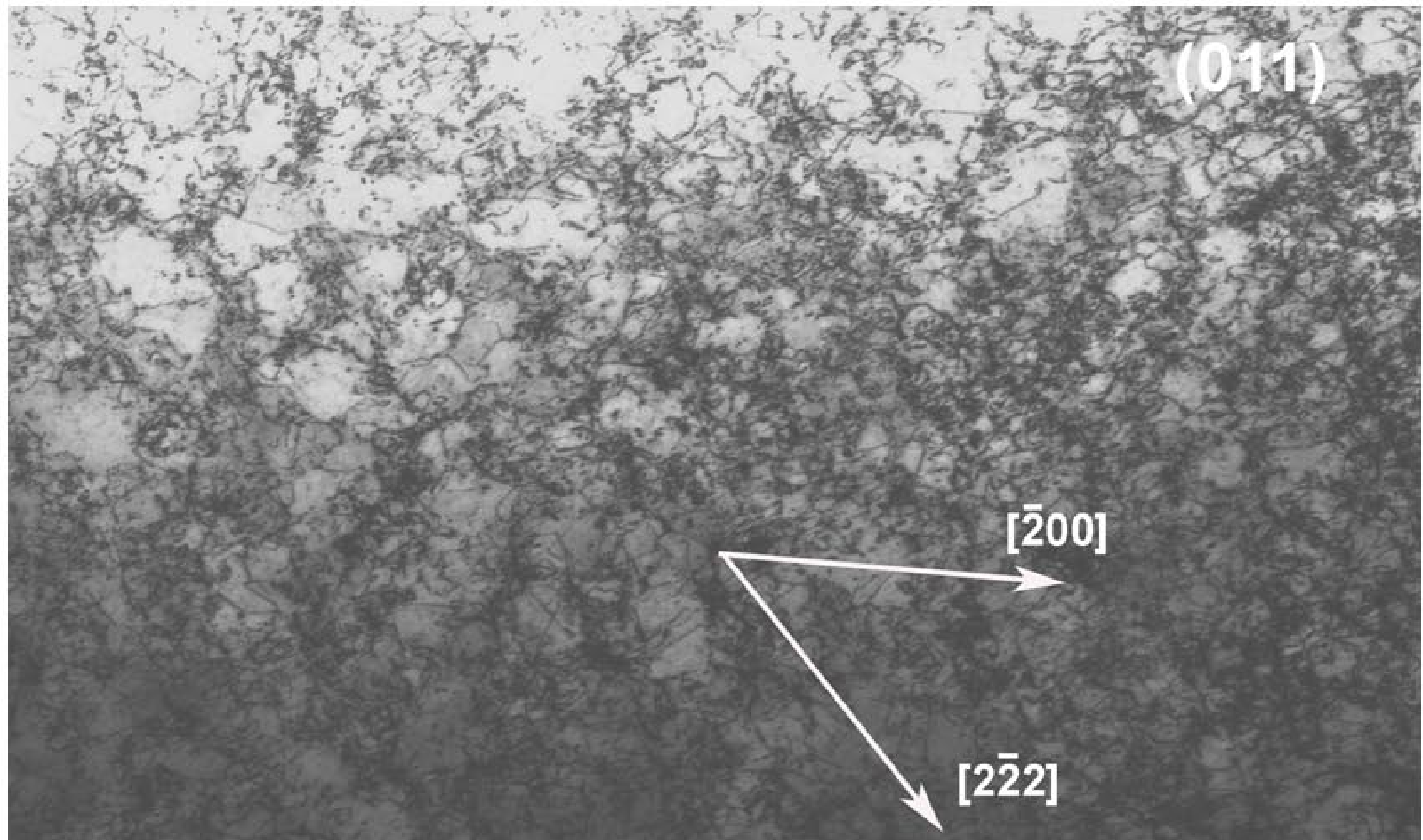

$500 \mathrm{~nm}$ 


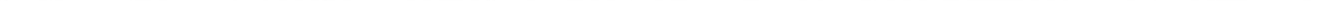




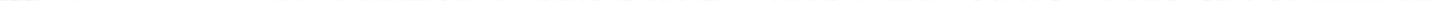


40

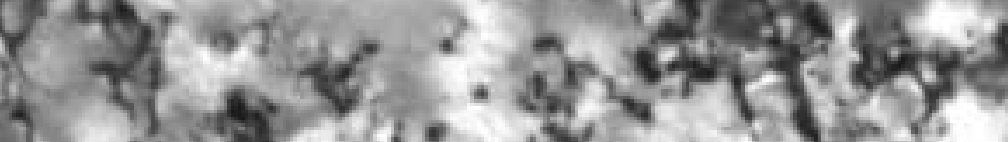

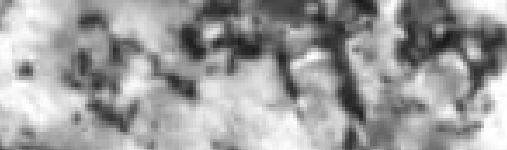

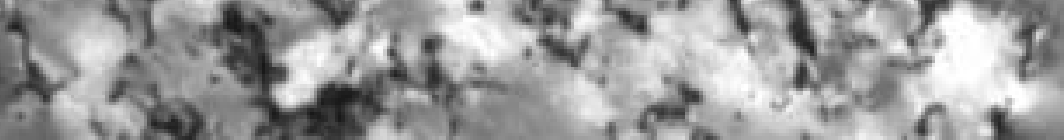

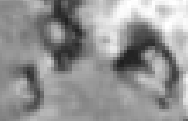

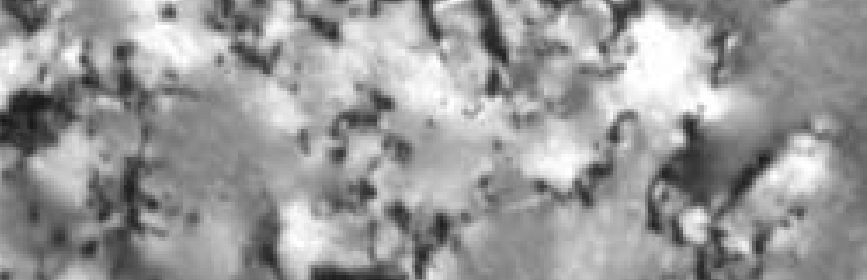

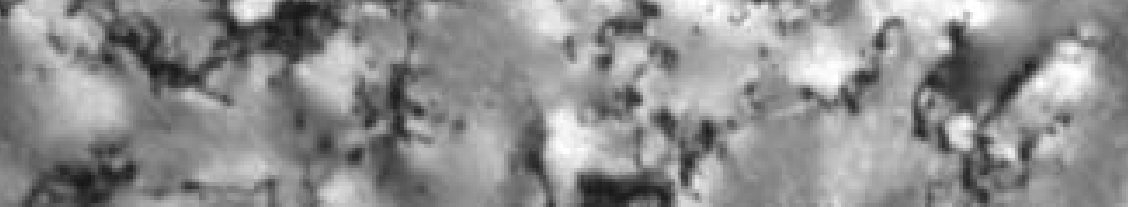

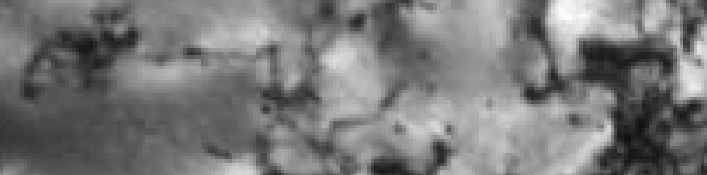

S

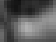

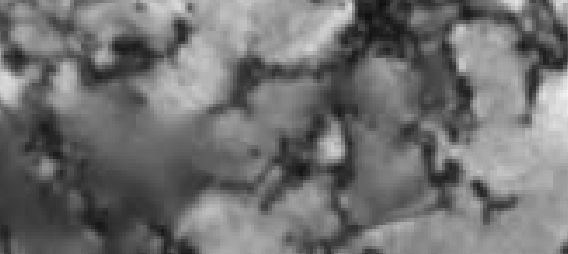

a

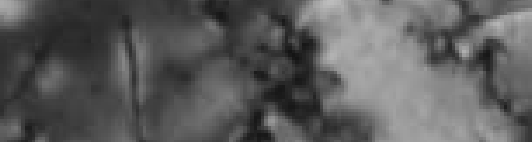

s

Antractose is

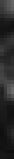

is?

$24-3$

1

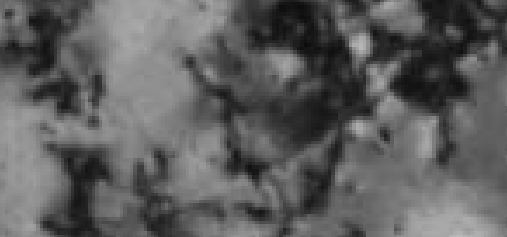

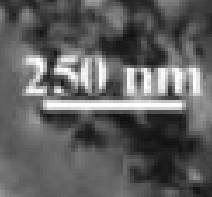

$x+x^{2}+3 x=$

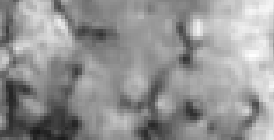
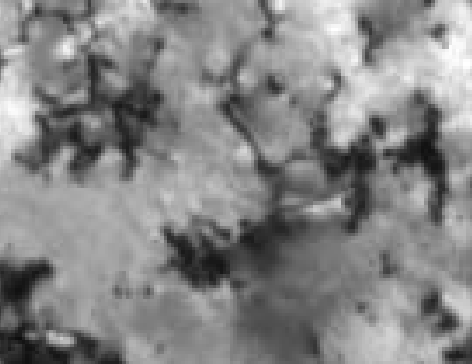

axs inte

$y^{2}+x^{2}$ 


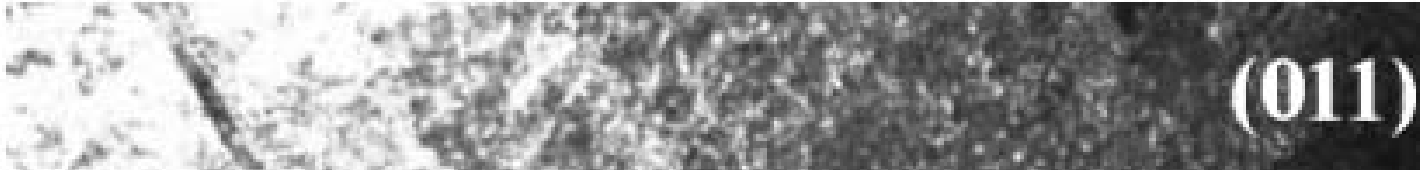

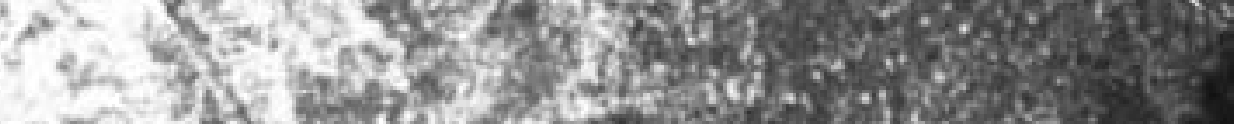

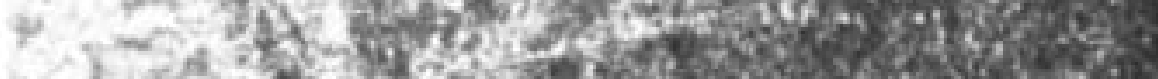

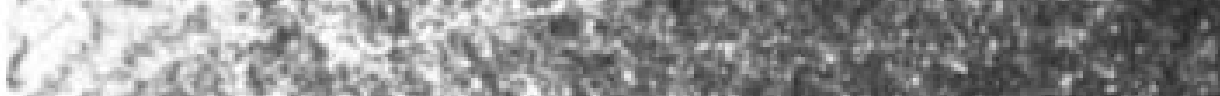

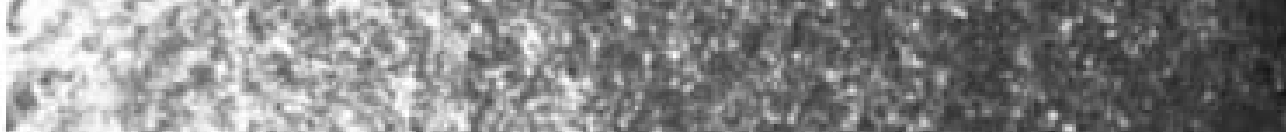

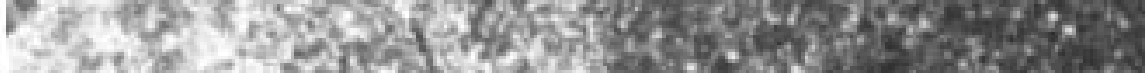

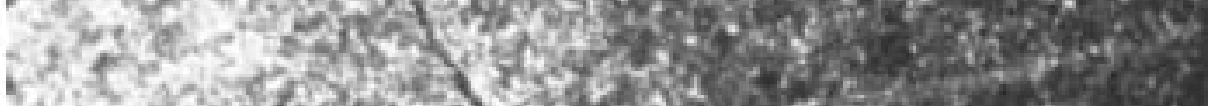

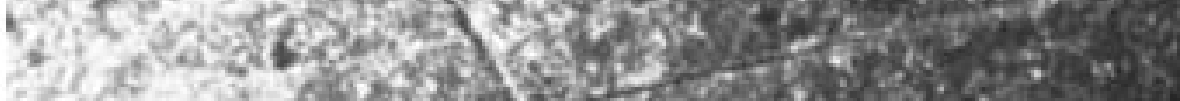

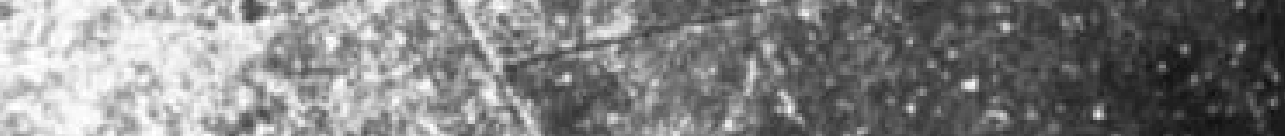

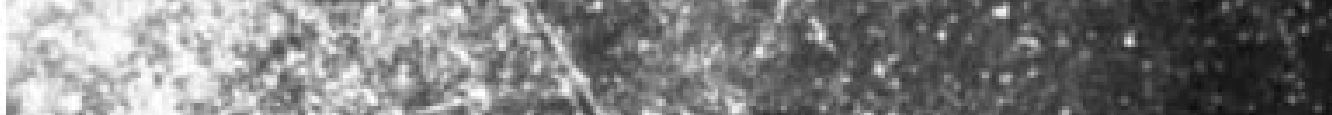

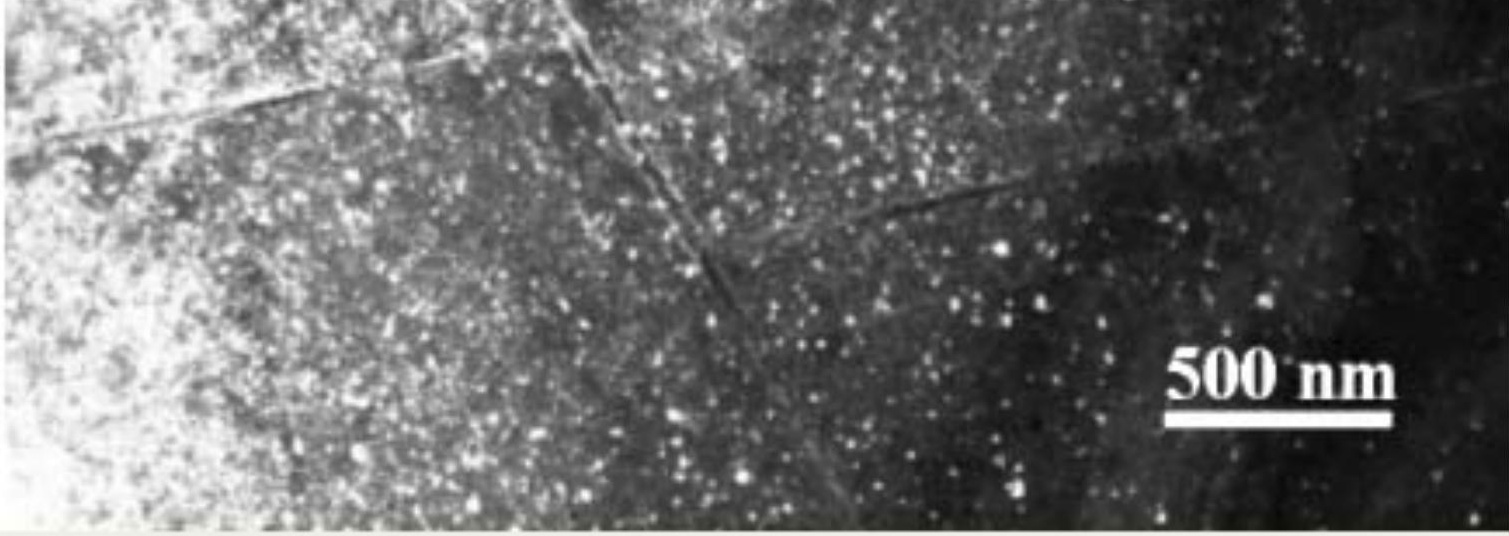




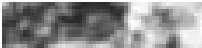 \\ $5 y^{4}$ \\ (2) \\ The \\ (001)

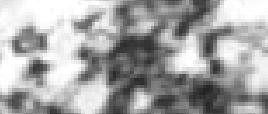

ing

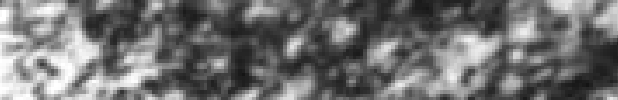

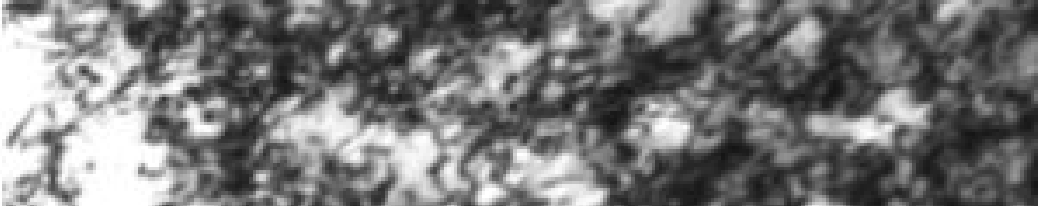


Hos 2 ass(011)

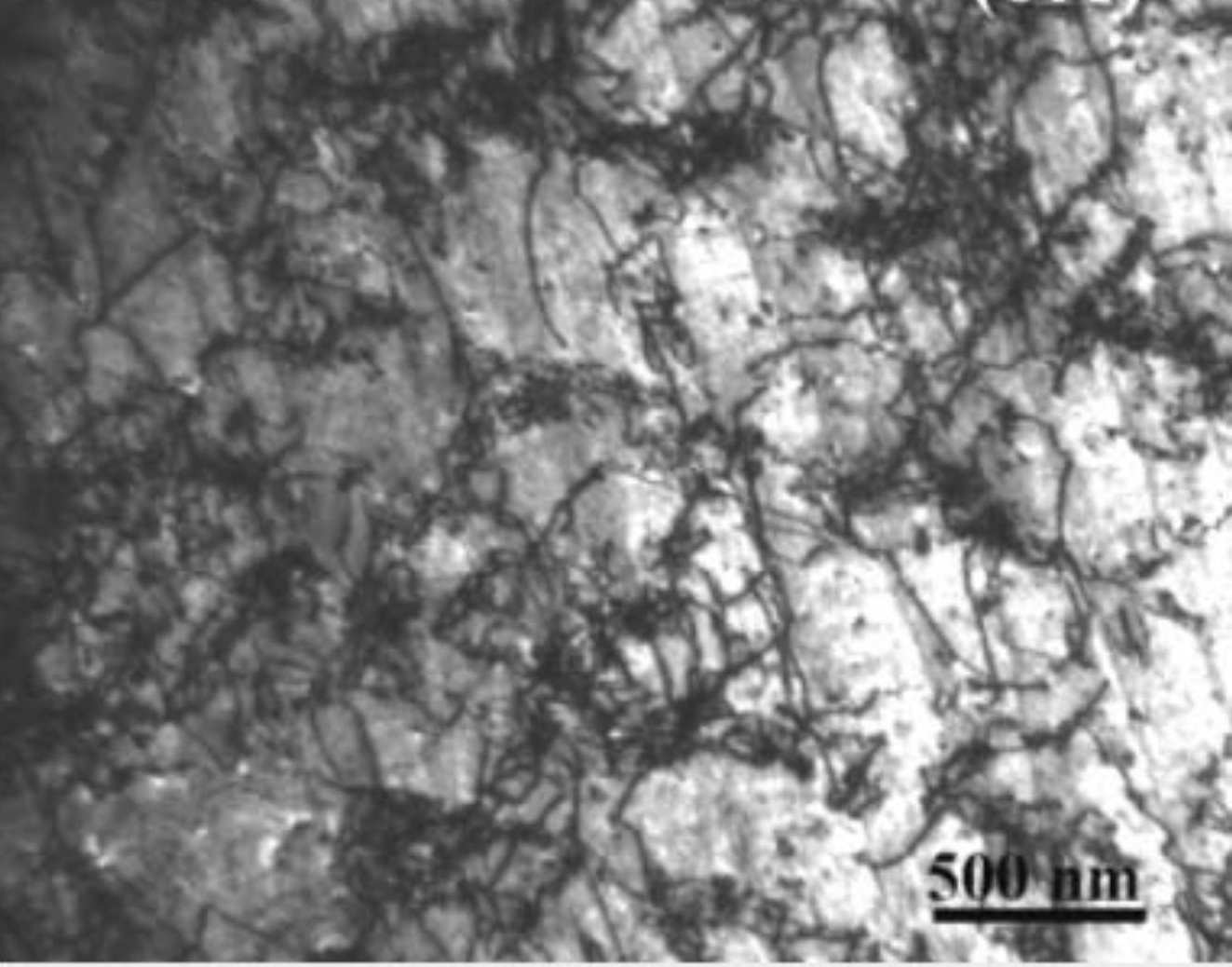




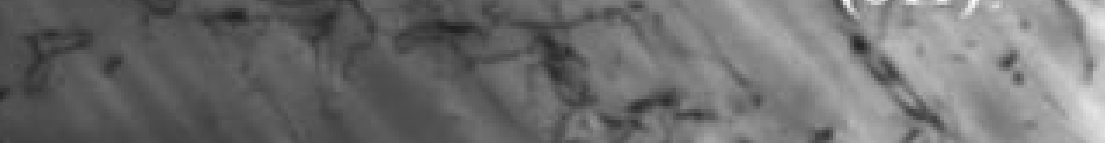

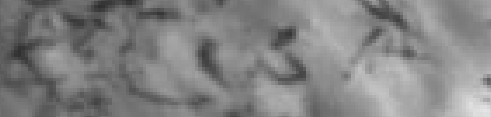

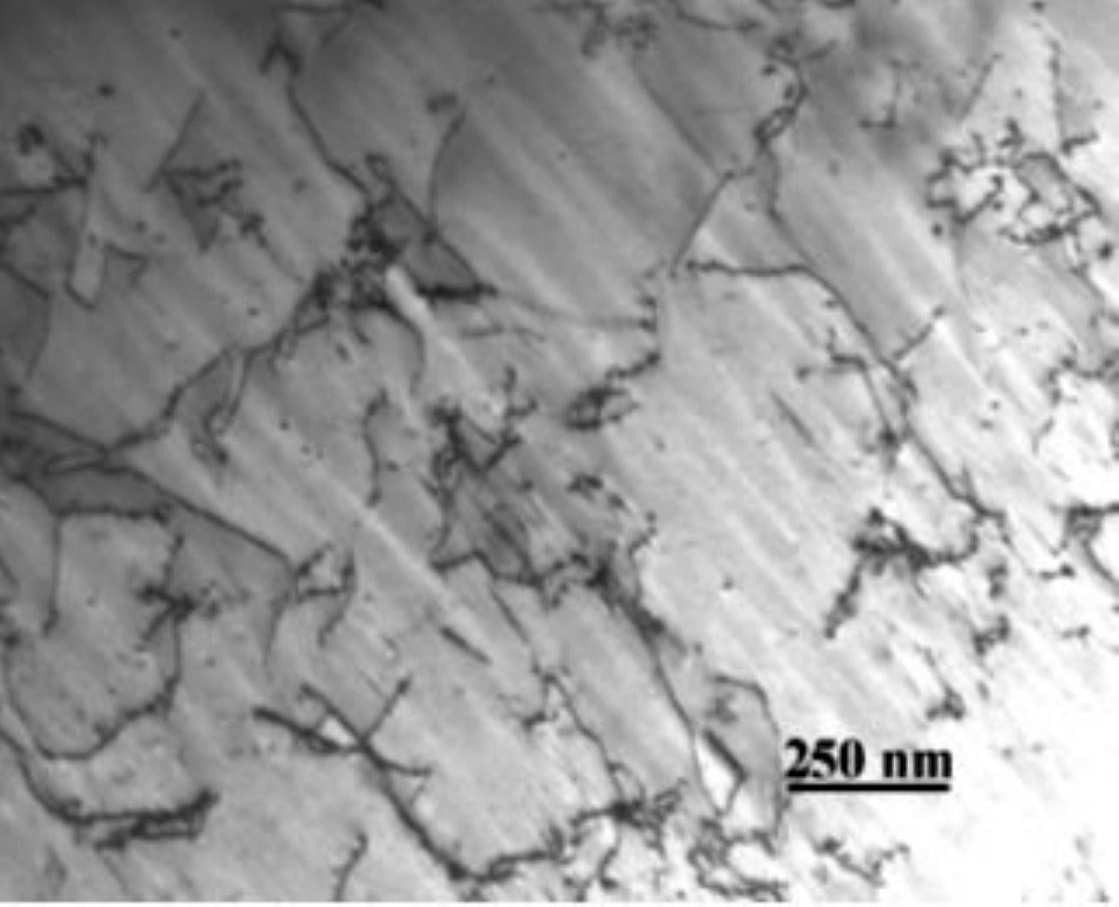




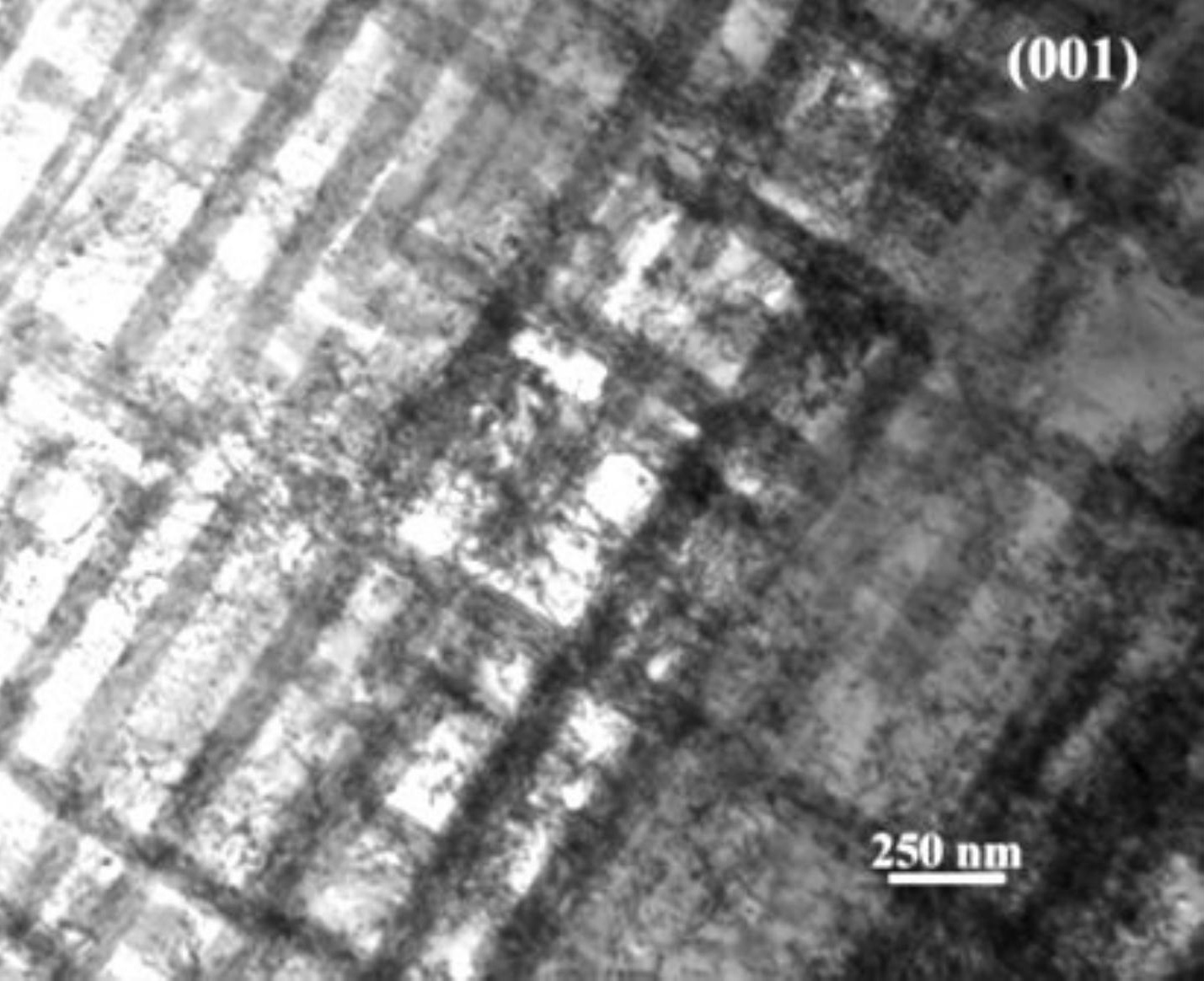




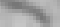

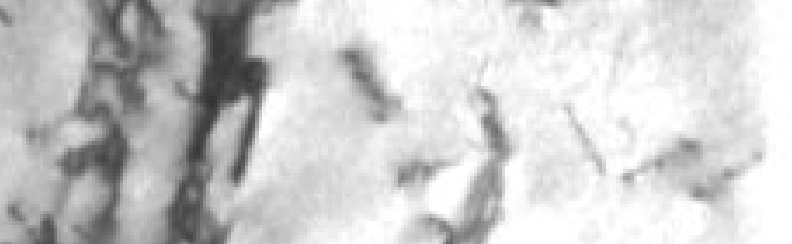

(6)

$=(001)$ cosinged

roy 207 latar 2 or
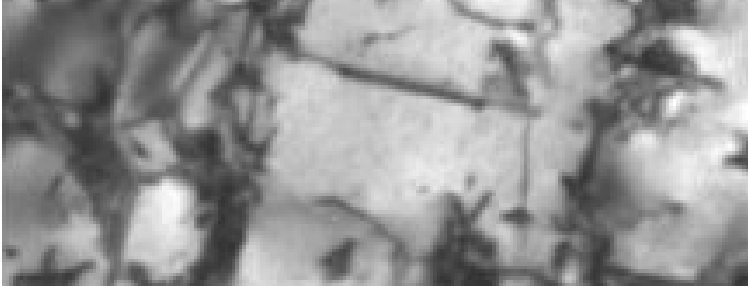

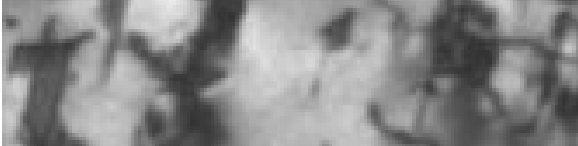

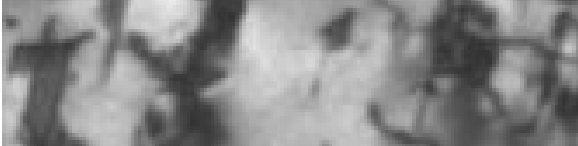

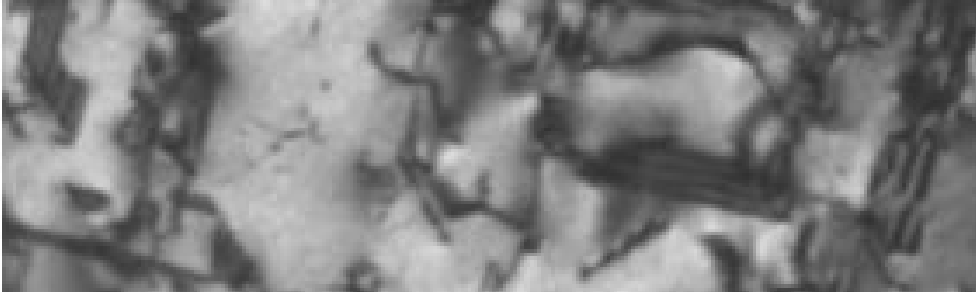

48

s pal
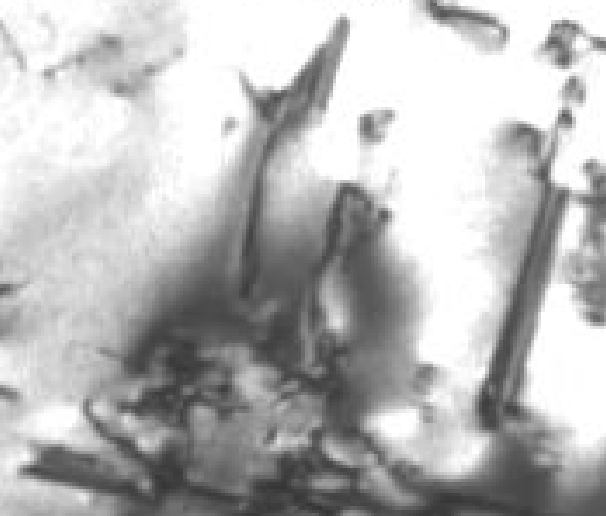


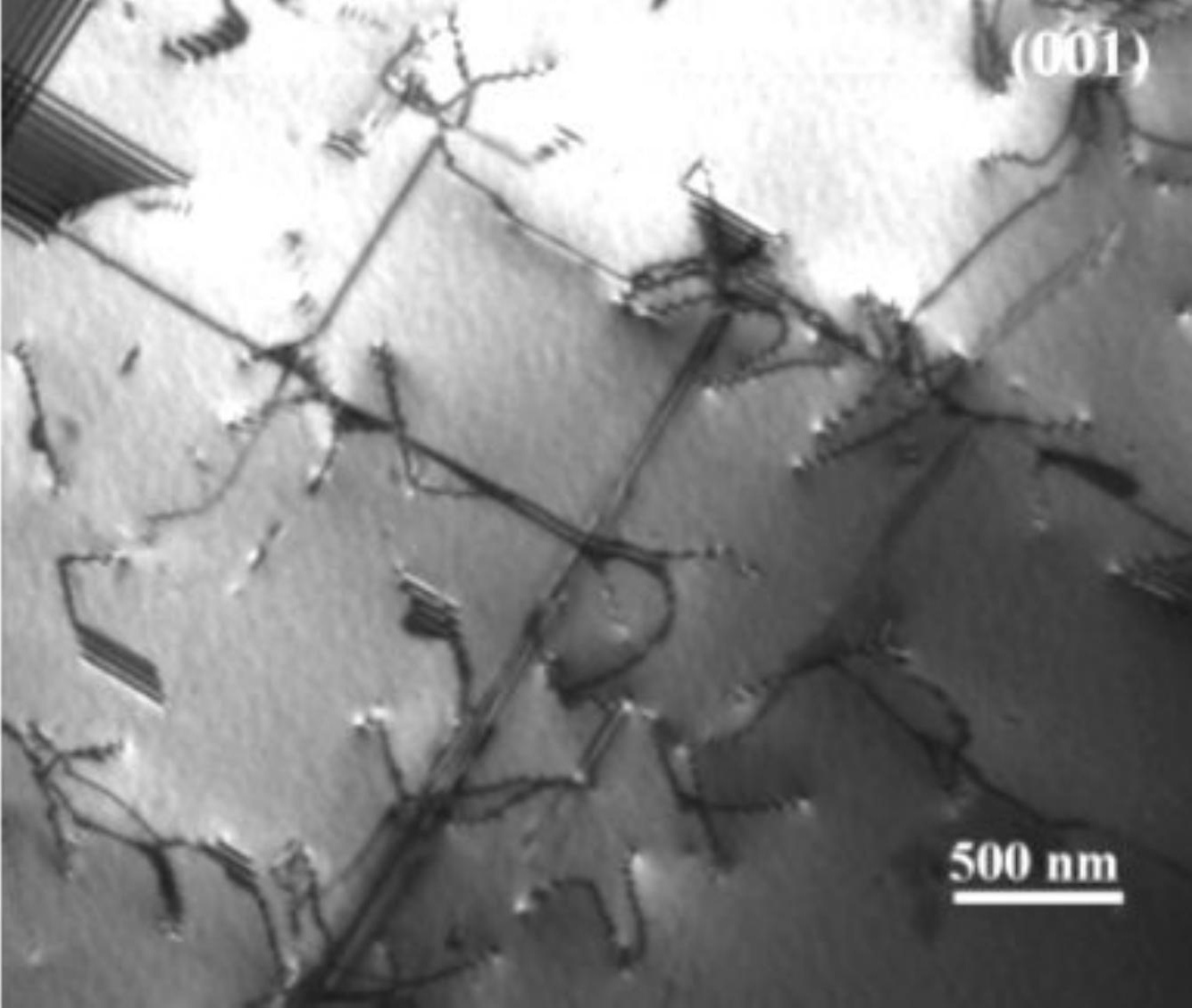




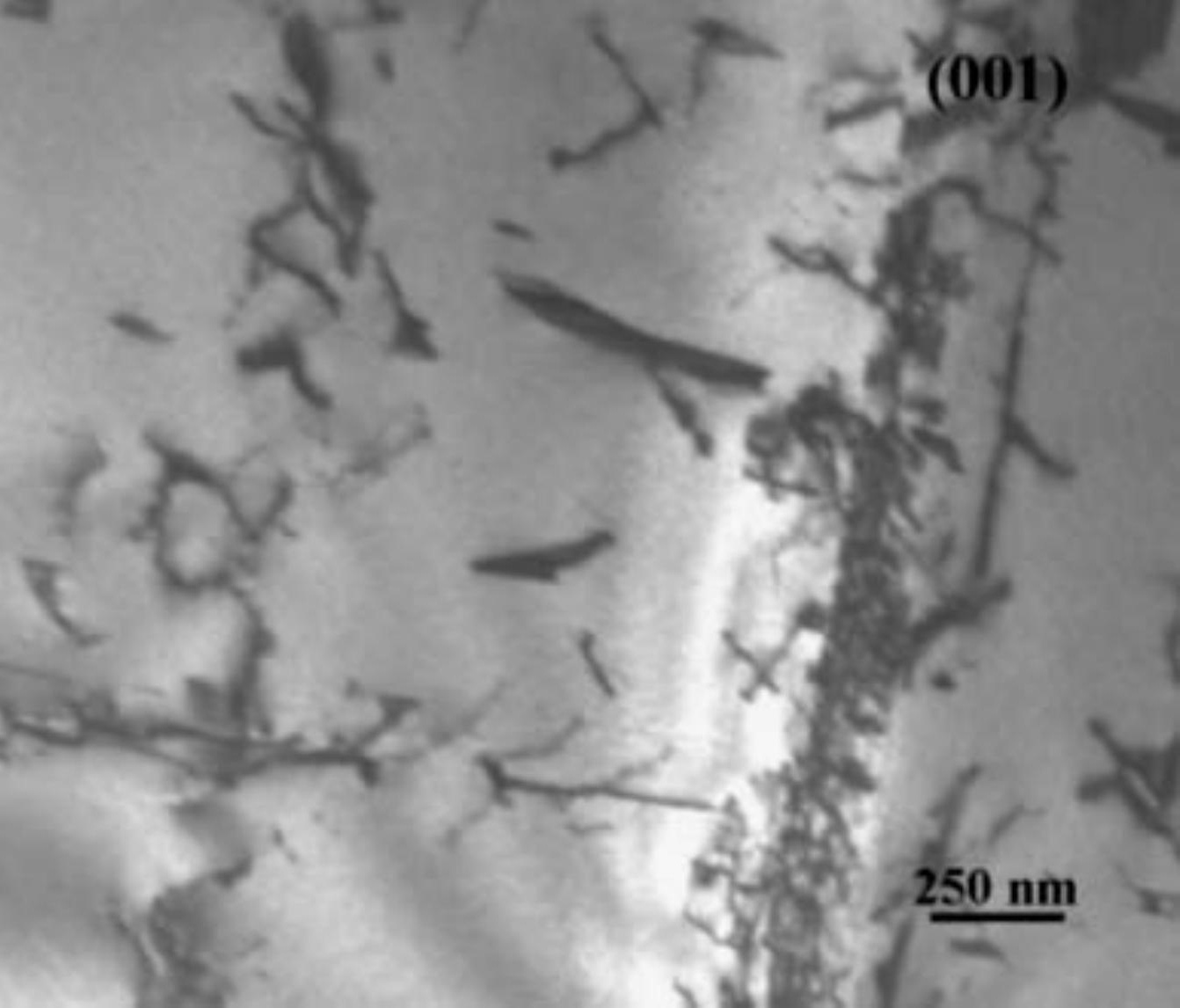




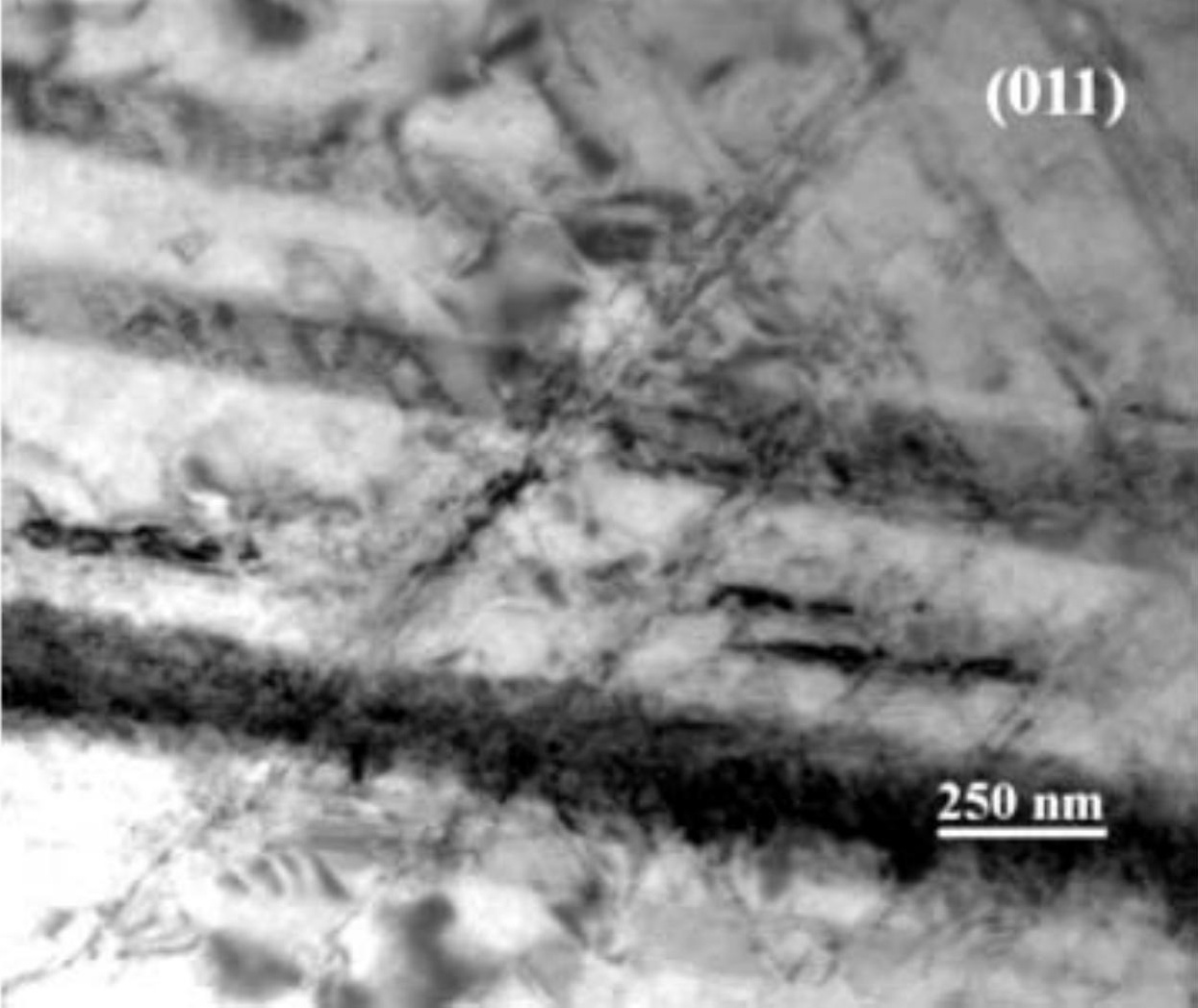




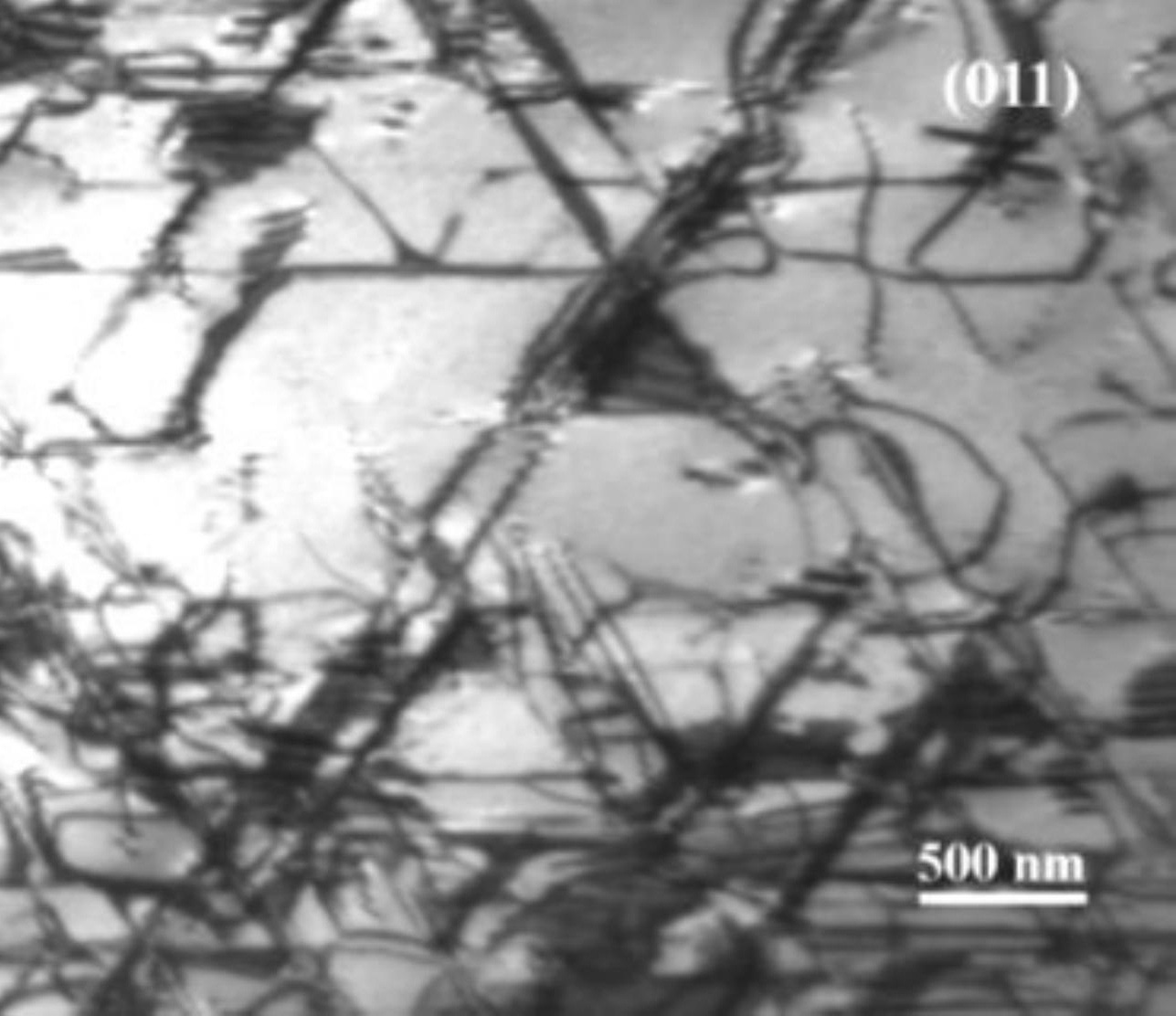




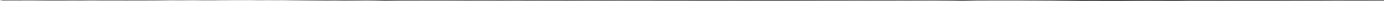




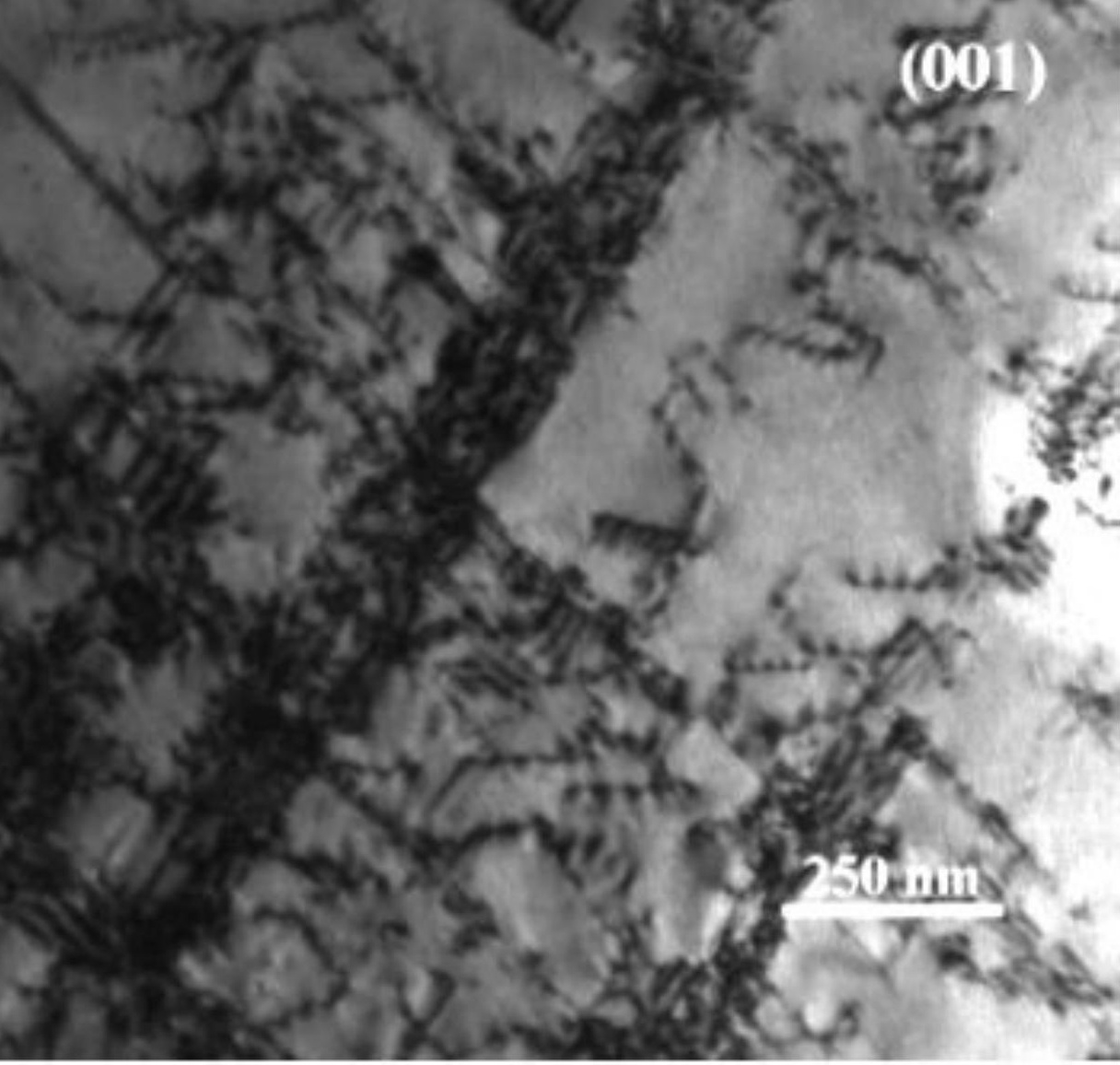




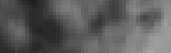




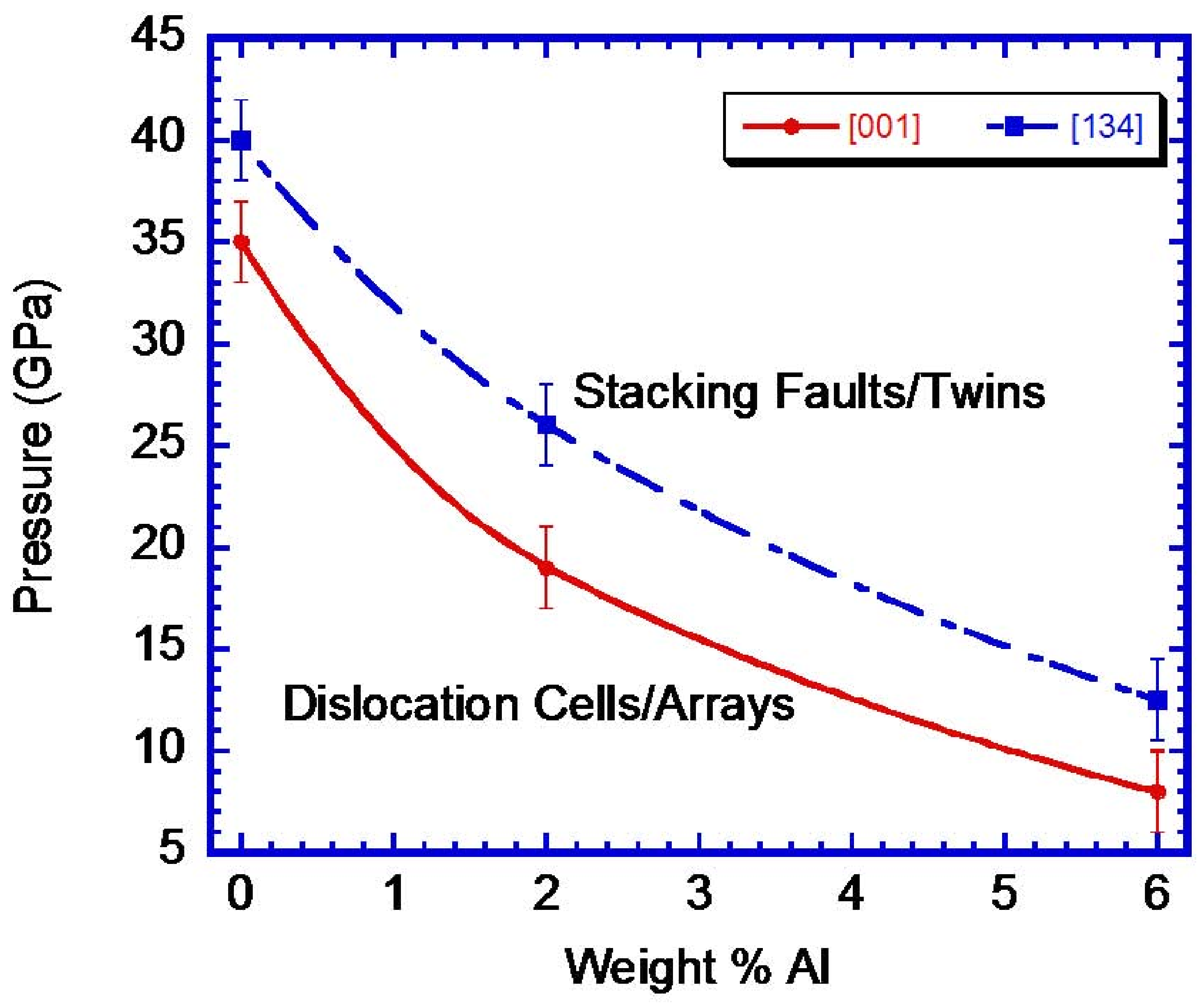




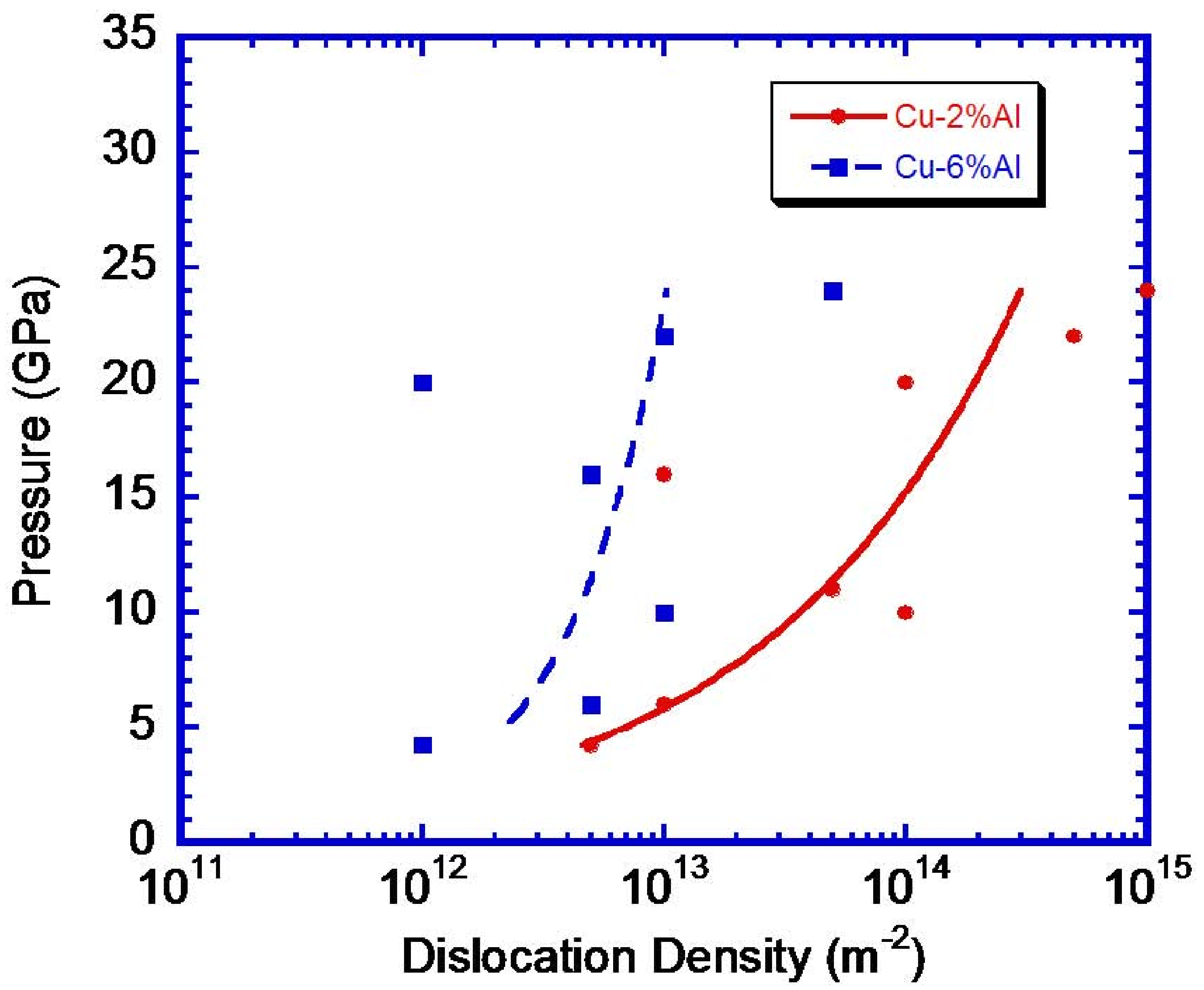




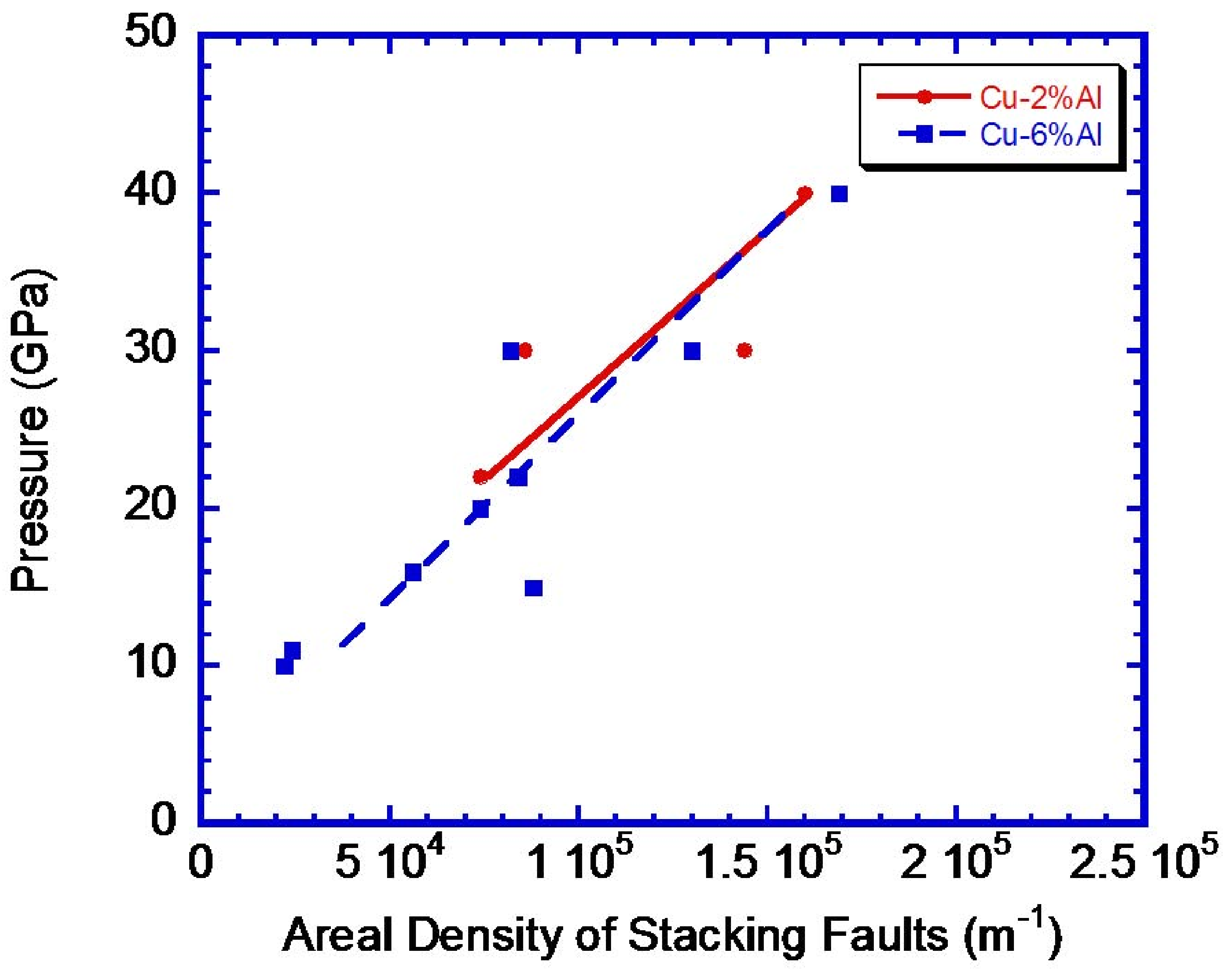




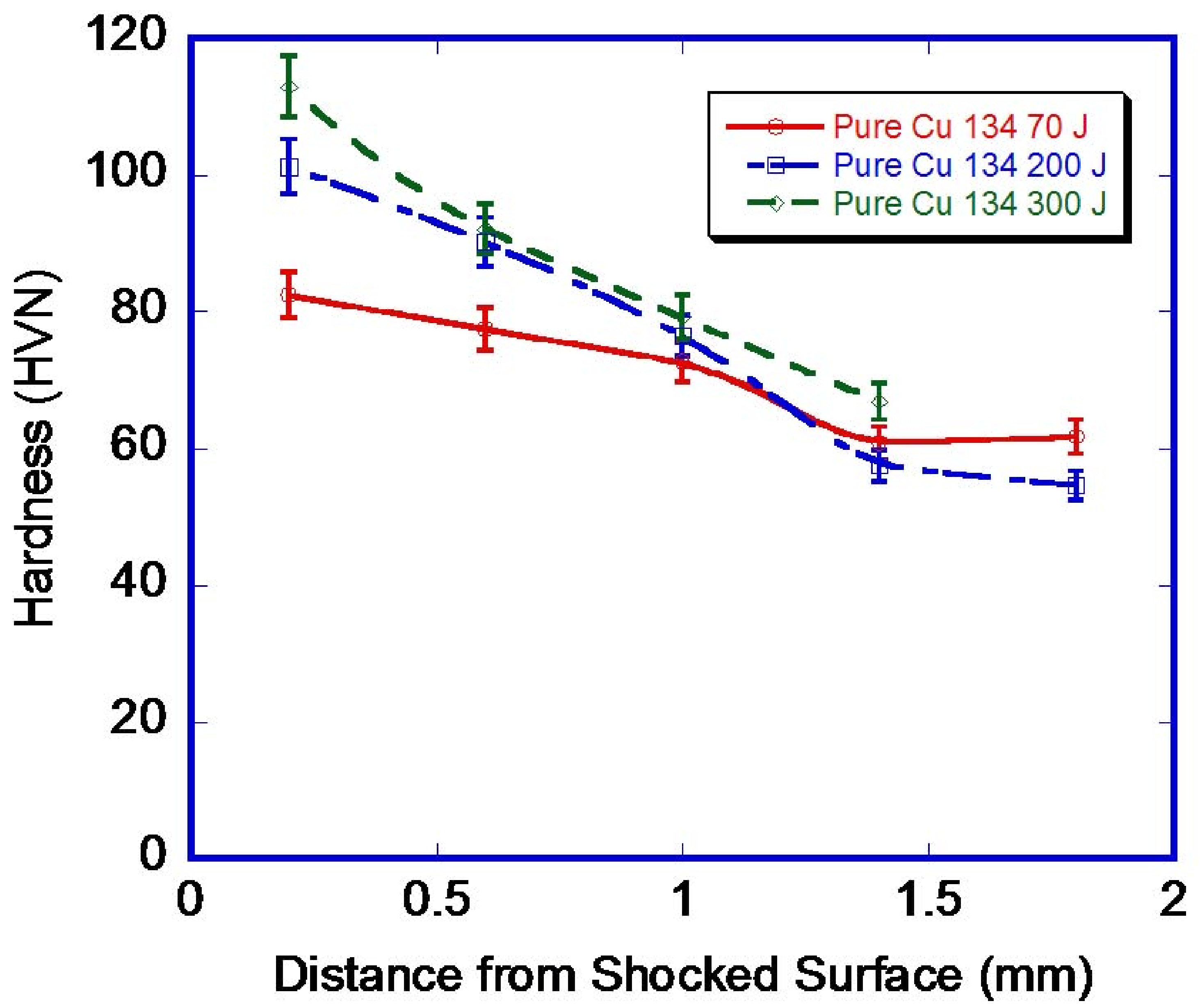




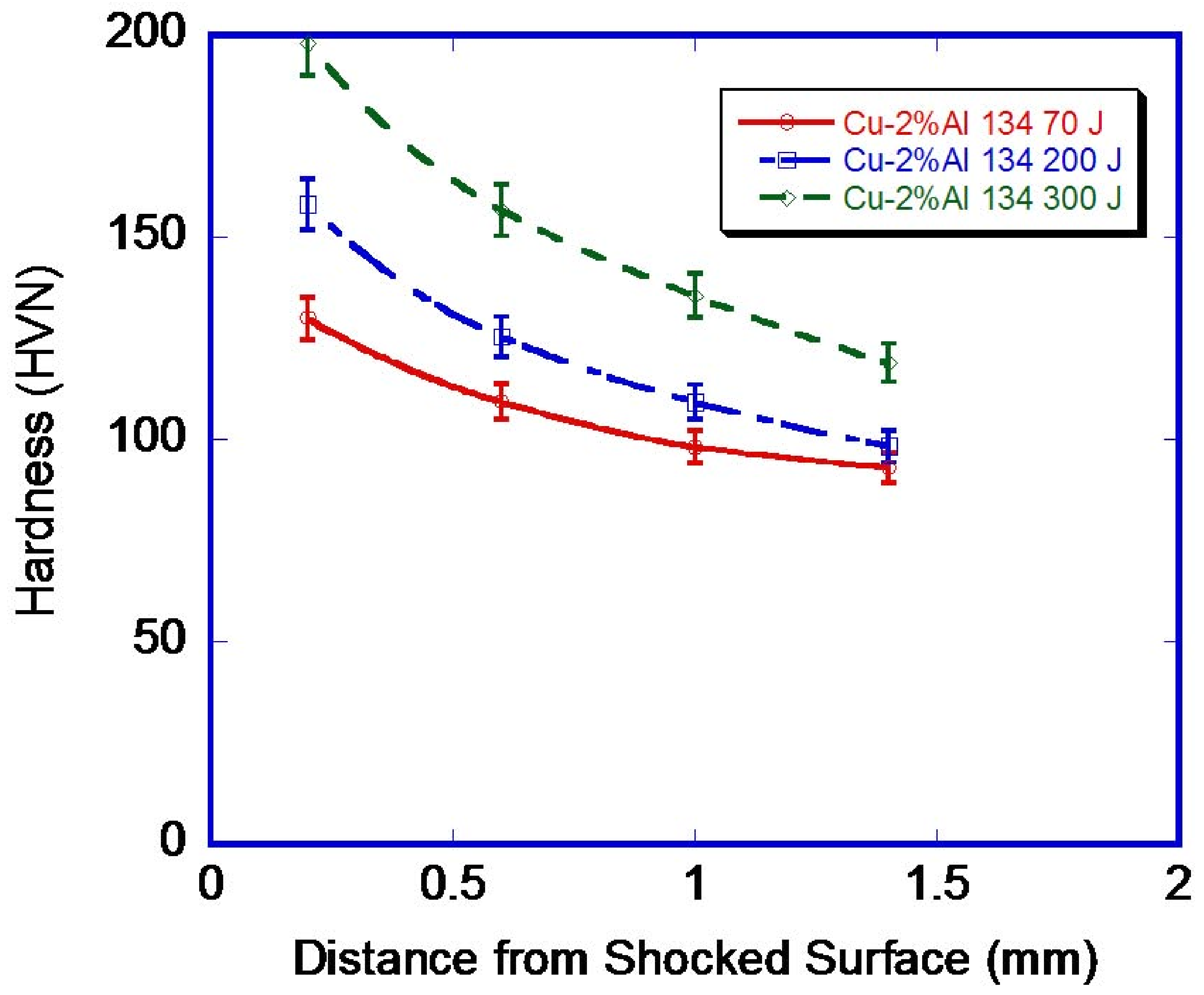




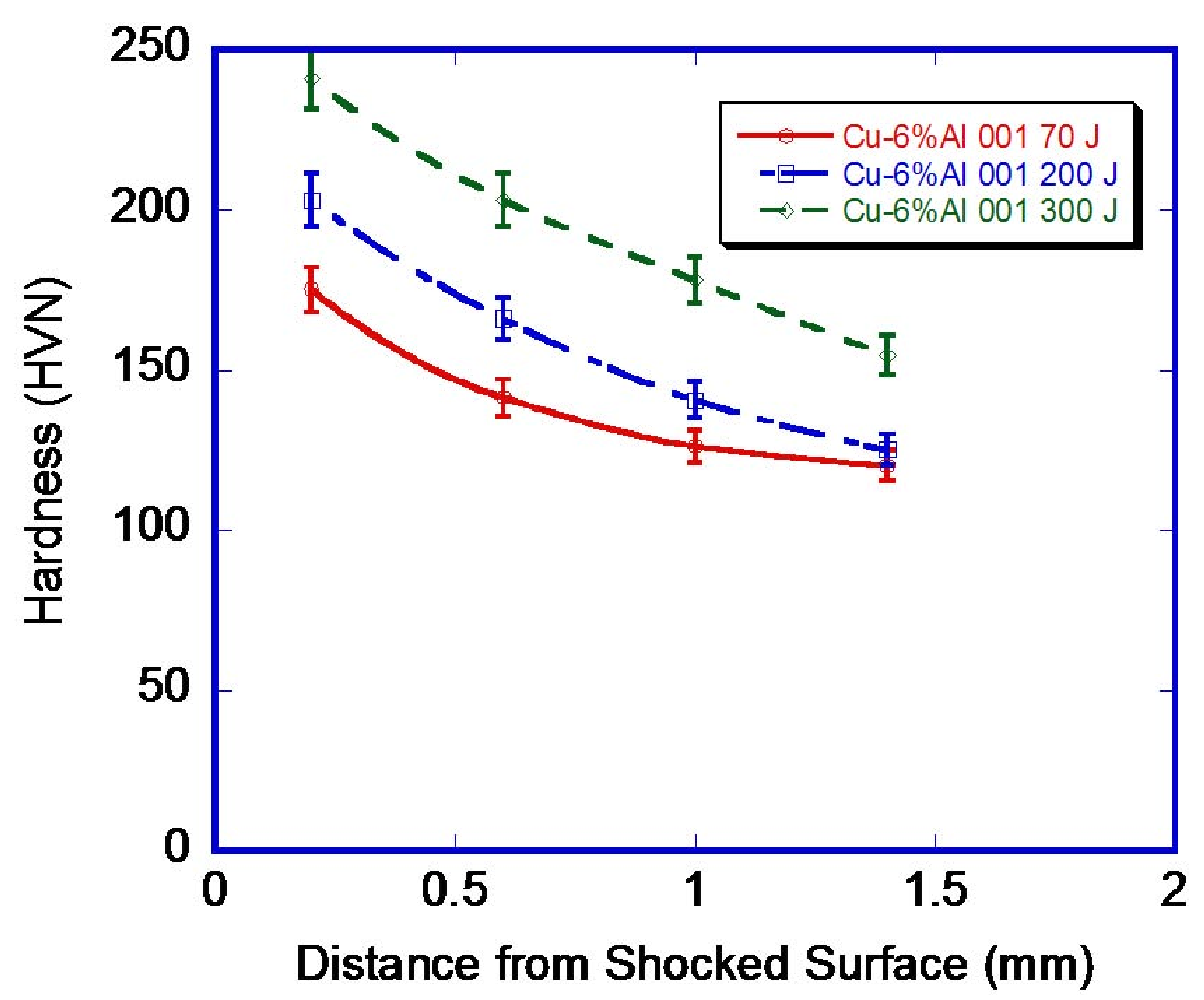




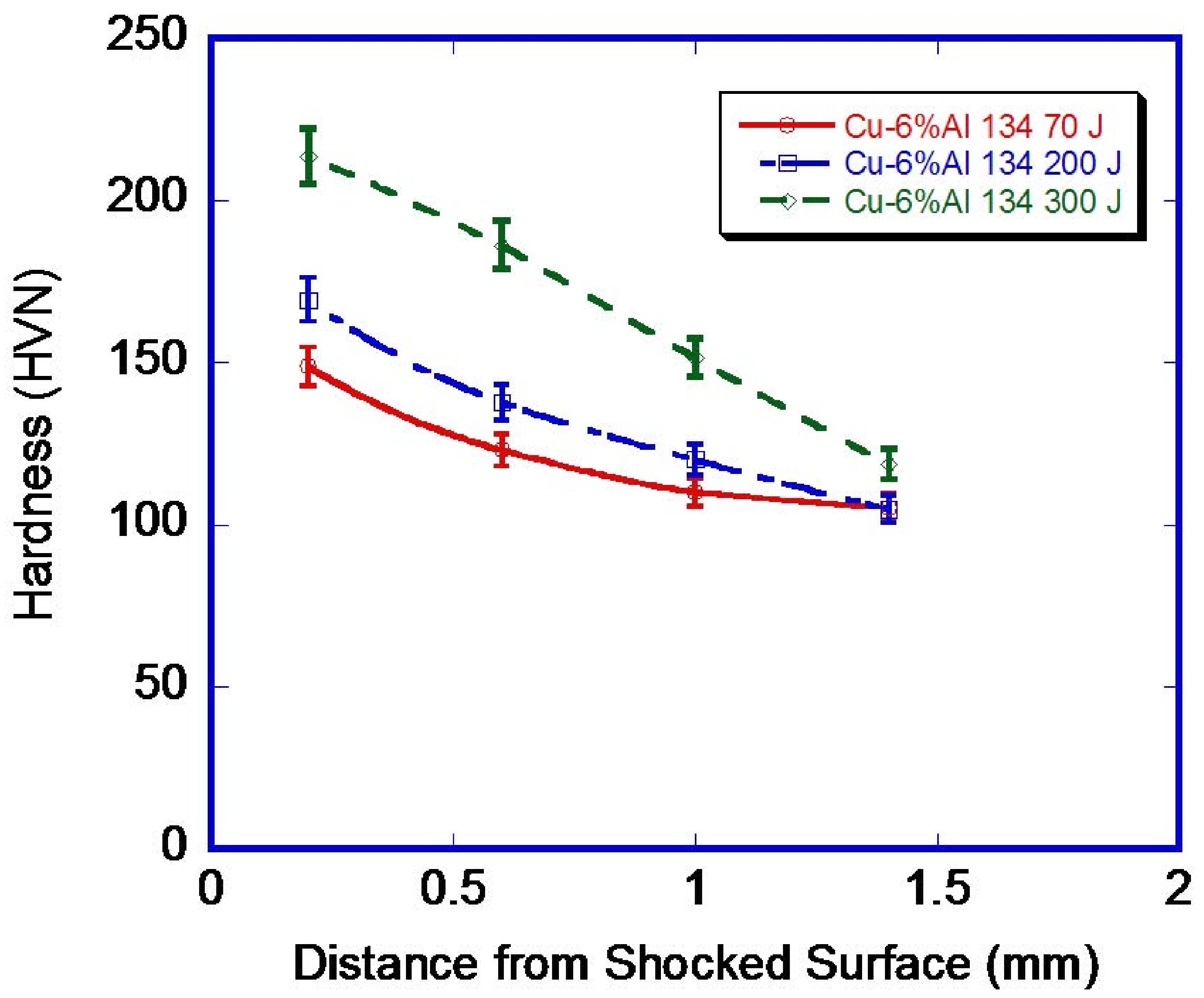




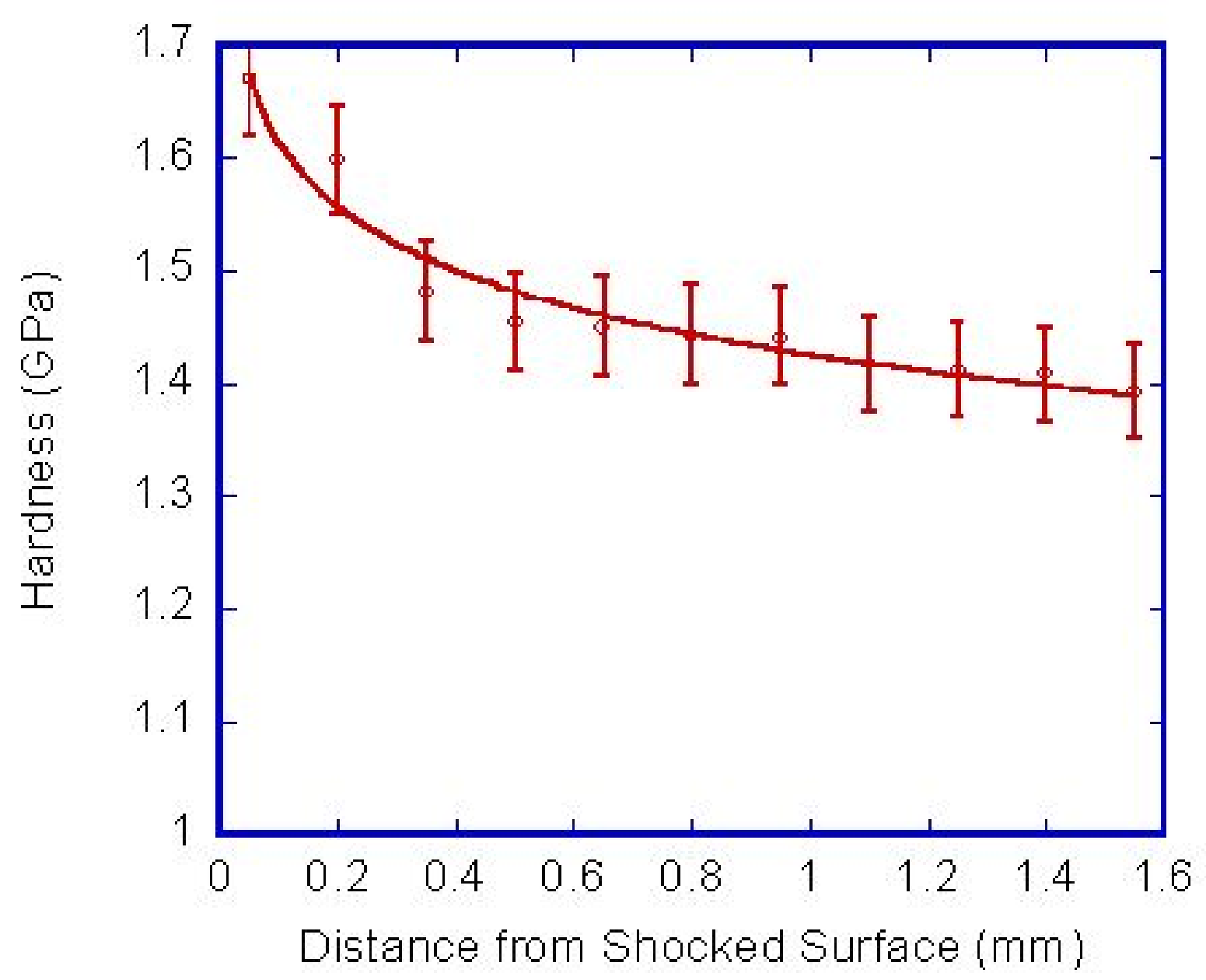




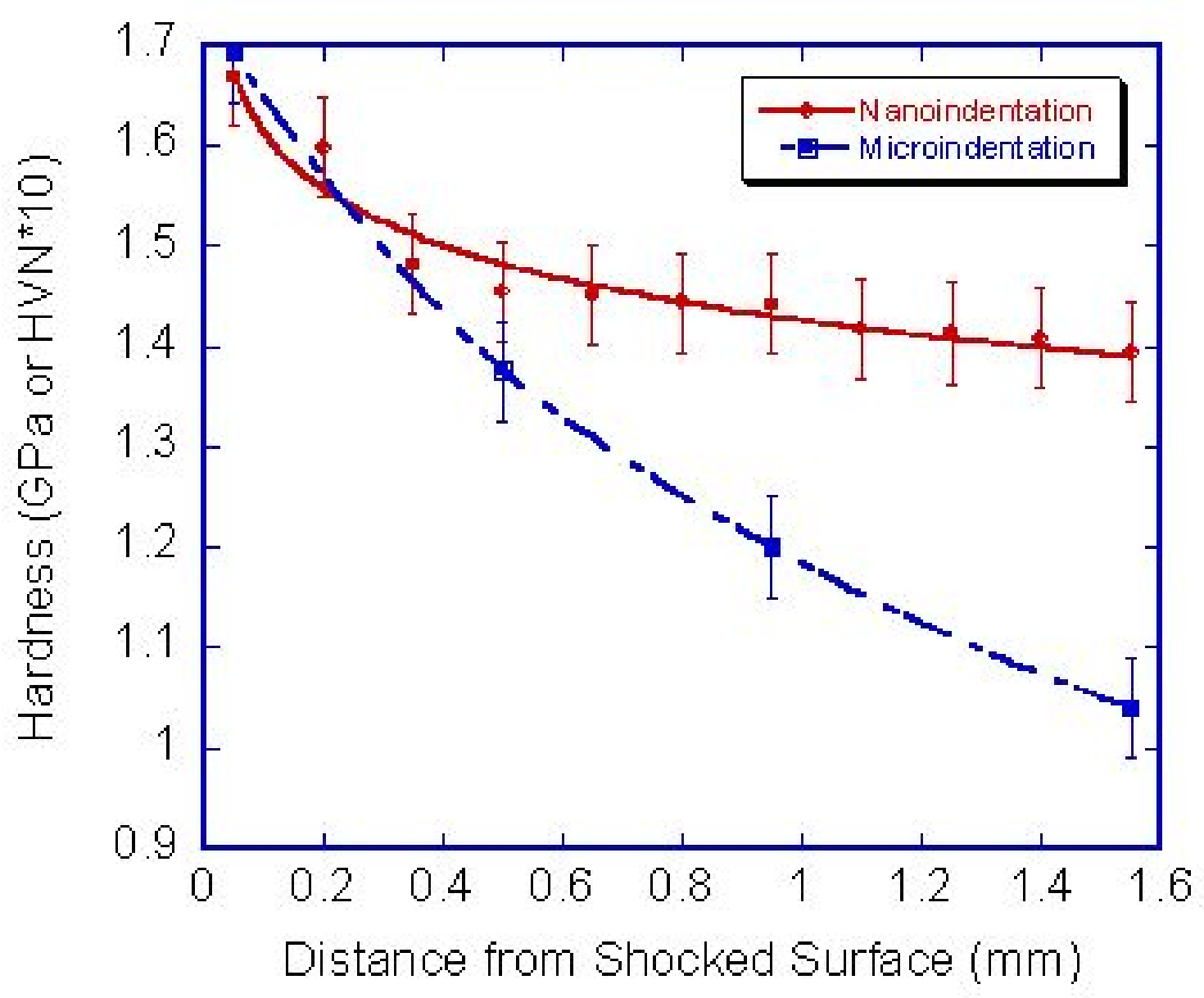




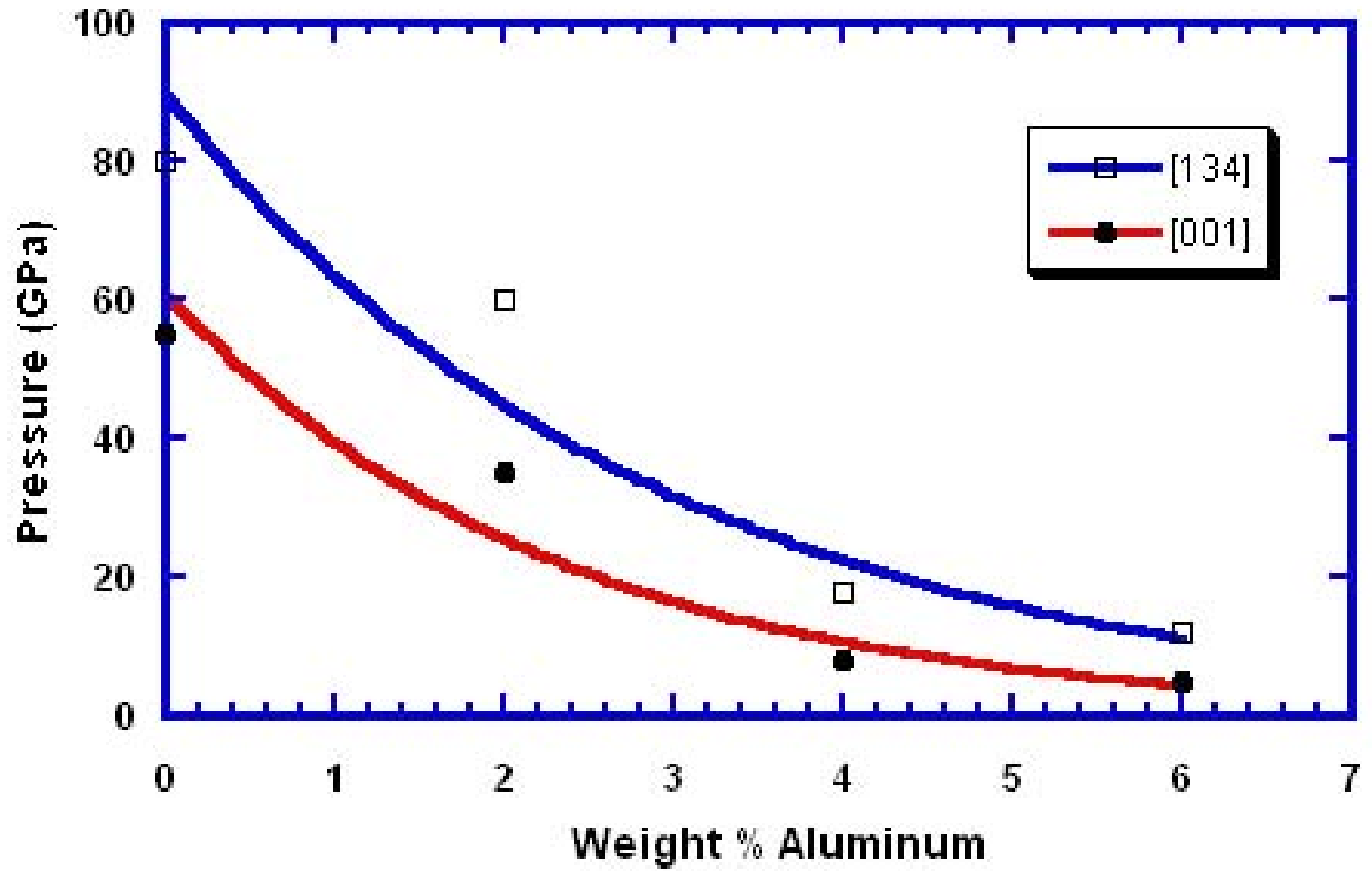




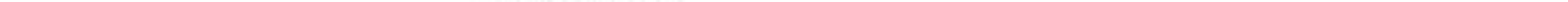




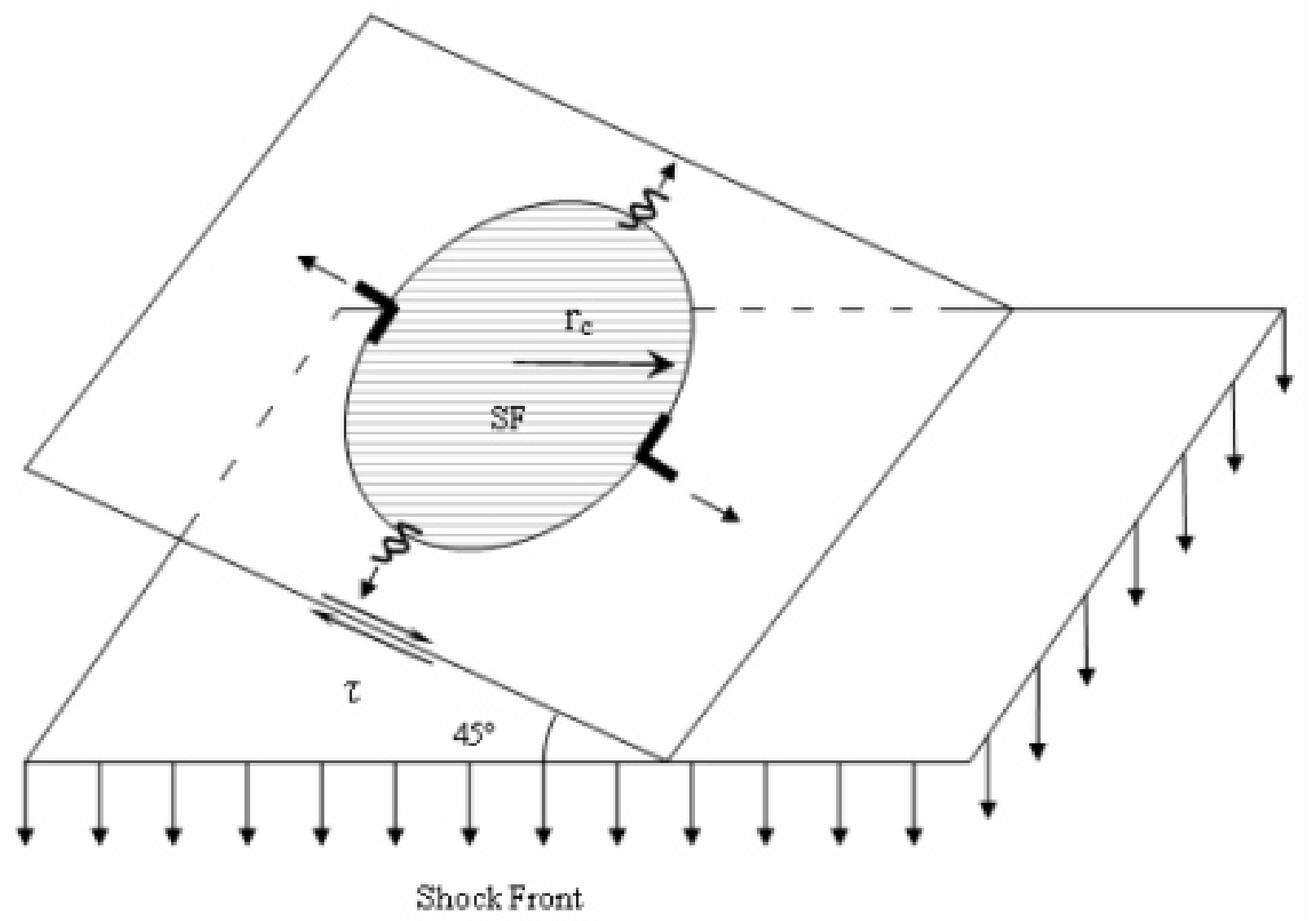




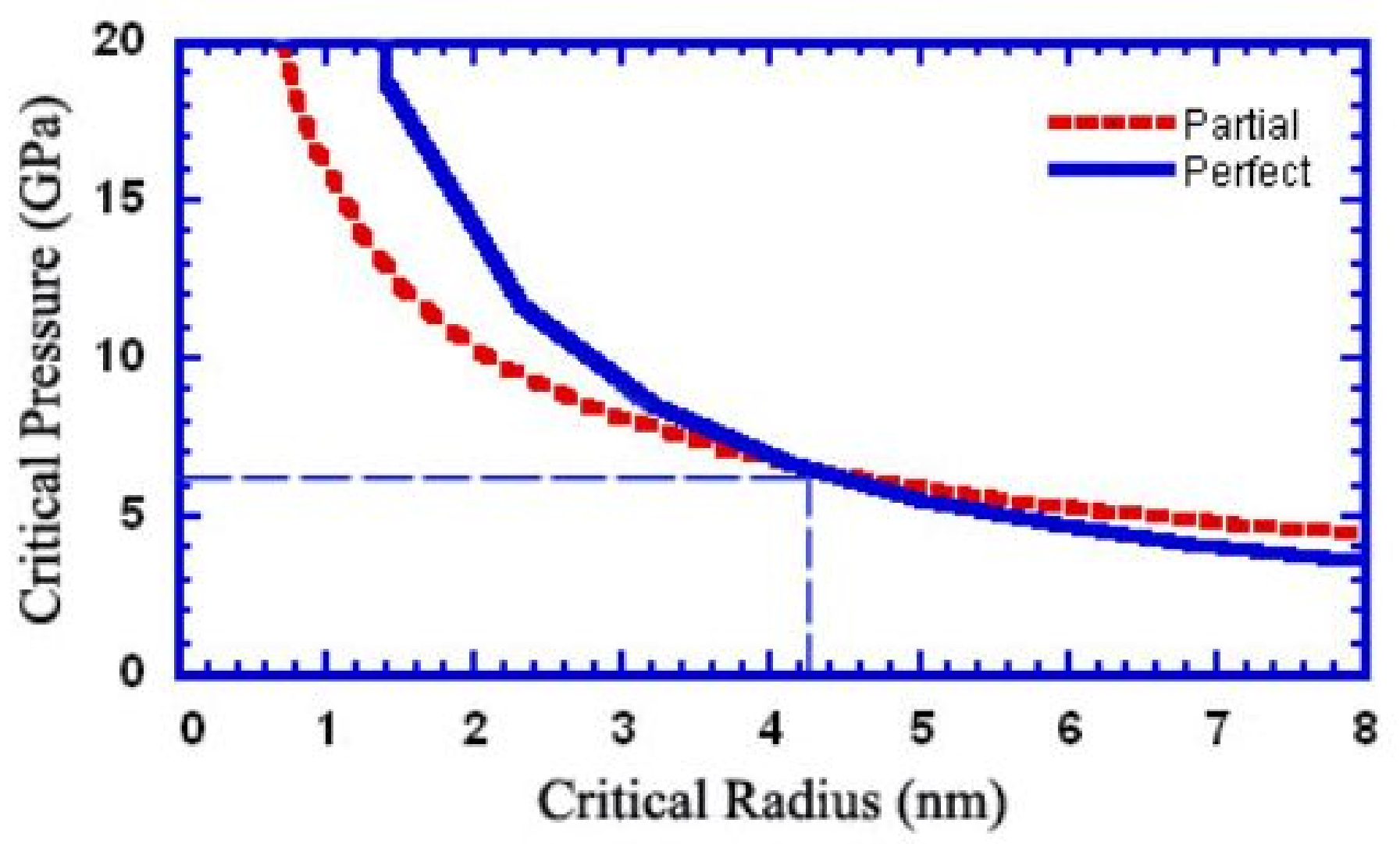




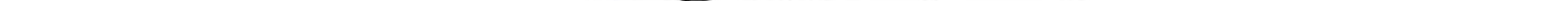




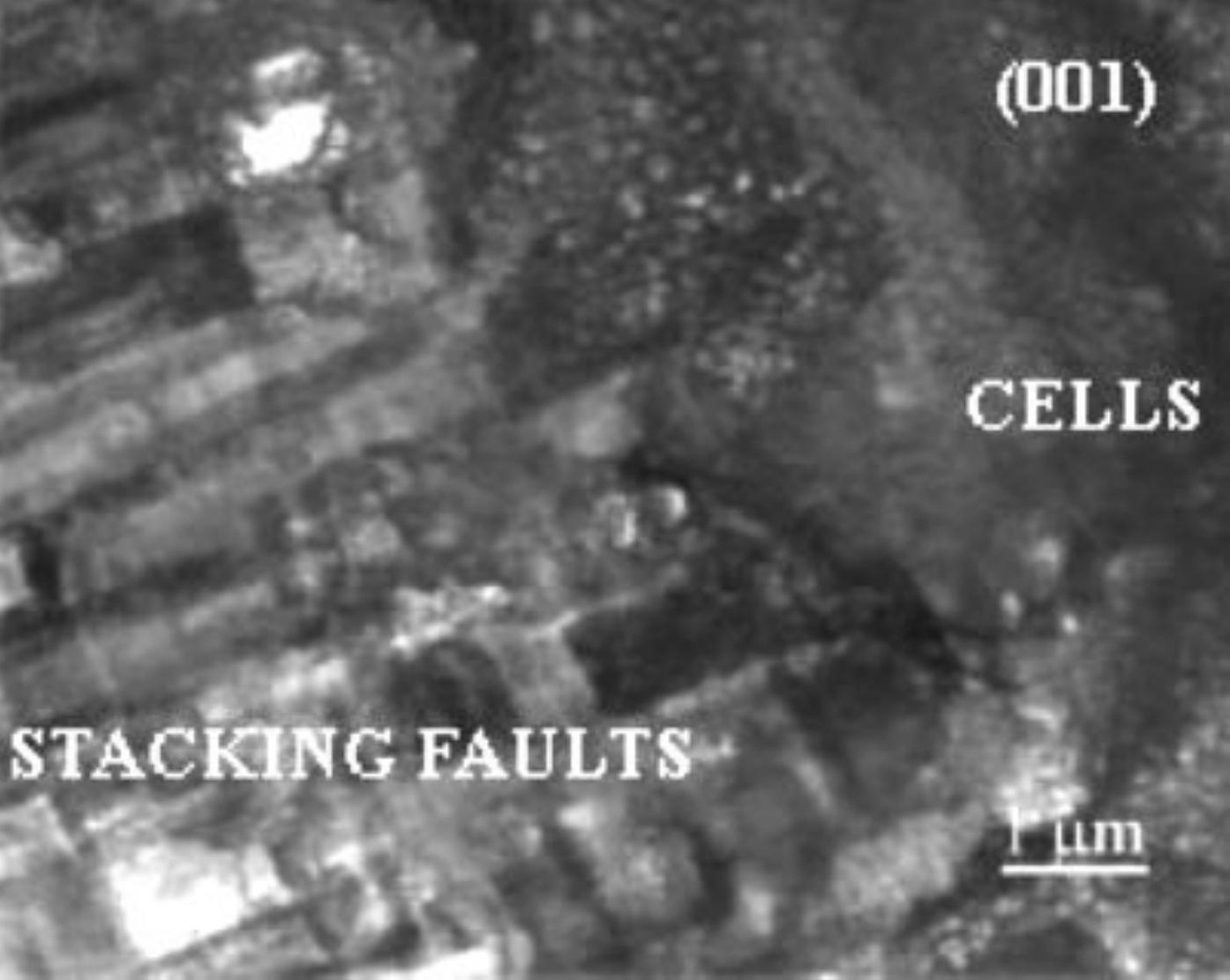

